\title{
The Endgame of Telecommunications Policy? A Survey
}

\author{
by INGo Vogelsang ${ }^{*}$
}

\begin{abstract}
Telecommunications policy has come a long way from regulation of vertically integrated monopolies to the current state of competition. As competition becomes selfsustainable, will telecommunications policy in the form of industry-specific regulation go away or, if not, what form will it take? The economics literature suggests that the regulatory efficiency frontier is shifted by new technological and market developments, such as convergence of networks, fixed-mobile substitution (and integration) and next generation access networks. The frontier is also affected by the existing capital stock and other physical and institutional characteristics of a country. The insights from a review of the theoretical and empirical literature are applied to five policy areas. They are: (1) termination monopoly; (2) local bottleneck access; (3) net neutrality; (4) spectrum management; and (5) universal service. While in some of them, deregulation and a move to competition policy will soon be the efficient state of the art, regulation will remain efficient in others for some time. Deregulation will likely become efficient for one-way access and universal service, with the exception of some universal service policies in remote areas and for the poor. Termination will move to bill and keep with a duty to interconnect. In addition, some (more symmetric) regulation should persist for net neutrality in the form of transparency requirements, (quasi-) common carrier obligations and minimum quality standards. Also, spectrum management, while moving towards full-blown ownership rights, will continue to see regulators providing zoning and other services, particularly for unlicensed spectrum. All these assessments are premised on the success of making additional spectrum as the key resource available. They are also premised on the absence of a killer technology like P2P FTTH that potentially dominates all other technologies. What determines the endgame in telecommunications regulation? Although technical and market developments will dominantly shape the regulatory efficiency frontier, institutional and political economy factors have an additional and mostly slowing effect on policy changes. (JEL: L43; L86; L96; L98. Keywords: deregulation; mobile termination; essential facility; net neutrality; spectrum management; universal service)
\end{abstract}

\section{Acknowledgements}

The author would like to thank Marc Bourreau, Wolfgang Briglauer, Carlo Cambini, Martin Cave, Ralf Dewenter, Michał Grajek, Steffen Hoernig, Christiaan Hogen-

* Boston University, vogelsan@bu.edu. 
dorn, Jan Krämer, John Mayo, Karl-Heinz Neumann, Patrick Rey, and Tommaso Valletti for very constructive comments on previous drafts.

\section{Forces driving telecommunications policy}

Telecommunications policy has come a long way from regulation and state ownership of vertically integrated monopolies to the current state of competition. However, in spite of predictions to the contrary, interventionist policies continue in the sector. As competition becomes self-sustainable, will telecommunications policy in the form of industry-specific regulation go away or if not, what form will it take? The current paper tries to answer this question in light of the telecommunication economics literature. In particular, the regulatory efficiency frontier is shifted by new technological and associated market developments but is also affected by the existing capital stock, other physical characteristics and the institutional endowment of a country. The policy developments follow three stages, roughly by past, present and future, where Stage 1 represents settled policies that are currently applied, while the transition Stage 2 represents policies dealing with changes associated with reaching the future Stage 3, which we associate with full IP convergence and ultra-fast broadband access of fixed and mobile broadband networks.

The economic rationales for telecommunications regulation have traditionally been economies of scale and scope on the cost side and network effects on the demand side. ${ }^{1}$ Economies of scale and scope (along with sunk costs) are primarily responsible for market power-related policies (asymmetric regulation), while network effects are primarily responsible for policies emphasizing interconnection (symmetric regulation) and universal service. Meanwhile, secondary responsibilities include market power issues arising from network effects. The presence of economies of scale and scope in the telecommunications sector has for a long time been used as a justification for vertically integrated (natural) monopoly positions that needed regulation to protect consumers from their market power. This regulation was in many countries associated with cross-subsidized regulated price structures that were viewed as favoring universal service by subsidizing access by usage.

Over several decades, starting in the U.S. in the 1950s, changes in technology, consumer demands and market behavior led to pressures from new market entrants for opening up the telecommunications monopoly markets to competition. This changed the policy emphasis from protection of end-users against the market power of the incumbent monopolist to the enabling of competition between incumbents and entrants. Such policies were viewed as necessary because the incumbents maintained market power through the possession of assets with remaining natural monopoly properties called "essential facilities" or "bottlenecks". These policies include the reg-

1 In addition, for spectrum policy externalities from imperfect property rights play a paramount role. 
ulation of bottleneck access and vertical separation of bottleneck activities from nonbottleneck activities of the incumbents. In this environment, cross subsidization was no longer feasible, because it invited cream-skimming entry that would undermine the basis for cross subsidization. Thus, universal service policies also had to be changed, by emphasizing interconnection between all network providers and by potentially involving explicit subsidies for access of disadvantaged population groups, such as the poor and those living in rural areas.

The geographic focus of this paper is on the U.S. and the European Union (EU), although experience and issues of other countries will be added if that helps the arguments. The main distinguishing features of the U.S. regulation are (a) distinct regulatory authority at the federal and state levels, (b) the possibility for federal preemption of state regulation, (c) a broad regulatory mandate for the federal regulator, and (d) strong implementable rules for the legality of the regulatory process (VOGELSANG 2006).

The U.S. regulatory system is quite unsystematic when it comes to the coordination of problem areas with different regulatory histories. This becomes particularly clear, when one compares the EU Telecommunications Directives with the U.S. telecommunications policies. The EU Telecommunications Directives set clear and common standards for the prerequisites of regulation for all parts of the telecommunications sector. They are based on the definition of relevant markets and the persistence of market dominance. The definition of markets and the analysis of market dominance are left to national regulatory agencies (NRAs), who also determine the remedy should regulation be required. The European Commission (EC) currently regulates mobile roaming and heavily influences NRA decisions on market definitions, market analysis and on resolutions against the adverse consequences of market dominance. ${ }^{2}$ The EC, however, does not otherwise act as the direct regulator. The EU model is therefore based much more on delegation than on separation. Although the resulting outcomes are often quite similar, the U.S. gets there through a very different process. As Marcus (2002) has pointed out, the European approach is logical and elegant, while the U.S. approach is legalistic and messy. ${ }^{3}$ An example of problems arising under the U.S. approach is its potential inability to deal with the demise of the public switched telephone network (PSTN), because it becomes IP-based and could therefore become an unregulated information service (WERBACH 2013).

2 Roaming is a nagging issue in EC policy but not on the same level of importance as the "big five" issues discussed below in this paper. International roaming is regulated at the EC level because individual NRAs cannot do it. In contrast, the U.S. have four national mobile networks that require very little roaming within the country. The remaining roaming issues outside national and EU jurisdictions may require coordination at the ITU level. In spite of cross-border consolidation of carriers we have only identified spectrum management as a second potentially important transnational regulatory policy issue.

3 This may be due to the ability of the EU to start from scratch or by the different legal traditions or by the EU's focus on opening services to competition. For a comprehensive legal treatment of US telecommunications policies see NuechterLin and WeISER (2013). Their lucid analysis was only available to me after finishing this manuscript. 
Both in the U.S. and in EU, the competition-enabling regulatory policies were initially viewed as temporary and as leading fairly quickly to deregulation. This interim stage, however, continues to this day. Nevertheless, three current developments appear to define an end game for the regulation of the sector. These are (1) IP convergence, (2) new fiber access networks (next generation access = NGA), and (3) broadband mobile networks combined with fixed-mobile substitution (FMS) and fixedmobile integration (FMI). ${ }^{4}$

Ad (1): Due to IP conversion and broadband access, networks originally specializing on the delivery of specific applications become multi-play networks, each providing similar sets of applications. As a result, former telephone networks, former data networks and former cable TV networks can now provide similar services and therefore compete with each other (on a differentiated product basis). While there could in principle evolve a single natural monopoly network, the presence of sunk costs and the associated path dependence have in a number of countries led to network duplication and therefore to true facilities-based competition (without the help of wholesale access regulation). Furthermore, the converging media come from different regulatory traditions with different regulators and different regulatory philosophies. There has been a monopoly and universal service focus for telephone regulation, a content-oriented and free speech focus for communications regulation and a free market and net neutrality focus for the Internet. Will these regulatory traditions converge as well?

Ad (2): New NGA networks require very large, mostly sunk investments and are associated with strong economies of scale so that they again could favor natural monopolies (at least outside densely populated areas). However, NGA access networks offer substitutable services to those offered by other networks, such as cable $\mathrm{TV}$ or $4 \mathrm{G}$, so that the natural monopoly properties may not be particularly strong but the investment may be particularly risky. ${ }^{5}$

Ad (3): FMS means that fixed as well as mobile networks, by becoming substitutes will compete with each other, leading to additional facilities-based competition (for a survey on FMS see Vogelsang 2010). Mobile networks tend to be more competitive than fixed networks because they do not require an expensive (and sunk) access network connecting each user's location with the network. Also, spectrum policy can be used to increase overall network capacity and the number of competitors. FMS has been going on for quite a while. What is new is that it extends to broadband services and will ultimately directly include services similar to NGA. Even then, mobile services will only be partial substitutes for fixed network services, limiting the competitive effects upon each other. Mobile competition is somewhat reduced by the simultaneous FMI, which is associated with quadruple play and favors network operators active in both fixed and mobile networks so that the scale economies of the

4 For other explanations of telecommunications sector reforms see VoGELSANG (2006),

5 To the extent that the NGA fully replaces, for example, a copper access network one of the potential substitutes vanishes. 
fixed network could reduce the number of viable non-integrated mobile competitors (Hoernig, Bourreau and Cambini 2013).

These three developments define an end stage, where several mobile and fixed networks can compete with each other, and that stage defines a different set of appropriate policies from those deemed efficient now. In particular, these three developments may suggest the potential for deregulation of bottleneck access. At the same time, the high level of mobile penetration (without specific universal service policies in many countries) and the ubiquity of access to interconnected telecommunications networks might suggest that universal service policies can at some point be abandoned. However, while technological changes and market forces drive regulatory developments, regulation changes more slowly and therefore deregulation may need some stimulus (TARDIFF 2007). ${ }^{6}$

The current regulatory policies represent an interim stage leading to this "end" stage. We will thus characterize three stages of policies, an initial Stage 1, an interim Stage 2 and an end Stage 3. Obviously, technologies and markets will develop further in the distant future so that the currently envisaged end stage is not final. However, it may well be final for the types of currently applied regulatory policies.

\section{Developments in specific telecommunications policy areas}

Currently, at Stage 2 in the above characterization, there remain five main policy areas that are economic (as opposed to technical policies [e.g., standardization] and legal [e. g., security and privacy]) in nature. They are (1) the termination monopoly, (2) local bottleneck access, (3) net neutrality, (4) spectrum management and (5) universal service. Each of the following sections will first characterize one of these policy areas and then delineate its emerging regulatory efficiency frontier, based on a balanced reading of the literature, including economic contributions to the frontier. Wherever possible, the empirical literature will back up theoretical propositions. ${ }^{7}$ The concluding sections will link the separate policies and develop a summary outlook.

\subsection{Termination monopoly}

\subsubsection{The problem and its current handling}

\subsubsection{The termination monopoly problem}

Interconnection between networks (also called two-way access) is a natural starting point for the analysis of telecommunications policy, because it forms the basis for

6 In this respect scholars associated with the Chicago school have always been ahead of the curve by suggesting deregulation all along. For a more recent example from this school for telecommunications regulation see Spulber and Yoo (2009). However, it is only now that they convince mainstream economists in the regulatory field. Their time may have come.

7 Ideally, that would lead to "results-based" regulation (MAYo 2013). 
network competition and for capturing network effects. The essential feature of interconnection is that competing networks terminate calls for each other, enabling communication across networks.

To non-specialists, the termination monopoly is a strange phenomenon that arises from the property of telephone calls to occur between specific people so that the calling person wants to talk to the receiving person who happens to be on a specific network. Thus, given that the receiving party has subscribed to this network, the calling party has no choice but to call the same network if she wants to reach the receiving party. Since the receiving network actually has to terminate the call, it can charge the calling network a monopoly price for doing so. Call termination between networks is therefore regulated quite generally. In particular, for mobile termination this regulation has substantially reduced termination charges over time.

In the EU, termination was first regulated only for the fixed network incumbents under the assumption that the monopoly power was simply part of the incumbency monopoly. Later, it was discovered that the termination monopoly just as well arises for terminating networks without market power on the end-user side and has received the name "competitive bottleneck" (ARMSTRONG 2002). ${ }^{8}$ Such bottlenecks showed up in very high mobile termination charges negotiated between mobile carriers in the 1990s and early 2000s, before regulation set in. During this time, mobile termination charges in the EU were often asymmetric, with higher charges paid to the smaller networks. Based on mobile termination rates from 48 European mobile operators from 2001 to 2003, Dewenter and Haucap (2005) show that with consumer ignorance about the exact termination charges (a) a mobile network's termination charge is the higher the smaller the network's size (as measured through its subscriber base) and (b) asymmetric regulation of only the larger operators in a market will, ceteris paribus, induce the smaller operators to increase their termination charges.

\subsubsection{The LRAIC approach}

Regulated mobile termination charges in the EU have moved on a decade-long glide path from unregulated charges to a level of long-run average incremental costs (LRAIC). ${ }^{9}$ While LRAIC are a good proxy for the average costs of an efficient firm (entrant or incumbent), they are most of the time substantially above the marginal costs relevant for price setting in competitive situations. ${ }^{10}$ It is therefore not surprising that the EU moved on from LRAIC to "pure" LRIC, which meant that common costs

8 Note that this applies both to calls between mobile networks and those from fixed to mobile networks.

9 Measuring the costs of wholesale services in a telecommunications network can be very tricky as, for example, demonstrated by Spulber and Yoo (2009) in their application of graph theory. In this paper we are not concerned with these measurement issues, though.

10 For a critique of LRAIC as the basis for regulated prices see BRIGLAUER and VogELSANG (2011). While LRAIC may characterize costs of an expanding network quite well, this no longer holds for contracting networks and in potential price-squeeze situations. 
with other services, such as transit and call origination, were excluded. This was a controversial step that led to a substantial price reduction.

An LRAIC costing approach was also for some time used in the U.S. for fixed network termination (FCC 1996). However, this led to the so-called "ISP reciprocal compensation problem" in the late 1990s. Small entrant networks attracted narrowband Internet service providers (ISPs) as customers with a huge number of incoming and very few outgoing calls. They therefore generated large net financial surpluses from reciprocal LRAIC-based termination charges with large incumbents, demonstrating that LRAIC was way above the decision-relevant costs of termination. This issue changed the attitude of U.S. incumbents towards low termination rates and made them accept inter-state (FCC jurisdiction) termination charges at fractions of a cent per minute, way below LRAIC.

\subsubsection{The Bill \& Keep approach}

Due to the receiving party pays principle (RPP) practiced in the U.S. for mobile networks mobile termination problems did not emerge because the receiving party can choose if it wants to subscribe to a network with high or low reception fees. On the contrary, at the beginning fixed networks charged mobile carriers for receiving fixed-to-mobile (FTM) calls. The FCC then installed the current mobile termination, which is largely based on bill and keep (B\&K).

Under $\mathrm{B} \& \mathrm{~K}$ no termination charges are paid between networks. $\mathrm{B} \& \mathrm{~K}$ is based on the idea of reciprocity. Network A terminates calls for Network B but Network B also terminates calls to Network A. Thus, termination payments would only be due in case of asymmetries in the calling patterns. The symmetry property is critical under voluntary agreements between Internet backbone networks, where some networks use socalled "peering agreements" meaning that they have an agreement to interconnect and the payment is essentially in kind $(=\mathrm{B} \& \mathrm{~K})$. The second type of Internet backbone interconnection consists of fee-for-transit arrangements that are largely capacity-based and bit-based in their pricing. B\&K as a general policy for all telephone networks will, in the future, be implemented in the U.S., but remains rare elsewhere. One reason for this difference could be that most other countries have calling party pays (CPP) instead of RPP arrangements for mobile calls (LiTTLECHILD 2006).

\subsubsection{Capacity-based Charging}

Termination charges are generally billed per-minute of calling. A small number of countries, however, have been using an approach of capacity-based charging (CBC). $\mathrm{CBC}$ relates to interconnect services, for which the maximal capacity utilization is booked in advance and paid in monthly or one-time fees, not triggering any further charges for usage within the specified capacity limit. CBC generally follows efficiency criteria more closely than per-minute charges (KENNET and RALPH 2007). What distinguishes $\mathrm{CBC}$ from per-minute charges is the tracking of network costs and the possibility for risk sharing between the dominant network operator and the other competitors.

While $\mathrm{CBC}$ was originally debated in connection with flat end-user rates, it has potentially more general significance for enabling new competitors to offer end-user 
rates that better reflect network costs. The UK was the initial leader in CBC. In the early 2000s, the competitors of BT (the dominant network provider) could buy a capacity-based call origination service called FRIACO that connected to specified numbers of Internet service providers. The FRIACO tariff showed how $\mathrm{CBC}$ can be introduced comparatively quickly and without major complications if focused on the particular purpose of enabling end-user flat rates (VogElsANG and WöHRL 2002). Introducing $\mathrm{CBC}$ on a broad scale, however, may require careful cost measurement and extensive planning. Only a few countries, like Spain and Portugal, have successfully introduced voice interconnection fees on a $\mathrm{CBC}$ basis. In these countries, capacity-based usage charging is an optional alternative to per-minute pricing.

\subsubsection{Conclusions on Stage 1 termination regulation}

The dominant Stage 1 termination regulation applies LRAIC-based charges for $\mathrm{CPP}$ regimes and $\mathrm{B} \& \mathrm{~K}$ for RPP regimes. There are some countries with $\mathrm{CBC}$ as an option besides per-minute charges.

\subsubsection{Theoretical and empirical literature about policies}

While the existence of termination monopolies is widely acknowledged in the literature (surveyed by Vogelsang 2003, Littlechild 2006 and Harbord and PAGNOZZI 2010), its effects and the remedies have been quite contentious.

\subsubsection{What is the efficient price level?}

In the past, the starting point for efficiently regulated pricing has generally been the Ramsey pricing approach. The termination monopoly, however, is embedded in a very complicated Ramsey problem with no simple solution. First, it concerns an input (a wholesale product) rather than an output, and it is a reciprocal pricing problem between firms. This input is complementary to other products. It is well-known that complementarity can lead to negative markups in a Ramsey setting. Second, there are potential externalities (network and call externalities), which can lead to positive or negative markups. Third, the firms are often constrained by imperfect upstream and downstream competition rather than by a standard Ramsey budget constraint. No paper in the literature seems to have treated all these issues. However, there are papers treating some of them, coming to the main conclusion that the welfare-optimal termination charge is likely to lie between below zero if downstream competition is imperfect and/or if the call externality is sufficiently strong and above LRAIC if there is a network externality but no call externality (e. g., in VALLETTI and Houpis 2005).

The first formal literature on profit-maximizing and welfare-maximizing termination charges (surveyed in VogELSANG 2003) was concerned with fixed-to-fixed (FTF) terminations in a developed country context. It therefore assumed reciprocal termination charges and a given full level of subscriber penetration, deriving a collusion result for reciprocal termination charges if networks use linear end-user tariffs and an indifference result between various reciprocal termination charges if networks use two-part end-user tariffs (LAFFOnt, REY and Tirole [LRT] 1998a and b, ARMSTRONG 1998). Thus, no clear relationship between profit-maximizing and wel- 
fare-maximizing termination charges emerges. ${ }^{11}$ However, under two-part end-user tariffs with on-net/off-net price discrimination profit-maximizing charges will be set lower than efficient levels so as to relax retail competition between mobile networks (GANS and KING 2001). This is puzzling since in reality, regulators are pushing termination rates down while being opposed to do so by network operators. This puzzle can be resolved in favor of profit-maximizing prices above cost with the assumption that consumers' expectations about the number of customers on each network are "passive but required to be fulfilled in equilibrium (as defined by KATZ and SHAPIRO 1985), instead of being responsive to non-equilibrium prices, as assumed until now" (Hurkins and Lopéz 2013; see also Hoernig, Inderst and VAlletti 2013). ${ }^{12}$

In principle, the GANS and KING (2001) result should extend to FTM calls. However, Armstrong and Wright (2009) note that mobile networks treat FTM differently from mobile-to-mobile (MTM) calls. For FTM calls the predicted market failure involves the termination charge being set at the monopoly level, while for MTM the predicted unregulated termination charge lies below the efficient level. However, wholesale arbitrage implies that a mobile network cannot sustain a FTM termination charge significantly above its MTM termination charge. Taking this supply-side substitution into account, Armstrong and Wright (2009) find that mobile networks choose their uniform termination charge to be below the monopoly level (at least when market expansion is not a major factor) but above the low level that they would set if MTM termination could be priced separately. This reduces the rationale for regulation relative to the earlier literature. In a similar deregulatory vein, CAMBINI and VALLETTI (2008) show that private negotiations over reciprocal access charges can induce first-best retail prices, when calls between parties trigger each other (information exchange).

Regarding the efficient termination charge, a group led by WRIGHT (2002a, 2002b) but vehemently opposed by DeGrabA (2002, 2003), argued that mobile termination charges should be above costs, because competition for end-users would induce mobile carriers to compete for customers (who would receive calls) and there-

11 The benchmark Ramsey-pricing solution in LRT has the access charge below marginal costs, because, due to imperfect retail competition, firms have positive markups in the retail market. This result is unambiguous because of assumed constant returns to scale. Under economies of scale, Ramsey access charges could be below or above marginal costs, depending on the degree of scale economies and the size of the retail markup. Jullien, ReY and SAND-ZANTMAN (2012) reconsider the question of the optimal level of termination fees between communication networks in the context of heterogeneous usage and elastic participation. As a result of the interaction between these two features the profit maximizing reciprocal termination fee is above marginal cost, while the welfare maximizing termination fee is also above cost, but below the former.

12 JEON and HuRKINs (2008) argue that the interests of network providers and regulators can be aligned by linking the termination charge mark-up paid to the rival firm to the average retail price mark-up of the firm making the call. 
by increase mobile penetration. Two major assumptions were driving this argument. First, above cost mobile termination charges would actually trigger an additional increase in mobile penetration. ${ }^{13}$ Second, an increase in mobile penetration was viewed as being desirable (beyond what would have happened under cost-based mobile termination charges). Following this network externality approach, Oftel in the early 2000s added an externality surcharge to regulated mobile termination charges in the UK. Wright's approach certainly was understandable at the time. However, since then mobile penetration has increased to exceed fixed penetration worldwide. So, this argument in favor of network externalities has faded away.

The position of researchers finding efficient termination charge levels above costs is fundamentally challenged by the observation that the utility of both the calling and receiving party is positively affected by a successful call (HARBORD and PAGNOzZI 2010). In particular, DeGrabA $(2000,2002,2003)$ argues that when both caller and receiver benefit from a call they should share its costs in proportion to the benefits that they receive. According to DeGraba, B\&K can approximate this sharing rule, because the caller (implicitly or explicitly) pays its carrier for origination and switching. Thus, the call externality would be endogenized by B\&K. ${ }^{14}$ Besides on the value of incoming calls, the approach to B\&K by DeGRABA $(2000,2002)$ is based on the ability of a network to charge its subscribers for this value either through line rentals or through usage charges for termination or even for origination (RPP). DeGraba's proposal for a widely applicable interconnection regime is COBAK (central office bill and keep), meaning that $\mathrm{B} \& \mathrm{~K}$ rules only between the user and the trunk side of the first central office independent of the type of traffic. COBAK is therefore not a pure B\&K proposal. However, according to DeGraba the COBAK rule would force networks under most realistic user preferences and network constellations to settle for a pure $\mathrm{B} \& \mathrm{~K}$ regime. While $\mathrm{B} \& \mathrm{~K}$ has been advocated before, DeGraba's position has put it on a sound theoretical footing. The discussion on B\&K has brought out the following additional aspects (HARBord and PAGNOzZI, 2010):

1. $\mathrm{B} \& \mathrm{~K}$ is almost always closer to marginal costs than LRAIC.

2. High termination charges induce on-net/off-net price differences that create barriers to entry and hinder growth of smaller networks, with larger price differences for larger than for smaller networks (DEGRABA 2003 and HoERNIG 2007). Modeling network competition with two-part tariffs and terminationbased price discrimination in the presence of call externalities BERGER (2005) shows that both the collusive and the welfare-maximizing access charges fall

13 In contrast, HoERNIG (2012) shows that with more than two networks consumer surplus may be decreasing with higher termination charges. HARBord and HoERnig (2012) also find this in a calibration of the UK mobile market. That is, higher MTRs would actually reduce penetration.

14 In contrast, HeRmALIN and KATZ (2009) show that the internalizing role for the termination charge can imply a nonzero charge to be efficient even in highly symmetrical situations, and that the efficient termination charge may be positive or negative. 
below marginal cost. Moreover, B\&K arrangements are welfare improving compared with cost-based access pricing. ${ }^{15}$

3. B\&K largely eliminates transaction costs from pricing. However, there may be transaction costs from other aspects of interconnection. In particular, a move from positive termination charges to $\mathrm{B} \& \mathrm{~K}$ could trigger carriers to switch from CPP to RPP for its final users. The literature on RPP is characterized by some strange findings. In particular, JEON et al. (2003) show that RPP could result in a connectivity breakdown. This, however, no longer holds if there are more than two networks (HoERnig 2012). Introduction of B\&K does not require a switch from CPP to RPP if traffic is sufficiently balanced and incoming and outgoing calls are highly correlated. More likely, monthly charges will increase and call charges will decrease (buckets and flat rates). Regulators resist RPP, because they fear that consumers have an aversion to it. This should not be an issue if regulators allow but not prescribe RPP. In that case, competitors will only be successful with RPP if consumers accept that payment system. Using data on political and institutional factors to instrument endogenous regulatory decisions, DEWENTER and KRUSE (2011) conclude that there is no significant impact of either RPP or CPP on penetration rates. Thus, regulators need not fear the consequences of a switch to RPP as a result of introducing B\&K.

4. B\&K could cause a reduction in network investment, because network operators might free ride on others by handing over calls to the other network early ("hot potato" problem). However, CAmBini and Valletti (2004) and Valletti and CAMBINI (2005) show that B\&K can actually provide additional investment incentives, because a termination charge below costs increases competition to attract subscribers. Also, the DeGraba version of B\&K (COBAK) presupposes sizeable investments by all participants.

5. Any issue of asymmetric costs between fixed and mobile networks is now much less relevant than in the past, because the cost of mobile termination has declined substantially and has moved closer to that of fixed network termination. Also, an ever-increasing share of traffic in modern networks is not subject to termination charges.

6. To the extent that $\mathrm{B} \& \mathrm{~K}$ is associated with low or zero calling prices, it could induce spam. RAO and REILEY (2012) recommend technological anti-spam techniques and legal interventions rather than externality taxes, because they fear side effects. Using termination charges would be such a Pigou tax.

Summing up, B\&K can be a very practical and efficient regime if (a) network externalities are small relative to call externalities and (b) the network investment problem can be solved via the design of the B\&K regime, such as the COBAK approach.

15 BERGER (2004) further finds that even under linear pricing, access charges below marginal cost may be used as a collusion device, while off-net calls are priced above on-net calls in equilibrium. Again, B\&K may be welfare improving compared with cost based access pricing. 


\subsubsection{The waterbed effect}

The more competitive the end-user markets are, the more comes the so-called "waterbed effect" into play (for a literature review, see SCHIFF 2008). It means that, because of the effect of free-entry competition, any regulatory reduction in termination charges will lead to an increase in some other charges by the regulated firms. Thus, while the structure of prices is changed by the regulation, the price level may not be (or will be less so). Without entry or exit of firms, the change in one price only affects other prices if there are cost or demand interrelations (e. g., two-sided markets). With entry and exit, there is an additional effect from fixed costs that have to be covered in equilibrium. Genakos and VALLeTti (2011a, 2011b) show empirically that a waterbed effect exists for mobile termination but that it is imperfect and works mostly for postpaid subscribers rather than prepaid customers. This means that an unregulated termination monopoly may lead to distorted prices but not necessarily to consumer exploitation. A partial waterbed effect is also indicated by GROWITSCH, MARCUS and WERNICK (2011), who nevertheless find that lower mobile termination rates (MTRs) tend to result in a lower average retail unit price. Their results suggest that lower MTRs (presumably operating through the mechanism of lower usage prices) tend to result in greater consumption of mobile services in terms of minutes of use per month per subscription.

Mobile users have in the past benefited from high FTM termination charges. While it is unclear if the waterbed effect from strong charge reductions in mobile termination leads to a slow-down in the expansion of mobile penetration, the associated increase in usage should be welfare improving, if penetration is already high, because at that point, the call externality has grown in importance relative to network externality. Since the empirical literature indicates only a partial waterbed effect, regulatory reductions in termination charges reduce profit margins of existing networks, something that could interfere with network investments, which would be required by the associated increase in network usage. This would hold particularly for mobile networks.

\subsubsection{Capacity-based vs. minutes-based charging}

According to KENNET and RALPH (2007), CBC is closer to the structure of costs of a telecommunications network than minutes of use. The costs do not primarily depend on the additional call minutes, but the main cost blocks are units of transmission and switching capacity, which are usually fixed costs. So under CBC, the NRA could impose the regulated firm's cost structure on the interconnection partners and thus reduce the asymmetries. In addition, CBC may be favored in the advent of all-IP "Next Generation Networks" (NGN), where minutes of use are no longer an appropriate measure of network utilization.

Critics argue that $\mathrm{CBC}$ could disadvantage small operators with low volumes, since they pay for the whole capacity without filling it up. This anticompetitive effect could depend on alternative operators' flexibility in ordering capacity. They would be systematically disadvantaged only if there is some lumpiness i) in capacity increments and/or ii) in time commitment. Also, if wholesale reselling of capacity is allowed, 
potential disadvantages become negligible because operators could resell unused capacities to small operators. Limited acceptance of CBC among NRAs is mostly due to a range of tricky implementation issues.

The key to $\mathrm{CBC}$ is to find an easily implementable approach that nevertheless captures the capacity utilization affected by calls and other services (BRIGLAUER and Vogelsang 2011). Simplified proposals are usually based on the capacity used for interconnections. ${ }^{16}$ That, however, does not capture capacity utilization beyond the first point of concentration in a network, which would be relevant for CBC to be meaningful for termination. If restricted to the first point of concentration, CBC would resemble B\&K (KENNET and RALPH 2007).

\subsubsection{Conclusions from the literature on efficient termination charges}

While the empirical literature on termination charges is very limited, the large theoretical literature on the profit-maximizing and efficient termination charges is quite disturbing because of its lack of clear results. The level of efficient charges depends on various parameters that would have to be determined empirically in order to establish the efficient charge level relative to the network costs involved. In particular, network externalities and call externalities can have opposing effects. In practice, only rough approximate assessments of these parameters are possible, as long as reliable empirical estimates do not exist. My conjecture is that over time, the network externality decreases because of saturation in penetration, while the call externality increases roughly in the call volume (although it may also suffer from saturation). This could suggest a clear distinction between policy stages 1 and 2. In Stage 1, the network externality dominates, justifying LRAIC-based termination charges, while in Stage 2 the call externality dominates, leading to B\&K as the more efficient policy. This is reemphasized by imperfect competition downstream that calls for below-cost prices. The literature is also ambivalent if profit-maximizing termination charges are above cost and by how much. Thus, it is not clear if regulation is really warranted.

$\mathrm{CBC}$ has had very limited applications in the past, but its time may have come for stages 2 and 3, when telephone minutes lose their relevance for the costs of networks.

\subsubsection{Implications of new technical and market developments}

Traditional telephony (POTS) is fading away. Convergence (IP telephony, OTT, VoIP) implies that minutes of use lose relevance as cost drivers. In fact, applying minutes of use to termination charges may inhibit the transition to all-IP networks (FCC, 2011). Minutes of use were never a good measure of network costs, unless accompanied by a strong peak-load pricing regime that would leave most minutes at a zero price. Technological change and predominance of non-voice services imply CBC.

16 They also relate to the maximum demand tariffs used for the Internet. 
Both $\mathrm{B} \& \mathrm{~K}$ and $\mathrm{CBC}$ address the issue of cost causality for terminations. CBC uses the property that terminations only cause costs in terms of availability of network capacities. Meanwhile, B\&K uses the property that both callers and call receivers cause the costs of terminations and should therefore share them in proportion to the benefits received. If that nets out to approximately zero and if the networks are symmetric, then the discussion about per-minute charges and $\mathrm{CBC}$ no longer matters. Otherwise, CBC should be applied to the net costs. When full penetration is reached, network effects vanish relative to call externalities. $B \& K$ is therefore most likely to approximate the optimal sharing if it is restricted to the access and backhaul part of termination and leaves use of the long-distance (backbone) part of network either to private negotiations (DeGrabA 2000) or to CBC (KenNeT and RALPh 2007). ${ }^{17}$ The issue of asymmetric termination costs between fixed and mobile carriers can be dealt with by charging retail subscribers for incoming calls (as part of buckets of minutes bought on a monthly basis) and will be less of a problem due to reductions in the cost differences between fixed and mobile termination and due to FMI as discussed below. In order to give the receiving party the choice of rejecting unwanted calls, the first minute can be free.

The fact that in many countries there are more mobile subscribers than inhabitants hints at the presence of multi-homing, meaning that callers can reach receiving parties via more than one terminating network so that there is no longer an undisputed termination monopoly (HAUSMAN and Wright 2006). ${ }^{18}$ Furthermore, HoERNIG et al. (2013) show that an integrated fixed-mobile operator prefers zero FTM charges. The combination of convergence, and FMI plus multi-homing implies that the termination issue will eventually go away in Stage 3. Furthermore, the works of ARMSTRONG and Wright (2009) and CAmbini and VAlLetTi (2008) suggest that deregulation for mobile termination rates may be in order even without these conditions. There is a slight chance of collusive outcomes if negotiations on termination also include quality of service issues (CHOI, JEON and KIM 2013).

Summing up, the regulatory efficiency frontier regarding termination charges appears to be moving towards $\mathrm{B} \& \mathrm{~K}$ and $\mathrm{CBC}$ (and bit-based) rather than minute-based termination charges because minutes of use have little relevance in packet-switched IP networks. In an all-IP network, we might not even know whether it is a call that is

17 Here it has to be kept in mind that traditional fixed network long-distance carriers have been fading away in recent years, mostly due to wholesale local loop access discussed below in Section 2.2. For that reason origination charges have also lost their importance. Under IP convergence there is a transit role for backbone providers that compete with each other.

18 Jan Krämer (in written communication) argues that this is not necessarily multi homing, but driven by the Internet of things, i. e. products/devices that communicate independently and therefore need a SIM card, for example, an emergency system in a car that automatically calls an ambulance in case of an accident. Also, some people obviously have two cell phones, but very often one is for work (without a choice of networks). However, Marc Bourreau points out to me that in African countries most people use multiple SIM cards. 
terminated or some other data packet. ${ }^{19}$ With B\&K as the backdrop, Internet-type voluntary interconnection arrangements could be negotiated between carriers. A universal right to interconnect (at this point, including IP interconnection) should be maintained in order to avoid interruptions of connectivity under the any-to-any principle (NoAm 2002 and Werbach 2013). As seen in Section 2.3 this line of argument is tied closely to the net neutrality debate.

In Table 1, we name efficient policies by stage. Under the stage variable a policy is considered as efficient in the past (Stage 1), in the present transition (Stage 2) and the end state (Stage 3).

Table 1: Efficient policies for termination charges

\begin{tabular}{|l|l|l|l|}
\hline & $\begin{array}{l}\text { Stage 1: Network } \\
\text { externalities from } \\
\text { MTRs dominate }\end{array}$ & $\begin{array}{l}\text { Stage 2: Call external- } \\
\text { ities dominate }\end{array}$ & $\begin{array}{l}\text { Stage 3: Minutes of } \\
\text { use have no meaning } \\
\text { in all-IP networks. }\end{array}$ \\
\hline Efficient policies & LRAIC, CBC, B\&K & CBC, B\&K & $\begin{array}{l}\text { B\&K with right to } \\
\text { interconnection; } \\
\text { termination issue may } \\
\text { vanish }\end{array}$ \\
\hline
\end{tabular}

\subsection{Wholesale broadband one-way access ${ }^{20}$}

\subsubsection{The problem and its current handling}

For both telephone access and broadband access, end-user regulation has largely vanished. This is likely to be irreversible. In contrast, wholesale one-way access regulation as described in Section 1 above continues in most countries based on the argument that the last mile remains a bottleneck.

\subsubsection{EU}

In the EU, bottleneck regulation of the wholesale access network occurs mostly via local loop unbundling (ULL) or bitstream access. It may or may not be flanked by vertical separation of the access network from the core network. ULL means that the access seeker rents individual local loops from the access network. The philosophy of ULL is that the incumbent's network can be accessed directly at the local loop by competitors thereby isolating the natural monopoly or bottleneck portion of the network. ULL therefore requires that the incumbent access provider allow the access seeker to collocate equipment in a switching office close to the customers so that the access seeker can pick up the access line of the customer and provide value added

19 I owe this observation to Jan Krämer.

20 We do not consider mandatory access regulation to mobile networks (mobile virtual network operators $=$ MVNOs), because there appears to be no real bottleneck problem. 
services (including transportation) from there. ${ }^{21}$ Thus, the access seeker needs to have a network built out fairly close to the users and needs to invest in collocation equipment, which is largely sunk. Bitstream access refers to high-speed access arrangements that allow entrants to provide similar services to ULL without needing direct access to the incumbent's local loops. Under bitstream access, the incumbent therefore provides some additional wholesale services and facilities besides the local loop, thus requiring a less developed own network from the access seekers than ULL. Bitstream access is less intrusive on the incumbents and less ambitious for the entrants. Under bitstream access the access seekers have, however, less ability to differentiate their end-product from that of the incumbent than under ULL. New access developments for NGA networks focus on virtual unbundled loops, allowing access at the same points as ULL and thereby potentially preventing stranding of networks built by entrants depending on ULL (EC 2013b).

\subsubsection{U.S}

While local loop unbundling in the U.S. goes back to some (then viewed as) progressive states before passing of the federal 1996 Telecommunications Act, it gained full traction only through the FCC's 1996 Local Competition Order. This, however, went further than local loop unbundling by including additional unbundled network elements, switching in particular. Later, entrants could "rebundle" all the elements and thereby offer local access services to end-users without owning a network at all. They received this rebundled access at a wholesale price equal to LRAIC plus a small contribution to common costs. This excessive unbundling of telephone networks came to be known as UNE-P and lasted until 2005, when it was abolished, following a Supreme Court decision in 2004. ${ }^{22}$ When UNE-P was no longer mandated, the largest access seekers, MCI and AT\&T, left the business and merged with Verizon and SBC. Since they have not been replaced by other access seekers, competition based on regulated wholesale access was almost eliminated in the U.S.

In contrast to many of the EU countries, the U.S. is now characterized by facilities-based duopolies between telephone incumbents and cable TV companies throughout most of the country. Until the early 2000s the U.S. had two different regulatory regimes for cable TV and telecommunications networks. The former was treated as "information services" with light regulation, while the latter was heavily regulated as "telecommunication services". ${ }^{23}$ This differentiation made little sense, after cable TV captured a dominant share in the broadband access markets. Following

$21 \quad$ Local loop access lines are generally owned by the incumbent rather than by the subscriber as suggested by SHY (2001).

22 Economides, SEIM and VIARD (2008) find that, nevertheless, the introduction of competition benefited end-users. FAulHABER (2003) had predicted the failure of local unbundling regulation based on its complexity and the incentive of incumbents to undermine it.

23 The law defines telecommunications services as restricted to conduit, while information services include content. In the case of cable networks the FCC did not see itself in a position to separate the infrastructure network from the provision of content. 
a 2003 Supreme Court decision, the FCC declared DSL an "information service" with less regulatory obligation, just like cable. This shows that after many years of waiting, convergence is finally occurring. ${ }^{24}$ Hence, the services most likely to be affected by convergence were taken out of the common carrier regulation system. Information services, which include the Internet, are deemed competitive and therefore not subject to the same regulations as telecommunication services. The FCC also declared that it would refrain from regulating new fiber-optic lines installed by incumbents. Today, cable is quite clearly dominating the fixed broadband market against ADSL and FTTH (FIOS), but mobile broadband is quickly increasing its share.

\subsubsection{Conclusions on current one-way access regulation}

Current one-way access regulation differs substantially between the EU and U.S. In the EU, LRAIC-based ULL and bitstream access regulation dominate, while the U.S. has moved to partial deregulation, maintaining ULL only for the vanishing legacy copper networks and requiring no wholesale access to new infrastructures. The EC (2013a and b), however, plans to catch up with the U.S. developments.

\subsubsection{Theoretical and empirical literature about policies}

\subsubsection{The essential facilities doctrine}

The theory of wholesale one-way access regulation is for the most part, based on the essential facilities doctrine in antitrust, which says that access should be mandated if (a) the bottleneck facility is only available from the bottleneck owner, (b) the facility is necessary for producing the output in question, (c) the access seeker cannot effectively duplicate the facility, and (d) the bottleneck owner does not provide it voluntarily, although provision would be feasible. While the essential facilities doctrine was originally developed as part of the U.S. antitrust policy, it only appears to work reasonably well in the context of ex ante regulation (AREEDA 1990).

In the U.S., two major competitors in a market are now deemed enough to avoid regulation. With at least two competing access networks, access is not an essential facility. As a result, regulation is only deemed justified if there are no viable infrastructure competitors (FAULHABER 2005). This contrasts with the so-called "three criteria" test of the EU. Under this (wholesale) test, markets are first defined according to competition law criteria. Regulation then may be called for in these markets if there is cumulative fulfillment of the three criteria (1) high and durable barriers to entry, (2) no increase in market competition expected, and (3) general competition law unsuitable to deal with the market failures described by criteria 1 and 2 . An enterprise with market dominance in a market fulfilling the three criteria is subject to ex ante regulation. This is a more regulatory criterion than relying on the essential facilities property, which would require monopoly rather than dominance.

24 In principle, the FCC could also have declared broadband cable a telecommunications service but that would have been inopportune. WERBACH (2013) finds that the FCC's interpretation of the law has "backed it into a corner". 
The essential facilities property provides for a sufficient reason to regulate wholesale access. Whether it is also a necessary reason depends on various tradeoffs that determine if regulation or competition policy is better in dealing with problems caused by insufficient competition (VogELSANG 2012). It is therefore understandable that the EU with its three criteria test takes a somewhat less deregulatory stance than the U.S.

The experience in the U.S., however, indicates the potential for collusion in duopoly markets. ${ }^{25}$ In particular, Verizon and cable firms have recently entered into joint marketing agreements for TV services. Those marketing agreements were restricted by the Department of Justice to areas where Verizon offers no FIOS (FTTH).

\subsubsection{Investment incentives as drivers for Stage 2 regulation}

Both the economic literature and the policy discussions on wholesale one-way access regulation have in recent years shifted from social welfare to investment as the main policy objective. Are investments the right performance metric? Do we need investment incentives because regulation hinders investments or because there are (natural) sunk cost entry barriers? Is it also because investments have external effects that are not captured in markets? The answers to these questions are not only important for bottleneck regulation but also for the net neutrality and for the universal service policies discussed below and for the links between those policies. Investment is not an end in itself but a means to the end of better and more affordable services. Thus, one should not avoid dealing with the tradeoffs between static and dynamic efficiency.

Starting with Röller and WAVERMAN (2001) and so far culminating in CzERNICH et al. (2011), the empirical literature has demonstrated the benefits of telecommunications investments in general and broadband investments in particular for the economy as a whole beyond the telecommunications sector. While, therefore, a case for furthering investment and for overcoming any barriers to investment can be made, finding the right policies remains difficult. A policy of over-emphasizing investments can lead to stranding as exemplified by the telecom industry downfall in 2000. Also, the costs of duplication may not be worth the benefits (HöFfler 2007). Policies favoring infrastructure competition should therefore be balanced against other policy objectives.

The following sections discuss the way the relationship between investment incentives and regulation are treated in the literature.

\subsubsection{Ladder of investment}

The U.S. and EU for some time followed related approaches toward entry help for local bottlenecks. In the U.S., it was called the "stepping stone" hypothesis that was incorporated in the U.S. Telecommunications Act of 1996 and implemented in the FCC Local Competition Order (1996). The idea was that entrants needed a foothold in the market before they would make investments that require substantial economies of scale. The 1996 Act therefore envisaged three steps of entry: resale, unbundled

25 See also PARKer and RöLler (1997) on collusion in mobile services and MACAvoY (1996) on collusion in long distance networks. 
wholesale access and full-scale network duplication. However, under the UNE-P policy described above entrants had neither incentives to use the resale option nor to build any network. In contrast, the EU followed the "ladder-of-investment" approach (CAve and Vogelsang 2003 and CAVe 2006), which tries to systematically relate the rungs of the investment ladder to each other by changing the investment incentives for entrants over time. While the public perception of the ladder-of-investment's objective has been the ultimate duplication of the incumbent's network, there has also been the argument that wholesale access regulation may avoid wasteful duplication (HÖFFLER 2007). ${ }^{26}$

Recent theoretical work by Bourreau, DoĞan and Lestage (2013) finds that (a) high levels of access (e. g., resale) accelerate market entry but delay infrastructure investments, (b) lower access prices for high level of access have the same effect, and (c) the socially optimal access price varies non-monotonically with the level of access. Furthermore, providing the entrant with a choice of several access levels delays infrastructure investment compared to having only one access level. Finally, the socially optimal access prices for multiple access levels follow the ladder-of-investment approach by being more advantageous for lower levels of access (e. g., for ULL) than for higher levels of access. These interesting insights are based, in particular, on the assumption that all investments are deemed sunk and exhibit no economies of scale. This means that investments for, e. g., resale, create an opportunity cost for moving to the next level, because the forward-looking costs at the current level are zero (replacement effect). At the same time, the forward-looking cost of moving to the next level is reduced by the sunk costs of the current level (sequential investment effect). The first of these effects delays further investment, while the second effect accelerates it. The authors show that the first effect generally prevails. However, the main point of the ladder-of-investment hypothesis is that (a) there are substantially stronger economies of scale at the infrastructure level than at the resale level and (b) firms can acquire market share only gradually by being in the market (AvENALI, MATTEUCCI and REVERBERI 2010). ${ }^{27}$ As a result, immediate infrastructure investment would lead to idle capacity for a while (or to suboptimal scale), which would increase the discounted costs. In contrast, starting with resale would allow for a profitable build-up of market share and infrastructure investment at a time when the capacity would actually be fully used, resulting in lower costs of the subsequent infrastructure

26 Note that the ladder-of-investment approach assumes that regulated wholesale access is provided to other than essential facilities or that the essential facility property can be overcome. Martin Cave (personal communication) has ,,always conceived of the ladder of investment as culminating in unbundled loops, simply because [he] could never visualize that further investment in a second copper or fiber loop by an unbundler would ever make any kind of financial sense. ...[H]istoric investment in cable is obviously a different matter.“

27 Bourreau and Drouard (2013) include another aspect of the ladder approach, which is the experience acquisition by entrants. They show that the acquisition of market experience in the phase of service-based competition delays the entrant's investment when the prospects for infrastructure investment are good, and accelerates investment when they are weak. 
investment. In addition, the risk associated with building large scale is reduced sharply. Last, the percentage of sunk costs is deemed to increase with each level of investment, as one moves from resale to infrastructure investment. These additional aspects make me conjecture that the BourreAu, DoĞAN and Lestage (2013) result of deceleration of infrastructure investment because of access opportunities does not hold in general but depends on the empirical strength of economies of scale, sunk costs and market share gains.

Empirical evidence on the working of the ladder-of-investment approach is scarce. For a set of EU countries, Bacache, Bourreau and Gaudin (2013) and for the UK Nardotto, Valletti and Verboven (2013) found support for a short ladder leading from resale and bitstream access to ULL-based competition, but not to broadband loop investments by entrants. ${ }^{28}$ This clearly shows the limits of the ladder approach but is, in my view, a natural outcome of the economics of fixed broadband access. Besides incumbents, only firms with prior access investments (either in other networks, such as cable TV, or in ducts, such as municipal electric utilities) have successfully invested in such networks.

Both the more theoretical and the empirical literature suggest that the ladder-ofinvestment hypothesis has only limited applicability. With the exception of some carriers in Italy ${ }^{29}$ and Illiad/Fre and SFR in France, the approach shows little suitability for achieving full infrastructure competition in classical essential facilities settings and in cases where infrastructure competition is inter-modal. Thus, while the ladder of investment is intended as a Stage 2 policy approach, in practice it stops short and remains anchored in Stage 1.

\subsubsection{Empirical estimates of regulatory effects on investment}

How does regulation affect investment? At a very general level the empirical study by GRAJEK and RÖLLER (2012) finds that wholesale access regulation reduces incentives for the regulated firm and for individual access seekers to invest. This main result only shows up if one recognizes the endogeneity of regulation. Thus, regulators have a commitment problem in that regulatory intensity is increased if the incumbent's stock of infrastructure is high (which would associate high regulation intensity with high investment). While this study has convinced many skeptics about the claimed negative relationship between intensity of regulation and infrastructure investment, it relates to investment at the firm level of multiproduct firms and not specifically to regulated access networks.

Based on their reading of the empirical literature is the more specific hypothesis by Crandall, Eisenach and Ingraham (2013) that unbundling regulation leads to low prices for DSL services but hinders investment in NGA. In particular, entrants would promote DSL more strongly than the incumbent, who did, for example, protect

\footnotetext{
28 In particular, Nardotto, Valletti and Verboven (2013) find for the UK that, relative to bitstream access, unbundling does not increase broadband penetration but increases the quality of service.

29

See Manenti and Scialà (2013).
} 
its second line business for narrowband ISPs. Thus, unbundling could increase broadband penetration in the short run but would hinder it in the long run. Furthermore, because of increased inter-modal competition from cable and wireless the benefits from unbundling are much smaller today than in the past. This has to be seen in the light of formidable practical challenges in implementing unbundling policies, such as creating operations support systems (OSS) and preventing quality discrimination.

Briglauer, EcKer and Gugler (2012) using EU panel data for the 2005-2011 period yield two very distinct results. First, infrastructure-based competition has an inverted ' $U$ ' effect on NGA investment. ${ }^{30}$ This result follows the AGHION et al. (2005) hypothesis that the largest influence on innovation (or innovative investments) is exerted in an environment that is neither perfectly competitive nor monopolistic. In the Briglauer, ECKER and GUGLER (2012) case, the main variable for infrastructure competition is the market share of cable. Obviously, a high market share of cable does not mean perfect competition (in fact, at $100 \%$ it is a monopoly), but rather appears to crowd out NGA investment, as can be seen in the U.S., where Verizon has restricted NGA investment to densely populated areas and AT\&T has hardly started. ${ }^{31}$ On the other end of the spectrum, the lack of cable presence relieves incumbents from pressure to cannibalize its own DSL infrastructure. The BRIGLAUER, ECKER and Gugler (2012) empirical finding is very plausible. What, however, are the policy consequences? Should one increase or reduce cable's market share if it deviates from the "optimal" $22 \%$ found by the authors? Handicapping cable in the U.S. (with its $60 \%$ share of broadband) is out of the question, but what should France (with 5\% market share) do to increase it? This low market share for cable in France appears to be the result of past policies constraining cable. ${ }^{32}$ While cable may be a good stepping stone for broadband and NGA, creating or expanding new cable networks in a greenfield fashion seems very difficult.

Second, in Briglauer, EcKer and Gugler (2012), service-based competition (measured by entrants' market shares) is shown to have a negative impact on NGA investment. ${ }^{33}$ It is not clear if this is the (indirect) result of low ULL charges or of service competition per se. This result is in line with other empirical findings (reported in CRANDAll, Eisenach and Ingraham (2013)), but may contrast with new results by GRUBER and Koutroumpis (2013). However, the latter paper only concerns the effects of wholesale access regulation on DSL investment, not on NGA investment. One can argue that these are two very different effects. If, as GRUBER

30 Not related to NGA Nardotto, Valetti and Verboven (2013) find that increased competition from cable increases broadband penetration. They do not estimate nonlinear effects, though. For most studies involving cable there may be a selection bias from the original location choice of cable providers.

31 Gruber and KoutroumPIS (2013) find a negative effect of inter-modal competition on DSL deployment, which could also just be the crowding out effect of cable on DSL.

32 Marc Bourreau in written comment.

33 In contrast, a positive relationship between service-based competition and NGA investment is found by CHOU (2013). 
and Koutroumpis (2013) show, wholesale access regulation increases DSL investment, then it may be that DSL investment has a negative effect on NGA investment rather than the wholesale access regulation. This replacement effect could also explain the comparatively high NGA share in some middle-income Central European countries, which had a low DSL penetration (CRANDALL, EISENACH and INGRAHAM 2013). ${ }^{34}$ In fact, Briglauer (2013) shows that, in contrast to Western European countries, there has been no replacement effect in Central European countries. ${ }^{35}$

Related but restricted only to Japan, Minimahashi (2012) shows how NTT's FTTH investment crowded out cable in the super-fast broadband market (based on 2005-2009 data). He emphasizes the role of low regulated ULL charges for copper access and FTTH access in increasing the FTTH market share against high-speed cable. ${ }^{36}$ The mechanism through which this works seems to be that low wholesale access charges lead to strong oligopolistic retail competition. The incumbent thereby increases its overall market share (including that of wholesale access seekers) even if the incumbent's retail market share is decreased. This presupposes, however, that the incumbent makes the necessary NGA investments in spite of the low wholesale price, which obviously was the case in Japan.

Related to the effects of regulation on investment is the question of whether deregulation increases investment. Wholesale access deregulation in the U.S. for advanced fiber networks triggered immediate excitement about the NGA investments this move seems to have induced. Deregulation of wholesale access was therefore seen as providing strong investment incentives, vindicating proponents of deregulation. However, this only seemed to work for a few years. In particular, the FTTH build-out by Verizon (FIOS) has been stopped for the foreseeable future. Was deregulation a failure? The answer is 'no' if suspension of the FIOS build-out is the efficient response by Verizon. FIOS is really no game changer relative to cable TV with DOCSIS 3.0. In particular, in areas of high cable TV penetration, conversion to DOCSIS 3.0 is cheap (Solon 2011). On the other hand, in contrast to NTT in Japan, Verizon has not been pushed by wholesale entrants to expand the FIOS market share aggressively. ${ }^{37}$

34 Martin Cave (personal communication) further notes a tendency in some Eastern EU countries to exhibit "free competition among networks strung from poles, trees and buildings, or buried in trenches conveniently opened up by compliant mayors. It seems to work pretty well there but may not travel."

35 Briglauer (2013), Briglauer, Ecker and Gugler (2012) and Gruber and KoutroumPIS (2013) use ULL penetration and other wholesale access penetration as regulatory variables rather than simply the date of their legal mandate (like Crandall, Eisenach and INGRAHAM 2013).

36 Since 2008 unbundling for GPON in Japan requires access seekers to lease all sub-fibers associated with a fiber line. As a result wholesale access to FTTH has declined and, as CRANDALL, EISENACH and INGRAHAM (2013) state, FTTH unbundling plays a small role today.

37 The failure to increase market share in the coverage areas of FIOS is similar to the case of Deutsche Telecom's VDSL, where only a small percentage of eligible customers subscribe. Elixmann, Neumann, and Stumpf (2013) blame lack of wholesale products for this slow take-up. 
In building out FIOS Verizon is losing its DSL customers. Since the cost of DSL is largely sunk, the FIOS customers must make up for the large profit contribution of DSL plus earn the investment cost of FIOS. However, if cable TV takes away the DSL customers, this replacement or cannibalization effect no longer occurs. Due to cable, the achievable prices for FIOS services are lower, though. This latter effect may be dominating in higher-cost lower-density areas.

While there is a sizeable empirical literature on the relationship between bottleneck access regulation and telecommunications infrastructure investment, there exist enough data problems and enough heterogeneity in the results to prevent clear-cut conclusions. ${ }^{38}$ Nevertheless, in my reading, two hypotheses emerge from the empirical literature. At Stage 1, ULL regulation has led to lower DSL prices (FAGEDA, Rubio and Termes 2013) and a likely increase in DSL penetration and a decrease in cable broadband before DOCSIS 3.0. At Stage 2, wholesale access regulation of copper loops (ULL and/or bitstream) and/or a high level of DSL penetration have decreased the follow-up investments in NGA networks. The interesting twist here is that successful Stage 1 regulation may delay the implementation of Stage 3. This is similar to the case of successful $2 \mathrm{G}$ mobile networks delaying $3 \mathrm{G}$ networks and may simply have to do with the sunk nature of existing technologies.

\subsubsection{Emphasis on investment and transition from copper to fiber under stage 2 regulation}

Since NGA networks are viewed as highly beneficial, investment in such networks is the subject of many policy initiatives. The emphasis on investment results in a more deregulatory frontier involving softer regulation, cooperative investment, and deregulation or regulatory holidays. While the advantage of a more deregulatory approach increases in the importance attached to investment in NGA, regulation may persist if vertical separation and investment subsidies are part of a policy to create NGA networks. What is largely missing in the literature (with the exception of HöFfler 2007, and MANENTI and ScialÀ 2013) is a problematization of the tradeoffs between fostering innovations and protecting competition/consumers.

\section{Softer regulation}

A prevailing view in much of the literature is that soft price regulation will provide strong investment incentives both for the incumbent and for bypass investments by other networks. There are detractors. For example, while much of the U.S.-based empirical literature shows a positive relationship between wholesale access charges

38 For a short review see Bourreau, CAmbini and DoĞan (2013). See also the longer and more critical literature reviews by CAMBINI and JIANG (2009), and by GERPOTT and WinZER (2013). CAMBINI and JiANG (2009) list 23 works on access regulation and infrastructure investment, but quite a few of these are either not really empirical (simulations and numerical examples) or financed by incumbents or organizations of alternative competitors. CAMBINI and JiAng (2009) note that "the lack of reasonable time-series data weakens the robustness of empirical analysis." 
and facilities-based entry, GARRONE and ZACCAGNINO (2012) find a negative relationship for the EU countries. Soft bottleneck regulation can also increase price-squeeze problems if there is inter-modal competition. It may therefore have to be accompanied by retail-minus regulation (BRIGLAUER and VogELSANG 2011). ${ }^{39}$

Emphasizing the necessity for regulatory commitment BRITO, PEREIRA and VAREDA (2013) show that the height of regulated wholesale access charges may have to be made dependent on investment. In particular, charges may have to be higher if investment occurs than if it does not occur.

Most approaches to implementing soft regulation are based on doing a better job at estimating the regulated firm's costs compared to conventional LRAIC cost modeling (VogELSANG 2012). In particular, adjustments are made for lumpiness (allowing for unused capacity) and real options lost through sunk investments (EvANs and Guthrie 2006). The advantage of such adjustments is that they are methodologically clean and therefore not discretionary. Adjustments can, however, also be made in a discretionary way by providing for "economic space" between measured costs and regulated prices, in particular, by increasing the weighted average cost of capital (WACC). Also, moves toward shorter regulatory lag periods mimicking rate-of-return regulation have been proposed.

An even softer regulatory approach is now being implemented by the EC (2013a) for NGA investment. It requires open wholesale access but relies only on price squeeze protection as a constraint on pricing. Such an approach could be used as retail-minus regulation so that wholesale access charges are adjusted automatically in case of a price squeeze (Briglauer and Vogelsang 2011).

\section{Cooperative investment}

Cooperative investment has entered the debate on new infrastructures as a means of avoiding costly duplication and thereby spurring investment, while at the same time allowing for competition between the cooperating investment partners. Bourreau, Cambini, and Hoernig (2013) show that these advantages only hold if cooperation either lowers costs (e. g., through lower costs of capital via risk sharing between partners) or allows for more product diversification (by allowing each partner separate strings of fiber rather than providing undifferentiated bitstream access). Furthermore, mandated wholesale access for others to the cooperative network is shown to reduce investment incentives via lower (or truncated) expected returns and by providing another option to potential cooperating partners. These incentives negatively affect coverage in less densely populated areas. Their results suggest a policy tradeoff between cooperative investment and mandating wholesale access.

KRÄMER and VogELSANG (2012) use laboratory experiments to test for potential collusion between the cooperative investment partners in the retail markets. In the absence of the specific advantages of cooperative investment identified by Bourreau, Cambini, and Hoernig (2013), Krämer and Vogelsang find no additional

39 Another justification for soft regulation is to reduce incentives for non-price discrimination (Mattos 2009). 
investment incentive but significantly higher retail prices under cooperative investment. In contrast, under the theoretical modeling by BOFFA and PANZAR (2012) cooperative investment could lead to efficient pricing if ownership shares were allocated in proportion to wholesale access usage by the cooperative owners.

The literature suggests at this point that cooperative investment may occupy a specific niche that would need to be identified before exempting cooperative investments from wholesale access obligations. In particular, relaxation of remedies may have to be tied to the number of investing firms. While collusion seems sustainable with two firms, it is certainly less likely with four. At the same time, the business case for the co-investors seems to be worse if there are many co-investors (RENDON SCHNEIR and XIONG 2013). This may limit the occurrence of co-investment to very few investors. A strict supervision by competition authorities therefore appears to be warranted.

\section{Regulatory holidays and deregulation for NGA networks}

Regulatory holidays are a wait-and-see approach, under which regulation only begins with a lag after conditions for regulation (the regulatory requirement) have been met. Regulatory holidays could act as innovation incentives similar to patents and could be compatible with later regulation, thereby preventing long-run monopolistic exploitation (CHOI 2011). GANS and KING (2002 and 2003) establish conditions under which access holidays can increase investment incentives for innovative infrastructure. Simulations by Nitsche and Wiethaus (2011) confirm increased investment incentives.

There are two commitment issues for regulatory holidays, one, that regulation will actually come at the stipulated date (or incident), and the other, that regulation will not come before that date. However, breaking the latter commitment and installing regulation may itself take time so that the commitment period is implicitly assured. This potentially long lag will have to be traded off against the danger that the firm building the new market may gain a long-lasting first-mover advantage (BRIGLAUER 2013).

Because of potential abuse, verifiable standards are needed to determine under which conditions regulatory holidays would be warranted. One such condition could be the creation of a new market. However, defining a new market poses itself severe difficulties, because the hypothetical monopoly test is usually hard to adapt to this case (GuAL 2003).

Stronger than regulatory holidays is full and therefore (initially) unlimited deregulation of innovations and particularly risky infrastructure investments. Criteria for such deregulation would have to be at least as strict as those for a regulatory holiday. Deregulation does not necessarily include a credible commitment against re-regulation. However, a long lag is likely before re-regulation becomes feasible. The FCC has some discretion of regulatory forbearance under the U.S. Telecommunications Act of 1996. It can refrain from regulation that reduces investment incentives. An example has been the lifting of unbundling requirements for the UNE-P in 2004. In contrast to regulatory forbearance the FCC can actually exercise deregulation as a more credible commitment, as it did for new fiber lines. 
The U.S. are thus far the prime example of deregulation of advanced networks. The investments triggered by deregulation at first were impressive, but have since faded. In spite of doubts about U.S. international ranking in broadband penetration (stagnation of FIOS), no re-regulation is expected. It is fairly clear that FIOS survives in high-density areas. However, in less densely populated areas the cost of building out FIOS is probably too much higher than DOCSIS 3.0. Thus, overall in the U.S. cable is likely to dominate both FIOS and versions of DSL, such as AT\&T's U-verse, while $4 \mathrm{G}$ is an emerging competitor in all regions. ${ }^{40}$ Access regulation can hardly improve this situation, although bitstream access for cable could be a helpful policy in view of cable dominance and the high U.S. retail prices for broadband access.

\section{Transitioning from copper access networks to NGA}

The move from simple broadband access to NGA networks requires large investments, while some of the older access networks become idle. Wholesale access regulation of the old network then becomes a policy affecting the transition with the policy emphasis shifting from static to dynamic efficiency. In a world with expected parallel operation of copper and fiber access networks over a long time span, Bourreau, CAMBINI and DoĞAN (2012) identify three effects that jointly determine the efficient wholesale access charges for the old technology. ${ }^{41}$

The replacement effect calls for a large enough copper access charge so that independent NGA investors have incentives to invest.

The wholesale revenue effect calls for a large enough difference between the copper and fiber access charge so that profits from copper alone are lower than profits from operating both a copper and a fiber access network. Replacing copper with fiber needs to be sufficiently profitable in order to induce fiber investment.

The migration effect calls for small enough price differences between copper and fiber access so that end-users have incentives to switch from copper to fiber, once fiber is offered.

The interaction of the three effects leads to a compromise level of regulated copper wholesale access price, not too high and not too low. A very different approach based on LRAIC is pursued by Neumann and VogelsAng (2013). They assume that a large fraction of the costs of old access networks is sunk but such networks will no longer be replaced because of the advent of NGA. Hence, LRAIC no longer represent the forward-looking costs of the old access networks. Rather, those are represented by the costs of an NGA network as the modern equivalent asset (MEA). Those costs, however, have to be corrected by a performance delta between the two technologies.

\footnotetext{
40 DOCSIS 3.0 can also deliver $100 \mathrm{MB}$ to 100 million people before the FCC target date of 2020.

41 See also Hoernig et al. (2012) and Nitsche and Wiethaus (2011). A regulatory requirement to run copper and fiber in parallel for a long time could hinder fiber investment. There are duplicative costs and cannibalization effects leading to lessened incentives for NGA investments. Also, the transition policies in terms of wholesale copper access pricing will be different. See Bourreau, Cambini and Doğan (2013).
} 
This leads to competitive neutrality (the "equivalence" in the MEA) between the old and the new network, meaning that the resulting end-user prices for copper-based services are just high enough to make wholesale access seekers of both copper and NGA indifferent between the two access modes. ${ }^{42}$ MEA-based copper access charges are therefore a compromise between favoring the migration effect (by inducing customers to switch) and the wholesale revenue effect (by giving the incumbent a wholesale price above the decision-relevant forward-looking costs). Nevertheless, as argued by Bourreau, Cambini and Doğan (2013), the copper wholesale access price as a single instrument cannot implement an efficient policy that is characterized by several tradeoffs. At the same time, if the copper access network and NGA run in parallel and if the NGA wholesale access charge is also regulated, then the two charges should not be set independently of each other.

The literature on copper wholesale access pricing in the transition to NGA is politically highly controversial. Setting a high copper access price makes continued parallel operation of copper and NGA profitable, provides funds to incumbents to invest in NGA and would make customers switch easily to NGA, once such a network has been built. However, the only incentive to actually invest the funds generated by high copper access charges comes from the bypass incentives created for independent investors in NGA. Such bypass could include investments by cable companies in DOCSIS 3.0. In the absence of such a threat, high copper access charges may just be profitable and would not lead to any NGA investments (or just to investments in VDSL/vectoring as happening in Germany and Italy now). In contrast, setting low copper access charges makes the move to NGA profitable for the incumbent, but lowers the threat from alternative investors and makes many subscribers switch to the new network only if the old one is shut down. It is not clear that a middle road will resolve this controversial issue, although the MEA approach could be promising. Another compromise would be a commitment contract with an escrow account. In that case, the regulated firm would receive a low wholesale access charge if it does not invest in NGA and a high charge if it does, the difference being held in escrow until the investment has occurred (NeU, NeUMANN and Vogelsang 2011).

\subsubsection{Geographic differentiation of wholesale access regulation}

Competition and the penetration of new infrastructures develop unevenly geographically between urban and rural areas. This is in part addressed in universal service policies (below in Section 2.5). It also concerns, however, the wholesale access policies.

In most countries bottleneck regulation has traditionally been uniform throughout the country. Should that change in the future? Until now one can argue that uniform

\footnotetext{
42 In contrast, BourreAu, CAMBINI and DoĞAN (2013) assume a ,wholesale migration condition", which makes access seekers prefer NGA over copper. Since numerical simulations in Neumann and Vogelsang (2013) show a persistent underestimation of their measured as compared to their theoretical performance delta, in reality fiber investment may also be favored under their MEA approach.
} 
national wholesale access charges (and geographic retail price averaging by the incumbents) export the benefits of competition (and low prices) from urban to rural areas, even if that does not give the rural customers a choice between suppliers. However, if there is sufficient competition in urban areas to allow for deregulation should deregulation also be exported to rural areas? In fact, the NGA development has been associated with moves toward differentiated policies for different geographic areas as done, for example, in the UK.

Modeling this policy issue Bourreau, Cambini and Hoernig (2012a) assume that a regulator may impose a uniform access price, set local access rates, or deregulate access locally. In their model infrastructure competition is viable in densely-populated areas but not elsewhere. They show that uniform cost-covering wholesale access prices lead to too much duplication of infrastructure in urban areas, while marginal cost-based access rules lead to suboptimal rollout and too little duplication. Deregulation in competitive areas is often welfare optimal but can raise wholesale prices in regulated areas. They also show that high regulated access charges in rural areas can increase investment in new infrastructure there, bringing out the tradeoff between expansion of coverage through high prices for wholesale access and high take-up in the covered areas through low prices for wholesale access (GöTz 2009). Empirical evidence from the U.K. confirms the conjecture that deregulation in competitive local areas increases infrastructure investment by both incumbents and competitors in those areas (FABRITZ and FALCK 2013).

Considering the possibility of regulated access to both copper loops and NGA, Bourreau, CAMBINI and DoĞAN (2013) show that geographically differentiated copper access charges can improve investment and welfare performance compared to uniform policies. In particular, making wholesale copper access charge regulation dependent on NGA rollout improves regulatory outcomes. In areas without NGA the copper access charge should be set at cost, while it should be set above cost in areas with NGA build-out. This is related to the escrow solution suggested above. However, in simulations by the authors an NGA access charge in addition to an undifferentiated copper access charge is welfare superior, because it applies to the incumbent and/or an entrant as the potential NGA investor. The authors differentiate between the case of an incumbent investing more in NGA than the entrant and the case of the entrant investing more in NGA than the incumbent. They show that in the first case the copper and NGA wholesale charges should be positively correlated, while they could be positively or negatively correlated in the second case. This differentiation could be particularly important for cities with alternative infrastructures that favor NGA build-out by public utilities.

The literature on geographic differentiation considers the three options (1) no differentiation, (2) differentiation in regulated charges, and (3) deregulation in densely populated areas and regulation in sparsely populated areas. The first option entails cross subsidization and resembles classic universal service policies addressed below in Section 2.5. The second approach reflects the different costs in different areas and is likely to be competitively neutral. The same holds for the third approach, which is in line with the generally pursued policy of successive deregulation, wherever it looks 
feasible. While the second and third approach may increase geographic coverage, they will lead to higher prices in low-density areas. ${ }^{43}$

\subsubsection{Fixed-mobile substitution and fixed-mobile integration at Stage 2}

To the extent that mobile markets are deemed competitive and that mobile competition exerts enough pressure on fixed network operators, wholesale access regulation of fixed networks could be revoked. Such direct competitive pressure seems already to apply to the markets for fixed-line calling in some countries, such as Austria (Briglauer, Schwarz and Zulehner 2011) and can be expected for other countries soon. It is not particularly interesting, though, because such markets for calling are often already sufficiently competitive, even without the additional pressure of mobile operators (STUMPF 2007). More interesting would be if mobile competition would sufficiently constrain market power in fixed access networks so that wholesale enduser access and/or unbundled local loops and back-hauls could be deregulated. However, currently measured demand elasticities are far below that hurdle (STUMPF 2007 and Briglauer, Schwarz and Zulehner 2011). This holds, although, because of the large difference between marginal cost and LRAIC for fixed network access, the relevant cross effect need not be large. While FMS certainly has reduced fixed network subscribership, it may have the additional effect of increasing NGA investment via an "escape competition" effect. This effect, however, appears to follow an inverted ' $U$ ' relationship and tapers off at high mobile penetration rates as shown empirically for the EU countries by BRIGLAUER (2013).

There is also a potentially countervailing effect to FMS coming from FMI. Assuming a fixed network monopoly, HoERniG, Bourreau and CAMBINI (2013) show that FMI leads to more efficient internal FTM prices, while external FTM prices are distorted upwards, amplifying the incumbency advantage of the integrated operator. These properties extend to the case of more than one fixed operator, suggesting that all fixed (mobile) operators should want to be associated with a mobile (fixed) operator. ${ }^{44}$ The authors discuss two remedies for the alleged market failure, a uniform (on-net/off-net) FTM price for the integrated firm or functional separation of fixed and mobile. A third potential remedy would be the provision of wholesale products in order to enable the non-integrated mobile networks to provide fixed services and therefore appear to be integrated as well. That would lead back to square one, where mobile operators impose little or no competitive constraints on fixed competition through FMS. It might even suggest MVNO regulation in order to have sufficiently many integrated fixed-mobile operators.

Since policy conclusions on deregulation of fixed networks crucially may depend on strong substitutability of fixed by mobile services, the empirical conditions for

43 Flacher and JENNEQUin (2012) consider the case of no regulation as well as wholesale price regulation with and without commitment and find that the level of infrastructure deployment (as well as social welfare and number of FTTH consumers) will be at its highest with a combination of price regulation (with commitment) and a minimum coverage constraint.

44 Also, according to (ZIMMERMAN 2007, 2008) integrated carriers have less interest in pursuing FMS than independent mobile operators. 
MFS versus complementarity and FMI should be further worked out in the theoretical and empirical literature.

\subsubsection{Conclusions on Stage 2 policies on one-way access}

Following the U.S. practice of making the essential facility property a necessary condition for ex ante regulation is more deregulatory than the EC approach of the three criteria test. While the ladder-of-investment approach was viewed as a Stage 2 policy that would ultimately lead to deregulation, its implementation and narrow applicability have left it as a stage 1 policy ending in ULL access. Investment incentives are the main objectives of Stage 2 policies, although these incentives have to be balanced against allocative and productive efficiency goals. The empirical evidence suggests that ULL and bitstream access policies have spurred DSL penetration but, so far, have had negative effects on NGA investment if only via negative effects of DSL penetration on NGA investments. This suggests light-handed wholesale access policies in the form of softer regulation, permission of cooperative investments, regulatory holidays or even deregulation. Due to uneven geographical developments of access competition, implicit or explicit geographical differentiation of one-way access regulation will have to be part of Stage 2 and Stage 3 policies. The need for such differentiation may go away if $4 \mathrm{G}$ becomes sufficiently competitive in rural areas.

\subsubsection{New technical and market developments}

\subsubsection{Technological developments characterizing Stage 3 for one-way access}

The main technological development associated with one-way access at Stage 3 is expected NGA deployment, which from the current perspective comes in three main forms.

First, FTTH is traditionally viewed as the one and only future-proof NGA technology. Most developed countries in the world strive for FTTH penetration that is as extensive as possible. At this point in time, FTTH comes in two variants: GPON and P2P. The tradeoff between GPON and P2P is that GPON is less expensive and easier to install incrementally, but that it provides significantly lower quality of service (QoS). The impact of the QoS difference is likely to depend on the worldwide penetration of P2P. If it remains low, so will be the impact of the QoS difference. Thus, there is likely to be a distinct tipping problem (also dependent on discovery of killer apps, which again will depend on penetration of P2P). If - as it appears now - the general expectation is that $\mathrm{P} 2 \mathrm{P}$ will only be built by few countries with a small number of inhabitants, then the QoS advantage of P2P will remain small and may not be worth the cost difference. In any case, it appears that P2P is currently the technology most easily suitable for cooperative investments. ${ }^{45}$

45 Under P2P, only as many fibers as there are cooperating partners would have to be laid, while under PON technologies the fibers of cooperating partners would have to be split. Under current GPON that would require a number of fibers equal to 64 times the number of partners. See, however, Rendon SchneIR and Xiong (2013), who calculate that the cost 
Second, cable TV has made a major step forward with DOCSIS 3.0. Its QoS is very similar to that of GPON FTTH so that the substantially lower incremental cost of moving from conventional cable broadband to DOCSIS 3.0 than from DSL to GPON will give DOCSIS 3.0 a decisive advantage over GPON in countries with a large cable TV footprint. This already shows up strongly in the U.S. There is, however, an intermediate solution for telecommunications networks, and that is VDSL with vectoring.

Third, mobile broadband is moving ahead in strides, driven by the incredibly high popularity of mobile apps. Thus, one can expect mobile broadband (4G) to compete at eye level with the two other NGA technologies and to play out its mobility advantage. Besides on technological advances this will depend decisively on the availability of sufficient spectrum (discussed in Section 2.4 below).

\subsubsection{Market developments characterizing Stage 3 for one-way access}

It appears that countries or regions in countries can be placed in three stylized categories, based on population density and prior infrastructure.

First, there are countries/regions with high cable penetration and/or with an alternative GPON/P2P provider, who has cost advantages that places it at the level or ahead of the telephone incumbent. Cable TV will see DOCSIS 3.0 to be fully competitive against GPON FTTH. GPON is no game changer and may, because of its high incremental costs, be delayed or even be dominated by vectoring with VDSL. P2P is currently the only NGA technology to dominate DOCSIS 3.0 in terms of QoS but at a very high cost. This leads to a likely fixed-network duopoly for NGA in areas covered by cable TV and with alternative GPON/P2P providers. FMS with 4G could turn the NGA duopoly into wider oligopoly. However, FMI could turn the mobile oligopoly back into an integrated duopoly. While this has not yet happened to a large extent (with exceptions, such as Vodafone and Telefonica in Germany), Verizon's highly priced acquisition of Vodafone's $45 \%$ stake in Verizon's mobile network signals that the synergetic and market power effects of full FMI are viewed as significant. Fixed networks (such as cable TV networks) may therefore start buying mobile networks and vice versa. An intriguing related development is that mobile service providers can supply fixed network services, relying on LTE and high-speed package access (HSPA) networks. AT\&T is currently doing that - at very high prices - in Verizon territory (FITCHARD 2013). This hints at the possibility that FMI may actually be available for "pure" mobile networks, though not for "pure" fixed networks. It also hints at potentially fierce competition between AT\&T and Verizon in each other's territories.

Second, there are countries/regions with little or no cable penetration and with only the incumbent GPON/P2P provider. In this case the only infrastructure competition comes from $4 \mathrm{G}$.

disadvantages under cooperative investments for PON technologies would not necessarily be insurmountable. 
Third are (rural) regions without land-based NGA, where only 4G will exist as a competitive force for ultra-fast broadband. ${ }^{46}$

This categorization suggests that without any regulation in many areas, at least infrastructure-based duopolistic broadband competition can be expected with some additional competition coming from independent $4 \mathrm{G}$ operators. However, the independent $4 \mathrm{G}$ operators may have a disadvantage against those integrated with accessbased fixed network competitors. In contrast, there will be less densely populated areas where only $4 \mathrm{G}$ competition appears to be viable and that only under separation of $4 \mathrm{G}$ from the incumbent's fixed network. In this case, access-based fixed network competition may remain essential. Also, there may be areas, where NGA can only be delivered with subsidies, giving rise to universal service policies discussed below.

\subsubsection{Application of literature to new developments}

Above we argued that convergence and FMS generate several parallel ways to produce closely related products. To the extent that these products are deemed to be in the same market no facilities could be essential because there are then at least two ways to produce the same products. Thus, the continued bottleneck regulation would lose its justification, once these different network operators can be shown to operate in the same market (allowing for new service combinations: Triple and quadruple play over the same platform). This is not yet the case but will likely be so in the future and will vary between countries depending, for example, on the extent of the cable TV infrastructure. However, even then it will not be easy to deregulate wholesale access because of the sunk costs incurred by the access seekers under ULL and because of potential asymmetries in market positions between the former telephone incumbent and these other networks. This leads to the question if the bottleneck property is required for justifying continued regulation or if the dominant position of the incumbent (or another network) is enough. ${ }^{47}$ Since there is no straightforward answer, the conclusions below on deregulation remain somewhat tentative. ${ }^{48}$

46 We are here neglecting developments of satellite technologies like ViaSat in the U.S. that may provide NGA-like services for some regions.

47 If a dominant market position is viewed as sufficient for requiring regulation then wholesale access to cable TV networks may also need to be considered in markets where cable dominates.

48 Bourreau et al. (2011) add an interesting twist to the essential facilities debate. The view taken by most applied regulation economists in the U.S. is that duplication of a facility makes access regulation superfluous, not because the access market now becomes competitive but because the retail consumers now have two choices from vertically integrated firms. What Bourreau etal. (2011) show is that the existence of independent non-integrated downstream firms can distort the competition between the integrated firms and, in particular, can lead to monopoly results. Since such outcomes are parameter-dependent, the question is nevertheless if ex ante or ex post regulation is required or if competition policy will do. 
In moving from wholesale access regulation of copper lines in Stage 1 to NGA in stages 2 and 3 the regulatory efficiency frontier has shifted in three ways.

First, the investments in new access networks are increasingly hard to finance. Thus, the regulatory emphasis shifts in Stage 2 from static (allocative and productive) efficiency towards investment and innovation, making soft regulation or cooperative investments potentially efficient options. The issue of investment incentives interacts strongly with net neutrality treated below.

Second, depending on the way NGA networks develop (P2P or GPON) ULL may no longer be the efficient regulatory approach and may have to be replaced by bitstream access. Countries currently depending on ULL may then have a harder time reaching the regulatory efficiency frontier because of the prior sunk investments in ULL technology. These investments will raise resistance among the affected competitors against the new technology. At the same time investors in the new access technology may direct their choices towards investments with less regulation (CRANDALL, EISENACH and INGRAHAM 2013). Fortunately, the emergence of virtual unbundling may prevent stranding of entrants' investments and may allow incumbents free technology choices. ${ }^{49}$ In my view, the new approach by the EC (2013a) of only relying on price squeeze protection for NGA may go too far, because it does not differentiate regions by the availability of other inter-modal competition. Instead, the approach just relies on competitive pressure on NGA from regulated copper access charges. On the other hand, it reverts to cost-based regulation of NGA wholesale access if there is neither inter-modal nor copper-based competition.

Third, at stage 3, deregulation will become possible in high-density regions, where high-speed access can reasonably be duplicated or is already duplicated by cable TV. Under cooperative investment with a single fixed infrastructure, a regulatory holiday approach may be efficient that would end if the cooperating partners are shown to collude. Furthermore, in Stage 3 NGA deregulation should occur in all but rural areas, once sufficient technical and market developments provide for enough competitive substitutes from, e. g., cable modem, vectoring or broadband mobile (that is not owned by a dominant fixed network operator). All this is premised on the assumption that there will be no dominating access technology with the essential facilities property and that enough spectrum is available for $4 \mathrm{G}$ to assert competitive pressure on fixed network technologies.

Table 2 captures the efficient policies for one-way access by stages, densities, and the presence of cable or other NGA networks. Under the density variable we only distinguish high population density (metropolitan areas) from low population densities (rural areas).

49 For a survey of model results for the cost differences between the different FTTH technologies see Crandall, Eisenach and Ingraham (2013). For an explanation of the technologies see Jay, Neumann and Plückebaum (2013). 
Table 2: Efficient policies for one-way access

\begin{tabular}{|c|c|c|c|}
\hline & $\begin{array}{l}\text { Stage 1: Fixed copper } \\
\text { access network }\end{array}$ & $\begin{array}{l}\text { Stage } 2 \text { : NGA penetra- } \\
\text { tion begins }\end{array}$ & $\begin{array}{l}\text { Stage 3: Wide NGA } \\
\text { penetration }\end{array}$ \\
\hline $\begin{array}{l}\text { High density areas } \\
\text { with full cable } \\
\text { penetration or with } \\
\text { other NGA } \\
\text { competitor }\end{array}$ & ULL, bitstream access & $\begin{array}{l}\text { Deregulation possible } \\
\text { if no market domi- } \\
\text { nance; otherwise ULL/ } \\
\text { bitstream for copper } \\
\text { and non-discrimina- } \\
\text { tory access (retail } \\
\text { minus) for NGA; } \\
\text { deregulation for coop- } \\
\text { erative investment } \\
\text { (with some oversight) }\end{array}$ & $\begin{array}{l}\text { Deregulation for sure } \\
\text { only if no market } \\
\text { dominance; otherwise } \\
\text { non-discriminatory } \\
\text { access (retail minus) } \\
\text { for NGA; wholesale } \\
\text { access to copper if run } \\
\text { parallel }\end{array}$ \\
\hline $\begin{array}{l}\text { High density areas } \\
\text { without other NGA } \\
\text { competitor }\end{array}$ & ULL, bitstream access & $\begin{array}{l}\text { ULL, bitstream access } \\
\text { for copper; potentially } \\
\text { non-discriminatory ac- } \\
\text { cess (retail minus) for } \\
\text { NGA, as long as com- } \\
\text { petitive pressure from } \\
\text { copper }\end{array}$ & $\begin{array}{l}\text { Deregulation only if } \\
\text { independent } 4 \mathrm{G} \text { with } \\
\text { sufficient capacity is } \\
\text { widely available; } \\
\text { otherwise ULL/virtual } \\
\text { access regulation for } \\
\text { NGA (end of regula- } \\
\text { tory holiday); whole- } \\
\text { sale access to copper } \\
\text { if run parallel }\end{array}$ \\
\hline Low density areas & Bitstream access & Bitstream access & $\begin{array}{l}\text { Potential deregulation, } \\
\text { once independent } 4 \mathrm{G} \\
\text { is widely available by } \\
\text { more than one opera- } \\
\text { tor; otherwise whole- } \\
\text { sale access to copper }\end{array}$ \\
\hline
\end{tabular}

\subsection{Net neutrality}

\subsubsection{The problem and its current handling}

In the last few years, net neutrality has appeared as a new policy issue in the context of the Internet access of content service providers (CSPs) ${ }^{50}$ It is a specific type of bottleneck problem similar to the termination monopoly because the CSPs need to get access to end-users via ISPs that own the access networks. ${ }^{51}$ The net neutrality issue demonstrates the nature of telecommunications as two-sided markets and the

50 Instead of content service providers CLAFFY and CLARK (2013) use the more general term of "complementors".

51 Bourreau and Lestage (2013), based on Krämer, Wiewiorra and Weinhardt (2013) frame this as a retail termination problem. 
key role of content for competition in the converged sector (VOGELSANG 2009), because networks act as platforms that bring together end-users and CSPs.

SChuETt (2010) distinguishes between net neutrality as a zero price rule and as a non-discrimination rule, where the latter is divided into menus of quality (second degree price discrimination including prioritization) and degradation of traffic (vertical foreclosure). The main examples of network neutrality violations so far are (a) blocking of certain content/application providers and (b) quality and/or price discrimination against or in favor of content and service providers. ${ }^{52}$ KRÄMER, WIEWIORRA and WEINHARDT (2013) note that the term "net neutrality" masks several distinct policy problems, each of which may require different remedies. Differentiating a network regime from a pricing regime, they include in particular, the policy issues two-sided pricing (the "termination fee" model), planned QoS differentiation (including the "CSP tiering" model and discrimination/blocking), and network management.

The net neutrality debate took its roots in the U.S. more than a decade ago. ${ }^{53}$ The FCC codified Internet freedoms in December 2010, stipulating that ISPs have to provide transparency on network management, performance and contractual terms for Internet services, have to treat all Internet traffic without unreasonable discrimination and cannot deliberately slow or block traffic depending on who created the content and where it is going. There is a partial exemption for mobile carriers. Reasonable network management is allowed for all ISPs. These rules are currently under judicial review with uncertain outcome, because the relevant services concern the Internet. Since the Internet is classified as an "information service", common carrier rules that are applied to telephone services appear to be a non-starter in the U.S. ${ }^{54}$

The EU has been a latecomer to the net neutrality debate. As late as 2008, the issue had not really arisen, something that was attributed to the presence of widespread broadband competition based on wholesale access regulation (CARTER, MARCUS and WERNICK 2008). However, net neutrality violations (e. g., prohibiting VOIP services) in relatively competitive mobile services have been widespread in the EU for some time. Also, Krämer, Wiewiorra and Weinhardt (2013) report that in 2009 the German cable TV company Kabel Deutschland was interfering heavily with data transmission. As a precaution, the EU included a specific provision in its regulations allowing national regulators to prescribe minimum service qualities (EU Directive 2009/136/EC of November 25, 2009). Furthermore, EU rules on transparency and blocking are similar to those ordered by the FCC (KRÄMER, WIEWIORRA and WeINHARDT 2013). The EC (2013b) is now proposing more explicit net neutrality regulations that would include mobile services and allow for priority service, as long as the QoS of other services is not impaired.

52 For literature reviews see SChUETt (2010), FAulHABER (2011), and, most systematically, Krämer, Wiewiorra and Weinhardt (2013).

53 See FAulHaber (2011) for more details.

54 The opposition of ISPs against common carrier obligations is peculiar under FRIEDEN's (2013a) claim that common carrier obligations convey substantial benefits to entities subject to them. 
Summing up, the net neutrality issue has emerged as a Stage 2 problem both in the U.S. and the EU.

\subsubsection{Theoretical and empirical literature about policies}

Quality and price discrimination problems similar to those claimed for net neutrality violations arise in many industries and cause much less policy concerns. They are usually addressed by competition policies. So, what is different in the ICT sector so that they should deserve special regulatory treatment? We address two-sided markets, externalities, network capacity limitations, and the convergence issue.

\subsubsection{Two-sided markets}

One distinguishing feature of the net neutrality issue can be that network operators want to charge CSPs for the delivery of content (not necessarily at higher priority) in addition to charging end-users. Most of the theoretical literature recognizes the twosided market nature of the net neutrality problem. Two-sided markets pose intriguing pricing issues. Efficiency can require payments by both sides to the platform provider, who in this case is the network operator (ARMSTRONG 2006, RochET and TIROLE 2006). One of the more general results on two-sided markets is that the market side benefiting more from the platform should contribute more to its costs. The observation that CSPs benefit more from ISP subscribers than vice versa may explain, why ISPs rather want to impose CSP termination fees than putting surcharges on subscribers.

If ISPs charge "termination fees" for delivering content to end users this increases CSPs' costs without increasing their revenues. ${ }^{55}$ This can reduce the number of CSPs and/or lower their ability to innovate, nurturing the argument that two-sided pricing may reduce internet innovation. However, the formal literature as reviewed by Krämer, Wiewiorra and Weinhardt (2013) shows that there will likely be a waterbed effect at work, implying that the imposition of a termination fee on CSPs will lead to a reduction in subscription fees making both CSPs and ISP subscribers better off. This needs to be qualified on account of potential heterogeneity of subscribers w.r.t. different content (ECONOMIDES and TAG 2012). Welfare improvements from termination fees extend to the case of capacity investments by ISPs (NJOROGE et al. 2010). This need not hold, however, if there are several non-competing ISPs terminating content for each other (Musacchio, Schwartz and Walrand 2009). Furthermore, the termination fee model could lead to a fragmentation of the Internet because subscribers mostly single home, while CSPs would not want to pay termination fees to all ISPs. In line with this Kourand, KRÄMER and VAlletti (2013) show that termi-

55 Most modeling of the net neutrality problem is based on CSPs financing their services through advertising, the exception being GEE (2013), who separately considers CSPs selling their services to end-users. In the latter case the network providers want to use discriminatory practices to share in some of the revenues of CSPs, while in the former case they want to share in the advertising revenues. 
nation fees actually increase the likelihood of Internet fragmentation. However, in their model net neutrality regulation in the form of a zero price rule is neither a necessary nor a sufficient condition for preventing fragmentation. They therefore suggest a noexclusivity rule as the appropriate remedy that forbids ISPs and CSPs from striking a deal on the exclusivity of content. Termination fees could also stand in the way of subscribers becoming more and more CSPs themselves (LEE and WU 2009).

Summing up, the literature on net neutrality violations via termination fees signals that there is at best a weak case for forbidding CSP termination fees. However, a non-discrimination provision and an exemption for very small CSPs may be in order.

\subsubsection{External effects on other markets}

Brennan (2011) argues that quality discrimination against CSPs creates negative network effects associated with links to other content. According to him, individual CSPs neglect such links and spillover effects when making their quality choices. ${ }^{56}$ In a formal model, Economides and Hermalin (2012) also show that cross-group externalities may provide a rationale for net neutrality regulation (zero fees for CSPs), but that net neutrality can be detrimental under some parameter values. This can hold both for monopoly and for duopoly network providers. Thus, net neutrality may not appropriately deal with some of those externalities and spillovers (FAULHABER 2011).

\subsubsection{Priority service (CSP tiering)}

Violations of net neutrality in the form of discrimination by mobile service providers in the U.S. and EU suggest that net neutrality is not a monopoly issue. Instead, CHOI, JEON and KIM (2013) suggest that net neutrality violations are an issue of dealing with capacity costs and capacity limits. Violations of net neutrality in the form of priority service or CSP tiering may then be a better way of rationing existing capacity (KRÄMER and WIEWIORRA 2012) and/or may provide incentives for expansion investments in order to provide faster service to those paying for it (e. g., Spulber and Yoo 2009). However, both these benefits are not universal.

Prioritization can increase rationing because of a re-congestion effect if the traffic of CSPs with priority service increases due to the better QoS they can offer their users (ECONOMIDES and Hermalin 2012). Because the CSPs compete with each other, they have interdependent demands so that price and quality discrimination can raise the price for all, which in this case reduces welfare (CHOI and КIM 2010, Cheng, BandyopadHYAY and Guo 2011). Network providers may have incentives to reduce expansion investment in order to induce CSPs to choose priority service. As a

56 Hogendorn (2012) makes the related point that ISPs, not CSPs, neglect the links. „So the ISP makes decisions based on the size of appropriable surplus that each CSP generates and its bargaining position with the CSP. But there is also unappropriable surplus (i. e. the consumer surplus plus any externalities and complementarities) generated by the CSP. This could be very large since we are talking about a general purpose infrastructure, and it may not be correlated with the appropriable part of surplus. That's where the potential welfare loss lies." (Christiaan Hogendorn in written communication) In his view, this is the justification for common carrier regulation. 
result, the best effort quality may be reduced so much that all CSPs choose priority service, which is known as the "dirty road fallacy" (SIDAK and TeECE 2010). However, even under efficiency, it is not clear that providing priority service at a higher price should lead to additional capacity investment. Just like peak-load pricing may efficiently reduce the required peak capacity, priority pricing may lead to less capacity being needed, because only those wanting priority would pay for it and those not needing priority might be required to live with slower services (Gee, 2013). Higher investment in superior network technology can nevertheless result from QoS differentiation that enhances the quality of content provision and therefore increases the demand for content with higher network QoS requirements (BARANES 2013). In particular, papers that allow for entry of new content make a strong case for the likelihood of capacity investments under priority service (KRÄMER and WIEWIORRA 2012, Economides and Hermalin 2012, and Bourreau, Kourandi and Valletti 2012). Thus, allowing QoS differentiation could lead to both better utilization of existing capacity and more efficient (not necessarily more) investment in network capacity.

Based on their reading of the literature, KRÄMER, WIEWIORRA and WEINHARDT (2013) note that CSP tiering is likely welfare enhancing if the dirt road fallacy can be avoided. Minimum Qos standards suggested by BRENNAN (2011) could achieve precisely that.

\subsubsection{Technology convergence of networks}

In my view, the net neutrality issue today is closely related to the technology convergence of networks, although the net neutrality arguments have a vintage that precedes the current convergence issues and goes back to over 10 years of developments related to the Internet's infrastructure. Originally, the Internet was governed by a "one-size-fits-all" approach, meaning that all users were faced with the same QoS. Convergence means integration of communications media and telephone services in the Internet, which suggests QoS differentiation by service requirements and incentives for bundling the services previously provided by specialized networks. ${ }^{57}$ Thus, convergence is associated with highly differentiated services that all travel over now competing networks. These differentiated services individually came from very different legacy networks, such as telephone and cable TV networks with very different QoS requirements than traditional Internet access. Cable TV and telephony are currently turning into full IP services that in some way are indistinguishable from the Internet but are still treated very differently by the cable TV and telephone companies, who give them "priority" treatment as compared to "ordinary" Internet services. To the best of my knowledge, regular telephone service has not yet been accused of violating net neutrality. ${ }^{58}$ However, telephone service is increasingly delivered over

57 For the high policy relevance of bundling content with retail access and an assessment of bundling advantages for cable TV networks see Pereira and VAREDA (2013).

58 KRÄMER, WiEWIORRA and WeINHARDT (2013) see this as a network management issue. Recently, ClafFy and Clark (2013) have taken up this issue as one of layered platforms. Their suggested platform approach provides a refreshingly new way of looking at the issue 
the Internet with priorities and other QoS attributes not available to other Internet connections. ${ }^{59}$ In addition, specific QoS requirements of many new Internet services have evolved. All this leads to an economic case for product differentiation. At the same time, because convergence implies technological similarity it leads to commodity type competition between "pure" networks that offer no content-related services. Such fierce competition would hamper financing the large-scale investments needed for NGN and NGA. Content therefore assumes a key role for networks in a converged environment, because it can counter-act the commoditization of networks. ${ }^{60}$

The net neutrality debate has in some sense reversed the monotonic trend towards deregulation. However, seen in the context of network convergence, it does not come as a surprise. While convergence commoditizes the physical networks, the different networks own complementary assets and know-how that differentiate them from each other. For example, cable TV networks have been associated with programming, while (former) telephone networks have not. Thus, (former) telephone networks in particular would like to gain preferred access to content in order to compete more successfully with cable TV networks. Seen from the content side, the increased competition between networks would increase economic rents going to content. In contrast, violations of net neutrality would reduce competition between networks and transfer content rents to the violating network.

Under convergence, CSPs can in principle access consumers directly and non-discriminately (net neutrality). Without net neutrality, CSPs no longer have guaranteed free access to networks and their subscribers. This changes the bargaining position of content vis-à-vis networks and particularly affects how CSPs compete with network/ content bundles of a network provider. In particular, lack of network neutrality makes exclusive contracts with networks more attractive to CSPs (by disadvantaging other content). Exclusivity arrangements restrict choice of subscribers for content and can lead to a fragmentation of the Internet or even to the tipping of networks in favour of one operator. This is similar to the age-old interconnection issue for telephony, where it led to universal interconnection as the solution.

Assisted by the feature that consumers are single homing, incumbents as ISPs can offer CSPs a large share of a content market. This makes them attractive to CSPs for

of what areas to regulate and what areas not to regulate. In my view, it is related to the EC approach of using market definitions to delineate areas potentially subject to regulation.

59 Content delivery networks like Akamai, while an important substitute for priority service, have also stayed mostly outside the net neutrality debate.

60 This links back to bottleneck access regulation discussed above in Section 2.2. Jan Krämer (in written communication) believes that the net neutrality issue (today) is really only driven by the fact that broadband offers customers the opportunity to circumvent the traditional telco services (voice, SMS), which resulted in diminishing returns from these traditional cash cows. In other words, they lost their gatekeeper position. This has caused network providers to rethink their position in the value chain and to become inventive in tapping new revenue streams. To him it is actually quite surprising that network providers did not find out earlier that they could monetize these gates. 
exclusivity arrangements, which lead to violations of net neutrality against other CSPs (and other networks) and can even exclude rivals without a margin squeeze. Even networks with small market shares can be "competitive bottlenecks", because they "own" access to their customers. However, in order to attract subscribers networks are interested in providing many types of content, a characteristic that would favor inclusiveness.

Thus, net neutrality violations pose a tradeoff for CSPs with market power. On the one hand, exclusive contracts with networks (or fixed take-it-or-leave-it offers) reduce double marginalization, but also reduce the portion of the market that can be captured by the content supplier. On the other hand, exclusive contracts with CSPs can increase market power of networks and exclude rival networks. That potentially reduces the surplus available to the content supplier but the increase in market power is valued by the network, which will likely pay for it.

Summing up, convergence enhances the incidence of net neutrality violations. It will, in particular, be associated with vertical integration, exclusivity arrangements between CSPs and ISPs and preferential treatment of CSPs associated with an ISP. The latter includes priority service for telephone and TV.

\subsubsection{Net neutrality, network competition and competition policy}

In the last section, we argued that net neutrality violations may be driven by the desire to reduce fierce competition between networks. In addition, net neutrality issues abound in the mobile sector with worldwide more robust competition than the fixed network sector (CHOI, JEON and KIM 2013). In contrast, the current section focuses on the effects of net neutrality violations as a function of network competition. Since the net neutrality issue resembles the termination monopoly issue of Section 2.1, this is not unlike the competitive bottleneck issue treated there.

In a two-sided market model with two competing internet platforms and a continuum of heterogeneous CSPs, Bourreau, Kourandi and Valletti (2012) show that in a discriminatory regime with priority pricing network investment and content innovation are both higher and welfare is increased compared to a net neutrality regime. Increased competition among CSPs resulting from discrimination may make CSPs worse off, though.

In contrast, the CHOI, JEON and KIM (2013) competition model with elastic demand (Hotelling model with hinterlands) establishes a somewhat surprising equivalence to a monopoly model with fixed demand. ${ }^{61}$ Thus, their model could explain how net neutrality violations reduce competition. The main feature driving this model is the assumption of QoS coordination for traffic between competing ISPs via reciprocal wholesale termination arrangements that lead to a collusive outcome based on the assumption of highly asymmetric traffic between CSPs and end-users. In my view,

61 Based on Kourandi, Krämer and VAlletti (2013) Jan Krämer (in written communication) notes that if one assumes that content multi homes, but consumers single home, then the results of the papers considering monopoly ISPs will by and large carry over to the case of competing (symmetric) ISPs. 
however, this assumption was valid some time ago (at Stage 1) but is no longer valid (at stages 2 and 3). ${ }^{62}$ Nevertheless, the collusive outcome is intuitively appealing.

Market power of CSPs is barely touched upon in the net neutrality literature, although the market power of Google, Amazon and the like is the subject of political debate and antitrust cases. ${ }^{63}$ There is thus a countervailing market power issue, which makes it unclear if large CSPs should favor or oppose net neutrality (KRÄMER, WiEWIORRA and WEINHARDT 2013).

Overall, it appears that network competition is likely to mellow the net neutrality problem. This would suggest that the "network diversity" approach (SPULBER and Yoo 2009) has merits under network competition.

\subsubsection{Network management}

ISPs have always managed their networks in order to provide their services. Some of these management techniques, such as blocking or tracking illegal content, very much look like violations of net neutrality. Thus, it can be difficult to distinguish network management from violations of net neutrality. In some cases the distinction becomes obvious. For example, blocking of the file-sharing software BitTorrent by Comcast occurred often during off-peak times, when capacity was not restricted in any way. However, views differ on whether prioritizing certain types of traffic, such as voice communications, and charging for priority represent reasonable traffic management. The murkiness of network management practices therefore justifies transparency requirements (FAULHABER 2011).

\subsubsection{Empirical evidence on net neutrality issues}

There are very few empirical cases of documented net neutrality violations. FAulhaber (2011) cites four cases in the U.S. over a period of ten years and doubts that a real net neutrality problem exists. Only the discriminatory practices in the mobile sector indicate frequent and continuing discriminatory behaviour. ${ }^{64}$ The lack of empirical evidence therefore raises the question if the net neutrality problem is largely restricted to specific problems of the mobile sector and if there are enough harms justifying specific regulation. A negative answer to the last question is further backed by the thorough reviews of vertical relationships between firms in general by

62 Their result on collusive outcomes is more complicated and less intuitive than the wellknown LRT (1998a) result mentioned in Section 2.1 above in that it includes prices and qualities and uses the off-net cost pricing principle (LAFFont et al. 2003: LMRT). DeGrabA $(2003,2004)$ has pointed out that for the off-net cost pricing principle to work requires extreme asymmetry in traffic between CSPs and content users. This assumption is also made by CHOI, JEON and KIM (2013). It may have been valid, when LMRT wrote their paper but holds much less today.

63 CHOI and KIM (2010) allow for different bargaining power between network and CSPs, while Hogendorn (2007) explicitly works out this issue. Not only CSPs but also device manufacturers like Apple can exert market power on networks. See HazLETt (2012).

64 See, however, FAUlHABER and FARBER (2010b), who argue that the alleged offences no longer persist in the U.S. 
LAFOnTAine and Slade (2007 and 2008), which demonstrate empirically that very few vertical "restraints" are harmful to consumers.

FAULHABER (2011) argues that any economic model concluding that net neutrality violations with detrimental effects for economic efficiency are very likely to occur must be based on new Internet developments that have not occurred over the last decade. We have, in particular, argued above that accelerating convergence will either require or at least be associated with more service differentiations that will look like net neutrality violations. However, they will not necessarily be harmful.

\subsubsection{Conclusions for net neutrality policy from the literature}

Net neutrality violations in the form of termination fees and paid priority services are likely to become part of the ISP tool set that should generally be allowed, subject to non-discrimination provisions and potential exemptions for small CSPs. The dirt road fallacy can be avoided through minimum quality standards and transparency requirements. Convergence will lead to net neutrality violations in the form of network differentiation. This will soften network competition and may thereby enhance network investment. It could, however, also lead to Internet fragmentation or network tipping, both harming consumers. While in principle the latter can be remedied under competition policy, the former may require policy tools like interconnection.

According to Kocsis and DE BIJL (2007) a clear policy recommendation on net neutrality and its violations can only be formulated against port blocking and deliberate quality degradation under lack of competition. In contrast, the net detrimental or net beneficial effects of CSP access tiering depend on the relationship between static inefficiency effects and dynamic efficiencies or inefficiencies. The static inefficiencies result from market power increases due to product differentiation and from impairment of competitors through vertical restrictions. In contrast, the potential dynamic efficiencies result from the higher profit opportunities from innovations in networks, while dynamic inefficiencies can come from reduced innovations in content. It is not clear if all these effects can be readily identified in practice.

\subsubsection{Application of the literature to new developments}

Since network neutrality is itself a new problem, the technical and market developments have already been included in the previous analysis. There are other neutrality issues looming up and down the value chain of the Internet (e. g., device neutrality and search neutrality), which pose some similar issues (KRÄMER, WIEWIORRA and WEINHARDT 2013).

Convergence is likely to lead to more net neutrality violations, most based on vertical integration, exclusivity arrangements between CSPs and ISPs and preferential treatment of ISP associated CSPs. Since these practices have the potential of being efficiency improving as well as being anticompetitive, there should be no ex ante prohibition but rather an ex post correction of any anti-competitive effects.

In spite of a potentially high incidence of net neutrality violations under ISP competition it appears that network competition is likely to mellow the net neutrality pro- 
blem. This would suggest that the "network diversity" approach (SPULBER and Yoo 2009) has merits under network competition.

While there is hardly any empirical literature, the theoretical contributions clarified the trade-off nature of net neutrality violations. But that precisely makes ex ante policies or per se rules unlikely to be optimal. Achieving net neutrality is hardly ever so good that we should prescribe it under all circumstances. There are cases where it may be better to have some differentiation or discrimination in the market. Those circumstances should lead to a policy of differentiating cases and adjusting to them rather than forbidding everything. While ex ante regulation is not good at dealing with such differentiated issues, ex post competition policy neglects externalities and is restricted to market power issues, when it comes to discriminatory practices. It might therefore need to be complemented by lower levels of regulation than a strict net neutrality policy.

The least intrusive form of such ex ante regulation would be some general transparency requirements for QoS and network management. QoS differentiations, once they come, will be very hard for consumers to evaluate. A particular danger is that, by providing an additional superior service, the networks may also want to deteriorate the current best effort service. Being forced to publish their QoS may induce the networks to become more competitive on the quality front (SLuiJs, SchueTt and Henze 2011). This should hold even though transparency will always be imperfect, because QoS across different networks will be subject to fluctuations and will be hard to guarantee. Nevertheless, transparency would hopefully suffice to let only reasonable discrimination survive.

Somewhat more intrusive would be a non-discrimination policy similar to a common carrier obligation. This would, in particular, include a prohibition of blocking or throttling of particular websites, while offering different service levels at different posted prices would be allowed. The non-discrimination provision should also apply to CSP termination charges where, in addition, an exemption for very small CSPs may be in order. The spread of IP-based telephony also calls into question the interconnection requirements currently applicable to telephone services. It is quite clear that an interconnection obligation will have to be adapted to an Internet environment (WERBACH 2013) in order to avoid a fragmentation of the Internet (KRÄMER, WiEWIORRA and WeINHARDT 2013) and the tipping of markets, which could happen if subscribers single-home. In the U.S., the FCC is leading the way to what FRIEDEN (2013b) calls "quasi-common carrier" status, meaning an obligation to interconnect but without a duty to publish the terms and to charge the same to everyone. In my view, in light of the empirical evidence on efficiencies from vertical integration, the integration of networks and content provision should also be allowed. Access of others to the integrated network would, however, have to be non-discriminatory (and subject to a price-squeeze provision). A stronger form of non-discrimination would be a no-exclusivity rule in order to prevent Internet fragmentation (KouRANDI, KRÄMER and VALLetTi 2013). Such a rule could, however, also be part of an ex post policy that only intervenes if fragmentation becomes serious. 
A third level would be minimum quality standards for a basic service based on the network externality argument (BRENNAN 2011), something that has already been the aim of net neutrality regulation in Europe (KNIEPS 2011). At the same time, priority service with a termination charge should be allowed. Minimum QoS standards could help avoid the dirt road fallacy.

The regulatory efficiency frontier for net neutrality is likely to involve three aspects. First, the more competitive ISPs are, the more likely that "violations" of net neutrality will be efficient (Bourreau, Kourandi and Valletti 2012). Thus, a general policy of prescribing net neutrality is likely to be inefficient (SCHUETT 2010). Second, while in many cases the tools of (ex post) competition policies are likely to be more efficient than ex ante regulation, they are not designed to deal with the network externalities problems associated with net neutrality violations and with discriminations in a competitive environment. This suggests intermediate policies such as transparency requirements, ("quasi"-) "common" carrier rules, or minimum quality regulation for a basic service. In the language of Stage 1 and Stage 2 policies, these are symmetric regulations rather than the asymmetric dominant carrier rules used for one-way access. In deciding which of these policies to apply, a wait-and-see approach may be appropriate. A transparency requirement may be applied right away, because it provides information on the necessity of the next steps, which would only be applied if significant inefficiencies occur. Third, there will be interactions between net neutrality and other policy areas. For example, to the extent that access policy increases network competition, it may obviate net neutrality policy. To the extent that net neutrality violations reduce network competition network access policy is less likely to interfere with desired NGN/NGA investment.

Table 3 shows efficient policies distinguished by policy issues. In addition, competition policy should be applied to all potential net neutrality violations. In my view, the net neutrality issue will have to play itself out in practice rather than through wide-ranging prohibitions. In particular, convergence of telephony, TV and the Internet will reveal the necessity of priority services that regulators will have to accommodate.

Table 3: Efficient policies for net neutrality

\begin{tabular}{|l|l|l|l|}
\hline Policy issues & Stage 1: Internet only & $\begin{array}{l}\text { Stage 2: Emerging } \\
\text { convergence }\end{array}$ & $\begin{array}{l}\text { Stage 3: Full-blown } \\
\text { convergence }\end{array}$ \\
\hline Termination fee & No issue & Common carrier of quasi-common carrier rule \\
\hline Priority service & No active issue & $\begin{array}{l}\text { Transparency requirements; minimum quality } \\
\text { standards }\end{array}$ \\
\hline $\begin{array}{l}\text { Blocking/throttling } \\
\text { and exclusivity ar- } \\
\text { rangements between } \\
\text { ISPs and CSPs }\end{array}$ & $\begin{array}{l}\text { Transparency requirements; common carrier or quasi-common carrier } \\
\text { rule }\end{array}$ & \multicolumn{3}{|l}{} \\
\hline
\end{tabular}




\subsection{Spectrum management}

\subsubsection{The problem and its current handling}

Spectrum management has become a focal policy instrument in many countries because it not only affects the availability of a valuable resource and helps increase competition in the mobile sector but also can provide substantial income to governments. With this combination of attributes, it is likely to stay policy relevant for a long time. Over the last 20 years, spectrum policy has significantly moved away from bureaucratic intervention. Market-based instruments in the form of spectrum auctions have replaced beauty contests for the assignment of spectrum and spectrum licenses have become more fungible with the possibility of being traded. In addition, unassigned spectrum has gained ground where spectrum is less scarce and where interference can be avoided (or overcome by new technologies). The aim of spectrum management is to maximize the economic value of spectrum use by getting more communication out of given frequencies and by increasing the amount of frequencies available for use.

\subsubsection{U.S. policy approaches}

\section{License system}

In the U.S., federal spectrum allocation preceded federal telecommunications regulation. In providing licenses to existing radio stations, the state limited market entry and assumed influence over programming principles (HAzLeTt 2008a). These licenses were renewable and therefore established strong property rights. ${ }^{65}$

The traditional approach to spectrum licensing in the U.S. has been first to allocate a slice of spectrum to a particular use (e. g., radio broadcasting) along with permitted technologies and business models. This administrative assignment of frequency ranges to particular uses has been criticized as inefficient, because it is not guided by the value of frequencies to alternative users and therefore not maximizing welfare. The fear of interference leads to endemic underutilization of administratively assigned spectrum (HAZLETt 2008a). In a second step, licenses are assigned to users, which was originally done on a "first come, first serve" basis (CAVE 2013), then in "beauty contests", followed by lotteries and, since the early 1990s, through auctions (HAZlett 2008a). Such licenses include restrictions on power levels and technologies, in order to avoid interference.

The system of cellular licenses has been associated with much broader rights than previously awarded licenses for broadcast stations and thereby has been moving towards "de facto spectrum ownership" (HAZLETT 2008a). In particular, cellular licenses have been de facto tradable. The necessity for such trading became particularly urgent for cellular spectrum licenses that had originally been handed out for

65 The licensees can expect their licences to be renewed without additional charges, as long as they meet some minimal standards, such as build-outs, quality of service and, in the case of TV and radio CSPs, basic standards of public decency. 
many small geographical areas on the basis of beauty contests and lotteries, which resulted in inefficient and disparate license areas of mobile network providers. Thus, early on in the mobile age, the mobile network providers bought and sold spectra in order to accumulate more efficient and contiguous areas. This was particularly true for MacCaw Cellular (later bought by AT\&T), Nextel (now Sprint Nextel) and Voice Stream (now T-Mobile), which were largely put together by spectrum acquisitions. Such acquisitions usually occur in the form of license transfers with all rights and obligations, and they are usually subject to FCC approval. Spectrum leasing is a newer form of transfer, under which the license holder (legally) remains the same. Leases can be short term or long term, the latter being a close substitute for spectrum trade. The potential role for secondary markets today goes further and includes the legal basis for spectrum sharing in the form of private commons, which would allow for concurrent secondary users.

\section{Unlicensed spectrum}

Unlicensed spectrum has for a long time been used for low-power local communication (incl. Wi-Fi). Users require no licenses but must use certified radio equipment and comply with technical requirements. The FCC has deliberately tried to increase the availability of unlicensed spectrum. For example, white spaces in unused spectrum of TV channels are scheduled for unlicensed use.

\section{Auctions}

In the U.S., spectrum auctions were first held in 1994 and are now required as the allocation method for spectrum licenses. Beauty contests and lotteries proved too slow and too bureaucratic for allocating spectrum for wireless communications (CRAMtOn 2013) and are no longer allowed. New types of so-called ,incentive" auctions are planned for the reallocation of spectrum from broadcasting to cellular use. Such incentive auctions will try to repurpose existing spectrum rights by encouraging existing broadcast television licensees to voluntarily give up spectrum in exchange for a share in the revenues generated from new licenses auctioned off for this spectrum. As a simple value proposition, this should be a win-win situation for cellular, broadcasting and the government, because the value of spectrum per $\mathrm{MHz}-$ pop for mobile services is estimated at 1.28 \$ versus only $0.11-0.15 \$$ for broadcasting (FCC 2008 and 2010, cited by Kwerel, LaFontaine and Schwartz 2012). Although the FCC cannot take away spectrum rights from broadcasters, it can move them into other bands ("repacking"). This facilitates auctions based on generic spectrum rights within the UHF spectrum range. There will be a complicated set of two types of auctions, one to relinquish spectrum ("reverse auction"), one to acquire spectrum ("forward auction"). As a by-product these auctions will also increase the amount of unlicensed spectrum (KwEREL, LAFontaine and Schwartz 2012).

\section{Market power issues}

In the U.S., market power has traditionally been a major issue for the assignment of spectrum to mobile carriers. In the 1990s, the FCC had instated spectrum caps, thereby effectively limiting the market power of winning bidders in spectrum auctions. At that 
time this was the only federal regulation of market power for mobile telephone providers and was ended in the early 2000s. As a consequence of this deregulatory move, the national mobile network oligopoly was allowed to grow tighter so that, effectively, only two market leaders and two followers survived. Competition in mobile services is currently characterized by the four nationwide competitors with an $\mathrm{HHI} \approx 2570$ (FCC 2013). With convergence and the prospects for quadruple play (i. e., the provision of Internet, video, telephone and mobile services as a single package) the position of the two market leaders may actually strengthen so that a de facto duopoly cannot be ruled out (unless the small mobile carriers merge with cable companies).

Today, spectrum caps have been replaced by spectrum screens that allow for more flexibility. However, the failed AT\&T/T-Mobile merger shows high policy sensitivity with respect to market power, and the planned incentive auctions have reignited the debate about spectrum caps vs. spectrum screens so that AT\&T and Verizon may face restrictions in upcoming incentive auctions. According to HAHN and Singer (2012), the large U.S. carriers currently face tighter spectrum license constraints than their smaller competitors (on a million subscribers per $\mathrm{MHz}$ basis).

Starting in 2008, an open access requirement has been included in the $700 \mathrm{MZ}$ spectrum auctions. While FAULHABER and FARBER (2010a) argue that the open access requirements led to decreased value of spectrum assets by about $60 \%$, CRAMTON (2013) contends that auction results across spectrum bands cannot really be compared. Nevertheless, the results suggest that open access policies may be costly for the economy.

\subsubsection{EU approaches}

Within the EU, the UK has been the pacesetter in spectrum policy. The UK has been moving towards an increase in flexible use spectrum, based on a suggestion by CAVE (2002). In 2003, the UK communications regulator Ofcom adopted a strategy of sharply reducing the percentage of spectrum that was allocated by command and control. This, however, turned out to be more difficult than envisaged. Nevertheless, by 2010 the share of markets as the allocation method had increased from $0 \%$ to $35 \%$ and the share of commons from 4\% to 5\% (CAVE 2013). Spectrum bands have been auctioned with some limited flexibility of use. Spectrum in some bands can be traded in secondary markets, but the trading activity has been limited so far. CAVE (2013) explains the lack of major trades by the property of spectrum as a strategic resource for mobile operators. Spectrum in bands with scarcity but no auctions is subject to administered incentive pricing (AIP, discussed below) based on the opportunity cost of spectrum. This includes spectrum held by government agencies. In non-scarce spectrum bands only charges covering administrative costs are levied. Furthermore, there has been refarming of spectrum freed up by the move from analog to digital TV. The UK has also pioneered new definitions of usage rights, where the rights of license holders are defined by maximum interference levels rather than maximum power levels (CAVE and WEBB 2011).

The EC (2013b) is taking initiatives for international coordination of spectrum policies and spectrum allocations. This is particularly important in light of the small size 
of European countries and the amount of unusable spectrum in order to avoid interference across borders (PCAST 2012).

\subsubsection{Conclusions on current spectrum policies}

Spectrum policy has come quite a long way from administrative assignment to auctions, tradable licenses, secondary spectrum markets and unlicensed spectrum. All these policies are part of Stage 1, but continue into stages 2 and 3 with further expansion and refinement.

\subsubsection{Theoretical and empirical literature about policies}

The premise to economic analyses of spectrum allocation is that spectrum is scarce and valuable. The most natural approach of economists to the allocation of scarce goods is the assignment of property rights, if feasible in the form of ownership (COASE 1959). A large part of the spectrum literature is therefore about the feasibility of different types of property rights and the discussion of paths to full ownership (CAve, Doyle and WeBb 2007). Interestingly, a competing approach calls for an increase in unlicensed spectrum and therefore much weaker property rights normally associated with commons (WERBACH 2004). The approach of strengthened property rights is based on the exclusion principle and the ability to sell rights to others so that the value of and the benefits from spectrum are maximized. Interference between different spectrum uses is avoided through Coasean bargaining or liability/tort action. A spectrum owner has the right to be free of interference inside its geographical area or spectrum range. In contrast, under unlicensed spectrum it is in the interest of every user to find spectrum that is free from interference. This is said to provide incentives for innovations in new radio equipment technologies that find such spectrum, easily travel from one wavelength to another or are otherwise robust against interference. In principle both approaches can result in high spectrum use. However, the unlicensed approach crucially depends on technical developments to avoid interference, while the approach of enhanced property rights benefits from such developments but does not depend on them. In fact, HAzLETT (2008a) argues that new technologies able to allow communications without property rights were first created for use under exclusive spectrum rights. Since unlicensed spectrum already plays a significant role in spectrum allocation, the experience there can be used to decide how much more spectrum should be unlicensed

\subsubsection{Licenses and associated rights}

KWEREL and WiLliams (2002) distinguish two types of spectrum liberalization policies, flexibility to particular users (e. g., secondary use) and reallocation of spectrum from one use to another. Full spectrum liberalization would mean that spectrum can be sold in secondary markets and can be used for other than the original license holder's services. In this case, one can expect two opposing effects (HAZLETT 2008b). First, additional spectrum from other frequency bands could become available for cellular use, leading to a price reduction for spectrum. Second, other uses and users will try to acquire spectrum that until now was used for cellular communications, 
leading to price increases. HAZLETT's (2008b) quantitative-empirical analysis of international frequency auctions in countries with and without restrictions on secondary markets shows significantly and $61 \%$ lower auction results for the liberalized markets, taking into consideration other influencing factors. This indicates a sizable reduction in spectrum scarcity. Spectrum liberalization therefore seems to be a good policy so that a case can be made for unregulated secondary spectrum markets (MAYO and WALLSTEN 2010).

Spectrum ownership rights are hard to define and complex (WEISER and HATFIELD 2007/2008). However, these difficulties in defining spectrum rights apply similarly to regulators as to private parties. HAZLETT (2008a) suggests that courts can fill the void of incompletely defined rights better than any administrative spectrum allocation can. ${ }^{66} \mathrm{He}$ points to the success of cellular license coordination and trading between carriers and to contracts between license holders and entities like On-Star or MVNOs for spectrum access. Hazlett further suggests that technical specifications by regulators can largely be replaced by well-designed dispute resolution mechanisms. The FCC can also set limits on interference and let license holders bargain over and monitor actual quality measures. A total lack of interference would signal underutilized airwaves (HAZLETT 2008a).

According to HAZletT (2008a), compared to case-by-case administrative decisions, spectrum markets eliminate unutilized spectrum and administrative delays in making spectrum available. Furthermore, conflicts are dealt with more efficiently and expeditiously. Tradeoffs between harmful interference with one communication and development of another communication can be dealt with based on economic rather than engineering parameters. Nevertheless, both technical and organizational developments are required before genuine ownership rights can be implemented for spectrum. In particular, spectrum sharing is gradually taking shape. CAICEDO and STINE (2013) develop ways to include spectrum consumption modeling (SCM) as a core element of a functioning market for spectrum sharing. They also argue that spectrum sharing requires an organized market, in which a regulator could well play a role just like today in organized markets for electricity. Altamimi, Weiss and McHenry (2013) analyze enforcement issues for spectrum sharing by government agencies, but similar enforcement issues need to be addressed by sharing between private parties. In particular, there are tradeoffs between ex ante rules that avoid interference and ex post rules on monitoring and compensation. Thus, spectrum sharing associated both with licensed and unlicensed spectrum raises the issue of defining and implementing usage rights (CAVE and WEBB 2011). While spectrum sharing can be profitable for primary license holders (Daoud, Alanyali and Starobinski 2013), not much sharing has happened yet and technological developments are slower than were expected a decade ago (Telecommunications Policy 2013).

66 SHLEIFER (2011) argues strongly that the ability of courts in efficiently resolving such issues is quite limited. 


\subsubsection{Spectrum auctions}

While the objective of auctions often is revenue maximization, this is not the proper goal of spectrum auctions, which should allocate spectrum to the users who value it most (CRAMTON 2013). Nevertheless, revenues are a welcome by-product in the political process and can soften politicians to give up idle or less productively used spectrum. Although design issues have marred a number of spectrum auctions outside the U.S., the overall experience has been a major success. ${ }^{67}$ Failures included the first auctions in New Zealand, where the second-price auction design led to very low auction revenues and overly high $3 \mathrm{G}$ auction revenues in the UK and Germany in 2000/ 2001, which (in spite of build-out requirements) may have stifled $3 \mathrm{G}$ investments in those countries. According to KLEMPERER (2002) and CRAmton (2013) the latter auction results were based on insufficient price discovery and on stock prices in a bubble situation rather than a solid analysis of values. Overall, however, there is no evidence that auctions have raised prices of mobile services or otherwise resulted in worse outcomes than beauty contests (MorRIs 2005 and KWEREL 2000). While spectrum auction design at this point has only marginal influence on whether auctions are being used or not, it can have large effects on the extent of regulation and the functioning of spectrum markets (for surveys see McMillan 1994, McAfEe and McMillan 1996, and CRAmton 2002 and 2013).

Starting in 1994, the U.S. has pioneered and refined simultaneous ascending auctions, which created a world-wide standard for auction design. The simultaneous ascending auctions are designed to allocate spectrum bands with a predetermined use. Thus, they require a prior step of assigning bands to particular uses. This then remains a major regulatory task that takes time and resources, and that may explain, why this auction format continues to be preferred by regulators. In contrast, the UK has more recently moved towards combinatorial clock auctions. The combinatorial clock auction allows bidders to sort themselves in such a way that the allocation of bands to uses can be achieved simultaneously with the auction (CRAMTON 2013). This is done through a two-step auction design, where in the first step the quantity of spectrum is allocated to winning bidders and in the second step the exact frequencies are assigned. While Cramton argues that the combinatorial auction format saves time and haggling for the allocation of bands to uses, there is experimental evidence that combinatorial clock auctions are too complicated for the bidders (BICHLER, Shabalin and Wolf 2013). This would preclude the theoretical efficiency gains from actually being realized. This raises doubts if the combinatorial clock auction can provide a more efficient allocation of uses than an administrative or political process.

Very different from the auctions for long-term spectrum licenses would be realtime auctions for spectrum (GANDHI et al. 2007). They would allocate licenses on a very short term basis just like real-time pricing for wholesale electricity. According to CRAMTON (2013) the technology of devices is not yet advanced enough to accommo-

67 Although, at least in Europe, the reputation of auctions among practitioners appears to be fading (Karl-Heinz Neumann in oral communication). 
date the flexibility required for such auctions. However, it is not clear that such spot markets could not be used alongside with long-term contracts. Those would, however require that long-term licenses co-exist with spot transactions.

Auctions are most suitable for fairly large chunks of spectrum (in terms of bandwidth, geographic coverage and license duration). Small spectrum users are therefore largely excluded (PCAST 2012). In order to include those potentially many users other allocation methods, such as sharing or leasing, have to be made available.

Another price mechanism as an alternative to auctions consists of AIP, which uses an opportunity cost approach. AIP means that spectrum users pay for spectrum use on a continuous basis. Compared to auctions this lowers the risk for spectrum users, because payment only occurs if spectrum is used and is adapted to opportunity costs of spectrum. Also, because of their property as variable costs such royalties can reduce competition in the wireless communications markets if the fees are directly linked to spectrum use (RHEE 2012). ${ }^{68}$ In contrast, spectrum auctions for licenses create fixed (and often sunk) costs that increase competition in the market but exclude rivals and reduce competition for the market. Measuring the opportunity cost of spectrum has been done for Italy by CAMBINI and GARELLI (2011) and for the UK by Ofcom, but this turns out to be a daunting task so that woefully crude approximations have been used (CAVE 2013). This makes AIP a highly imperfect pricing method that nevertheless could be applied in cases where auctions are inappropriate, such as for spectrum used by state agencies.

\subsubsection{Market power issues}

Since spectrum is one of the main determinants of wireless capacity, the ability to command spectrum combined with the scarcity of spectrum can allow spectrum holders to foreclose competition. Thus, the willingness to pay (WtP) for spectrum may be higher for large incumbents if, by acquiring spectrum, they can foreclose market competition. On the other hand, spectrum caps for large players increase their costs/lower QoS relative to smaller players with same amount of spectrum. Thus, using spectrum caps as a policy instrument requires a delicate balancing act between curtailing market power and tilting the playing field in favor of entrants.

Market power cannot only be applied in the downstream wireless markets but also in the auctions, thereby influencing the amount and quality of spectrum acquired and prices paid by dominant firms. Such market power and collusion problems have been issues in simultaneous ascending auctions (CRAMTON 2013).

The market power of large players in the spectrum market is likely to lessen the more versatile spectrum becomes. Reduction of market power is therefore a potential side benefit of spectrum liberalization.

68 Such competition-reducing effects in the market as opposed to for the market would also hold for license royalties as a percentage of service revenues. Furthermore, such royalties would not reflect scarcity values. 


\subsubsection{Unlicensed spectrum}

Some experts, such as Werbach (2004), and the U.S. President's Council of Advisors on Science and Technology (PCAST 2012) support a vast extension of unlicensed spectrum way beyond its current uses. What is missing in the literature is a comparative evaluation of the advantages and disadvantages of licensed versus unlicensed spectrum that would allow informed decisions on the appropriate sphere for each. While "commons" have a bad reputation among economists, they can save on transaction costs and can lead to greater spectrum use and to the development of devices that avoid interference.

Generally, unlicensed spectrum (as a commons) works best in an environment with little or no scarcity, such as for devices requiring little bandwidth or power, the prime modern example being Wi-Fi (CRAMTON 2013). However, more recently, new technological developments have opened up the potential for more uses via devices that can find and move to unused parts of the spectrum.

While HAzLetT (2008a) observes that the governmental restrictions placed on emission levels etc. for unlicensed spectrum effectively still exclude most wireless activities, CUI and WeIss (2013) claim that "offloading" strategies of wireless carriers are crowding out genuine unlicensed activities. Even if unlicensed spectrum gives users the freedom and incentive to economize on its use the allocation of spectrum bands to the unlicensed bandwidth remains administrative and therefore not subject to the same cost-benefit calculation that actual users would make (FAULHABER 2006).

In principle "unlicensed" spectrum could be part of a licensing regime, where license holders could set aside spectrum for open uses and charge license fees from the makers of devices using such spectrum (KWEREL and Williams 2002). Such an approach would allow for a unified property regime that eliminates ad hoc administrative allocations of spectrum (HAZLETT 2008a).

Related to unlicensed spectrum is the unlicensed use of licensed spectrum bands with the provision that licensed users are not hindered by interference. This may open up vast resources in spectrum bands occupied by government users who cannot be moved, but occupy large bandwidth. In combination with tiny cells and therefore low power requirements such bandwidth can support LTE services (PCAST 2012).

\subsubsection{Conclusions on the literature on spectrum policies}

Spectrum policy can be characterized by a proliferation of various market-based approaches that successively replace administrative spectrum allocation. Already in Stage 1 liberalization advances by expanding property rights of license holders to trade licenses and allow for secondary use of licensed spectrum. Also restrictions on uses have been reduced. First-time assignment of spectrum by simultaneous ascending bid auctions has been successful and has matured, but it does not cover assignment of spectrum areas to specific uses, which is still done administratively. The large task for Stage 2 is the reassignment of spectrum currently used for broadcasting to mobile communication. This will be done in incentive auctions in the U.S. but may also be done through combinatorial block auctions that combine assignment of spectrum to specific uses with assignment to specific bidders. In Stage 2 market power 
issues in auctions and for spectrum may lessen, as more and more spectrum is traded in market-based processes. Unlicensed spectrum is likely to expand. However, determining the appropriate range of unlicensed spectrum may have to depend on new technical developments.

\subsubsection{Application of literature to new technical and market developments}

In recent years, the amount and value of spectrum used for cellular mobile telephony and broadband has increased rapidly in absolute terms and relative to the value of spectrum used for broadcasting (HAZLETT 2008a). As a result, one of the main tasks of spectrum allocation is to shift spectrum from broadcasting to cellular uses and to make additional (government) spectrum available. On top of that the available spectrum needs to be used more thoroughly.

Shifting spectrum use from broadcasting to cellular mobile telephony and broadband could in principle be achieved under private spectrum ownership. However, such a lumpy shift requires more coordination and planning than the market could achieve in the time required (Kwerel, LaFontaine and Schwartz 2012). ${ }^{69}$ Consequently, the FCC would have significant advantages repurposing spectrum rights within the relevant spectrum bands, in which spectrum users with similar architectures can be grouped together. Thus, if one wants to use real estate as an analogy the regulator's role would be that of zoning frequency bands and making sure that the zoning laws are followed but otherwise allow for private ownership. This requires a specialized regulatory agency (WEISER and HATFIELD 2007/2008). Even where government usage of spectrum cannot be moved to other frequency bands, sharing (at lower priority than the government) may be possible and avail private users of enormous resources (PCAST 2012), but the technical developments may take time to come to fruition (Telecommunications Policy 2013).

Table 4: Efficient policies for radio spectrum

\begin{tabular}{|l|l|l|}
\hline $\begin{array}{l}\text { Stage 1: New assignment of } \\
\text { spectrum to uses }\end{array}$ & $\begin{array}{l}\text { Additional features of Stage 2: } \\
\text { Changing spectrum uses }\end{array}$ & $\begin{array}{l}\text { Additional features of Stage 3: } \\
\text { Liberalizing spectrum uses }\end{array}$ \\
\hline $\begin{array}{l}\text { Simultaneous ascending } \\
\text { auctions; spectrum caps; } \\
\text { renewable licenses with sec- } \\
\text { ondary trading possibilities; } \\
\text { unlicensed spectrum }\end{array}$ & $\begin{array}{l}\text { Incentive auctions for repur- } \\
\text { posing spectrum; first } \\
\text { attempts with combinatorial } \\
\text { clock auctions; secondary } \\
\text { trading possibilities across } \\
\text { uses; more unlicensed } \\
\text { spectrum }\end{array}$ & $\begin{array}{l}\text { Refined combinatorial clock } \\
\text { auctions; widespread spec- } \\
\text { trum sharing; possibly } \\
\text { moving to full-blown spec- } \\
\text { trum ownership; unlicensed } \\
\text { spectrum could become part } \\
\text { of a unified property regime. }\end{array}$ \\
\hline
\end{tabular}

In relation to the choice between private ownership and unlicensed spectrum our current reading of the literature is that unlicensed spectrum will continue to play a

69 CAVE (2013) expresses a similar view held by the UK and other governments. 
legitimate and possibly increasing role in spectrum allocation but has limited applicability. Thus, as illustrated in Table 4, the future regulatory efficiency frontier is characterized by both, unassigned spectrum as a commons and fully tradable spectrum ownership/licenses, each for a different part of the spectrum. Again, there may be large international differences, depending on level of economic activity and on population density. Eventually, the bands for "unlicensed" spectrum may also be assigned in a combinatorial clock auction, where the new "license" holders will generate revenues from appliance makers. Thus, auctions will be used both for assigning licenses and for repurposing of spectrum. The property of being unlicensed would then emerge from private commons. Regulation will be limited to running auctions, facilitating repurposing and acting as an arbitrator between contending issues, such as interference. There will be gradually more and more liberalization, leading to a better allocation and less market power issues.

\subsection{Universal service}

\subsubsection{The problem and its current handling}

\subsubsection{Narrow interpretation of universal service}

Traditionally, universal service has meant the provision of basic telecommunication services to all residents of a country at reasonable charges (PARSONS and BIXBY 2010). ${ }^{70}$ Universal service policies particularly concern connectivity of the poor and high-cost areas to traditional networks. The traditional universal service policies include cross subsidies and direct subsidies to users and/or networks in order to achieve $100 \%$ telephone penetration. Like the "security of energy supply", "universal service" is a political catchword in the name of which many inefficient policies have been implemented. In the U.S. in particular, universal service has been used as the main argument for promoting cross subsidies that both enhanced and prevented competition against the entrenched AT\&T monopoly. They enhanced competition for the long-distance services that subsidized local services and they prevented competition for the latter. For a long time universal service policies were in the interest of (the old) AT\&T and the recipients of cross subsidies but allegedly did not increase telephone penetration, which was enhanced by technical progress and competition (MUELLER 1997).

What is the economic basis for a universal service policy? There are four justifications. First and most traditional has been that of network externalities generated by additional subscribers, whose WtP for subscriptions is less than the price of subscriptions but whose benefits to others would more than compensate for the gap. ${ }^{71}$ How-

\footnotetext{
70 This definition contrasts with MuelLeR's (1997) observation that historically "universal service" in the U.S. has meant a unified telephone network. Mueller's definition would be more closely related to interconnection than to our current view of universal service.

71 For a skeptical view on externalities as a justification for universal service policies see BARNETT and KASERMAN (1998).
} 
ever, that argument only holds for marginal subscribers and does not justify price distortions for all subscribers. Since network externalities decline as penetration approaches $100 \%$, costly universal service policies based on the network externality argument lose their justification at high levels of penetration. ${ }^{72} \mathrm{~A}$ move from telephony to broadband (and NGA) as the universal service target, however, makes a lot of sense under the network externality objective (RIORDAN 2002). A second related rationale concerns productivity and spill-over effects to other economic activities and the economy in general (Röller and WaVerman 2001, Czernich et al. 2011). Third, there is an argument for political participation made possible by universal connection of all citizens and for participation in the social and political interactions of the community. Complementing the first three demand-related justifications is a costrelated justification based on economies of scale. Additional subscribers lower the average costs of subscription and thereby benefit all subscribers. They should be added if their WtP exceeds the incremental costs of their subscriptions rather than the average costs. This argument is stronger for adding additional subscribers in a given area rather than adding additional low-density areas (RIORDAN 2002). All four justifications have to be weighed against the effects of price distortions (including those caused by raising direct subsidies) necessary to gain the benefits. In fact, sometimes the distortions directly cancel out the benefits via the effects of cross elasticities. Thus, higher calling prices made necessary by reduced subscription charges may lead to a lower number of subscribers (HAUSMAN et al. 1993 and WOLAK 1996).

The declared aim of U.S. universal service policy has always been high penetration throughout the country. The means of achieving high penetration included cross subsidization through interstate access charges and business rates and, more recently, explicit subsidies raised as surcharges on telephony. The main subsidy flow today occurs from high-density states to low density states and, within states, from highdensity to low-density areas. This policy has become very costly, and it includes substantial amounts of redistribution. The policy is administratively cumbersome and is likely to delay and distort competition.

After the introduction of competition, the rebalancing of cross-subsidized telephone charges proved to be harder and a greater issue in the U.S. than in EU (CHERRY and BAUER 2002). ${ }^{73}$ This may be due to the larger discrepancy in population densities between regions and the more heterogeneous population in the U.S. Until now fixed termination charges vary strongly between inter-state and intra-state jurisdictions. Intra-state (state PUC jurisdiction) charges are much higher than inter-state and can be up to 12 cents per minute. Such intra-state termination charges are used as subsidies for rural telecommunications. The large termination charge differences have been sustainable because of the requirement for geographically averaged retail charges. In contrast, rebalancing of end-user prices implies that subsidies for maintaining univer-

72 There is, however, little empirical evidence on the size of network externalities (RIORDAN 2002).

73 However, as early as 1996-2002 the U.S. has successfully made efforts of rebalancing in order to accommodate competition (Rosston, SAVAGE and Wimmer 2013). 
sal service policies have to be made explicit. A new U.S. policy on termination charges was started in 2011 as part of the federal policy of gradually moving all, federal and state, termination charges to $\mathrm{B} \& \mathrm{~K}$ over a lengthy time period ending in 2019. This policy shows the interdependence between different policy areas and is linked to compensation payments to rural carriers (for giving up excessive termination charges) via a universal service fund (USF). Before the new rules were issued, small rural carriers on average received only $30 \%$ of their revenues from end-user, but $35 \%$ from termination charges and 35\% from the USF (KWEREL, LAFONTAINE and SchWARTZ 2012).

Newer U.S. universal service policy puts additional emphasis on education and healthcare, on modern technology (and global competitiveness) and on direct universal service subsidies rather than cross subsidization. While these subsidies are still funded by surcharges on other telecommunications services, they are at least compatible with competition. Interestingly, they may fall heavily on the rural users they are supposed to benefit (Turner, 2006), and that may limit their effect on increasing penetration. In addition the U.S. comparatively low broadband penetration can be explained by its high poverty rate (TURNER 2006).

In contrast to the U.S., with the exception of some funding mechanisms in France and Italy, the EU has little to show under the narrow interpretation of universal service policies. European universal service policies are usually much weaker and, as a result, potentially less distorting. In particular, in contrast to the U.S., the European policies have not stood in the way of rebalancing of end-user prices. While European countries generally have geographically uniform rates within each country, the U.S. has local service prices that often geographically vary inversely with costs (ROSSTON and WIMMER 2001).

\subsubsection{Broad interpretation of universal service}

In the last few years, countries have introduced new policies aimed at increasing the desired penetration of advanced broadband services. While these are not officially billed as universal service policies, they fulfill exactly the same function. In contrast, the ubiquity of mobile telephone access around the world has obviated most traditional universal service policies. Today, many countries have plans in place to increase the footprint of broadband and NGA networks, in particular Australia and New Zealand (GIVEN 2010). The tools to do so include subsidies for the build-out, regulatory relief and regulatory holidays. A prime example is the EU Digital Agenda for Europe.

In the U.S. the FCC has issued plans on broadband build-out but has not implemented more than its wholesale access deregulation and the auctioning and repurposing of spectrum that could be used for $4 \mathrm{G}$. At the state and municipal level there is a state-by-state fight over the ability of cities to build their own FTTH networks. As a result, few cities have actually built NGA networks, some to them helped by Google. For a limited time, there have also been federal investment subsidies from economic stimulus programs. 


\subsubsection{Conclusions on current universal service policies}

Stage 1 of universal service policies can be characterized as concentrating on cross subsidies and subsidies aimed at increasing telephone penetration for the poor and rural areas. Stage 2 policies concentrate on direct subsidies and include mobile services (U.S.) and broadband. ${ }^{74}$ They also include geographic wholesale price differentiation. Under the broad interpretation of universal service fall policies with state financing of NGA networks. Overall, in this policy area the U.S. does not exhibit the same level of planning and determination as the European digital agenda.

\subsubsection{Theoretical and empirical literature about universal service policies}

The traditional cross subsidization policy of universal service should have been dead at least since the arrival of competition (which it accelerated if not initiated). The qualification "at least" applies, because a case can be made that it hardly ever led to an increase in telephone penetration. RIORDAN (2002) in his survey of the empirical literature concludes that there has been some small increasing effect on telephone penetration in rural areas and among the poor but that it came at a high price by taxing services with higher demand elasticities. ${ }^{75}$ More subtle forms of intentional cross subsidization survive in the form of uniform pricing and coverage constraints. Valletti, Hoernig And Barros (2002) show that such constraints can have unintended effects. In particular, uniform pricing tends to lower coverage. This is essentially the same issue addressed in Section 2.2.2.7 above on geographic differentiation of wholesale access charges.

RIORDAN (2002) doubts that most of the claimed cross subsidizations from the U.S. universal service policies actually satisfy the FAULHABER (1975) tests (that rarely find cross subsidies). In particular, there is no rigorous showing that long-distance services have subsidized local exchange services. His suggestions for improved policies include third degree price discrimination for both subscriptions and usage in favor of poor households. He is more sanguine about price discrimination in favor of rural areas because of the higher connection costs there. He also favors optional tariffs as a policy tool. In my view, such pricing may actually materialize under competition without universal service policies (as shown by the vast proliferation of mobile telephony in developing countries).

The tension between competition and universal service as policy goals can be bridged by switching to direct subsidies as policies but those naturally reveal the policy costs. OĞUZ (2013) argues that the literature has a good handle on the costs of universal service policies but little on the benefits. As a result, benefits are discussed in political and social frameworks, leading to a prevalence of non-economic considerations in the debate on the need for universal service.

74 In Europe, full mobile coverage is usually assured through build-out requirements stipulated in spectrum licenses.

75 See also Hauge, JAmison and Jewell (2008), who show that participation in programs for the poor has been spotty. 
Broad universal service policies are either directly part of the four policies discussed above in section 2.1-2.4 or they relate to public sector financing or provision of telecommunications services. Related to the latter policies HAUGE, JAMISON and GENTRY (2008) compare the types of markets that municipally owned telecommunications providers in the United States serve to the types of markets that competitive local exchange carriers (CLECs) serve. They find that CLECs focus on potential profitability while municipalities appear to respond to other factors, such as political considerations or the desire to provide competition to incumbents. As a result, municipal providers tend to serve markets that CLECs do not and therefore the presence of a municipal provider in a market does not affect the probability that a CLEC also serves that market. Their results suggest municipalities may not pose a significant competitive threat to CLECs and do not preclude CLEC participation but their work does not extend to the investment incentives of incumbents. FORD (2007) (cited in KRÄMER and SCHNURR (2013)) gets broadly similar results on municipal electric utilities that have economies of scope with broadband deployment. A further positive assessment of municipal utility investment is given by GiLlett, LeHR and Osorio (2006), while Troulos and Maglaris (2011) additionally emphasize the role of municipal initiatives on stimulating NGA demand in rural areas. KRÄMER and SCHNURR (2013) make a strong case for mandated open access to government-financed networks as stipulated by the European State Aid Guidelines.

State ownership is known to have certain advantages and disadvantages over private ownership. In particular, state ownership tends to result in lower prices for consumers but fails to innovate and to minimize costs (SHLEIFER 1998). Public provision of telecommunications networks appears best at the civil infrastructure level because of economies of scope with municipal networks (KRÄMER and SCHNURR 2013). A case in point may be the NGA investments in Switzerland by municipal electric utilities. $^{76}$

\subsubsection{New technical and market developments}

The switch from landline phones to cellular as the dominant subscription mode changed the nature of universal service policies. For fixed networks the main cost is in connectivity, while for mobile networks the main cost is in usage. As a result connection of individuals to networks has become less important than the penetration of highcost areas by networks. For example, the U.S. has now turned to (reverse) auctions as an allocation method for universal service subsidies for increasing mobile coverage. The Mobility Fund Phase I (reverse) auction in September 2012 allocated subsidies to

76 In my view, in cities like Zurich Swisscom saw itself at a cost disadvantage vis-a-vis the municipal electric utilities and was afraid of duplicative investments. So, the cooperative model looked more attractive. The municipals also liked the cooperative model because of the lower financing requirements and because they lacked the market presence of Swisscom and were therefore dependent on access seekers. So, here we have a case with comparative advantages for cooperation and for public provision. 
mobile carriers in remote areas based on cost-effectiveness measures (WALLSTEN 2012). Difficulties in generating participation caused by the remoteness were overcome by simultaneously awarding multiple areas that competed against a fixed total dollar amount (only 300 million \$). Because bidders bid in a discriminatory auction against bidders in other areas, it did not matter that $97 \%$ of the areas received only a single bid. As an innovative auction feature, road-miles were used as the measuring rod for subsidies. The FCC first identified biddable roads, only a fraction of which were awarded portions of the limited total subsidy of $\$ 300$ million. Because of the skewed bidding distribution very high-cost areas received no subsidies.

NGA and the high mobile penetration imply a shift in emphasis of the universal service policy objectives from telephone connectivity to broadband. At this time, broadband connectivity certainly carries network externalities and spill-over effects for the economy as a whole (CZERNICH et al. 2011). ${ }^{77}$ This should, however, hardly be a longrun policy issue, because of enough available radio spectrum in rural areas so that rural areas can be supplied with wireless broadband at reasonable costs. Thus, mobile broadband may make universal service policies superfluous both for telephony and for NGA.

\subsubsection{Application of literature to new developments}

The efficiency frontier for universal service policies clearly depends on the success in the four other policy areas. Will efficient policies in policy areas 1-4 give enough (from a political perspective) access to rural areas and the poor? If not, is there a market failure and therefore a reason for subsidies? Table 5 provides tentative answers.

Table 5: Efficient policies for universal service

\begin{tabular}{|c|c|c|c|}
\hline & Stage 1: Telephone & $\begin{array}{l}\text { Stage 2: Mobile and } \\
\text { broadband }\end{array}$ & Stage 3: NGA \\
\hline High Density Areas & $\begin{array}{l}\text { Subsidies for mobile } \\
\text { and broadband access } \\
\text { of the poor }\end{array}$ & $\begin{array}{l}\text { Subsidies for broad- } \\
\text { band access of the } \\
\text { poor; geographic } \\
\text { wholesale price differ- } \\
\text { entiation, state finan- } \\
\text { cing of NGA networks }\end{array}$ & $\begin{array}{l}\text { Subsidies for broad- } \\
\text { band access of the } \\
\text { poor? Voluntary } 2^{\text {nd }} \\
\text { and } 3^{\text {rd }} \text { degree price } \\
\text { discrimination }\end{array}$ \\
\hline Low Density Areas & $\begin{array}{l}\text { Subsidies for mobile } \\
\text { and broadband access } \\
\text { of the poor; subsidies } \\
\text { for mobile and broad- } \\
\text { band build-out }\end{array}$ & $\begin{array}{l}\text { Subsidies for broad- } \\
\text { band access of the } \\
\text { poor; subsidies for } \\
\text { NGA build-out or } \\
\text { public NGA build-out; } \\
\text { geographic wholesale } \\
\text { price differentiation, } \\
\text { state financing of } \\
\text { broadband networks }\end{array}$ & $\begin{array}{l}\text { Subsidies for broad- } \\
\text { band access of the } \\
\text { poor? } \\
\text { Voluntary } 2^{\text {nd }} \text { and } 3^{\text {rd }} \\
\text { degree price discrimi- } \\
\text { nation }\end{array}$ \\
\hline
\end{tabular}

77 These results may or may not carry over to NGA networks. 
At Stage 3, subsidies, -if any-, will only be justified for the poor or in high-cost areas. Their efficiency is doubtful (and wasteful) even here because of the availability of mobile broadband with less spectrum restrictions in high-cost landline areas and because of the tendency of networks to offer optional and discriminatory tariffs.

\subsection{Interaction of the policy areas}

Termination monopoly, wholesale bottleneck access, net neutrality, spectrum access and universal service interact in various ways that may influence the efficiency frontier for each one of them. Unfortunately, the literature contains little about these interactions. One exception in the net neutrality context is that the termination monopoly may again act as a collusion device, as ISPs negotiate over QoS and pricing, thus potentially increasing the net neutrality problem (CHOI, JEON and KIM 2013). ${ }^{78}$ As a second exception Bourreau and Lestage (2013) show that the relationship between wholesale access regulation and net neutrality is quite complicated. They consider net neutrality violation of the no-price rule for CSPs and show that wholesale access prices and charges to CSPs may reinforce or compensate each other, depending on parameter values. Thus, higher wholesale access charges can lead to either higher or lower termination charges for CSPs.

Without further direct guidance from the literature the following three tables capture conjectured interactions between the five policy areas. Tables 6 and 7 describe interactions between the two policies spectrum management and universal service with each other and with all the other policies. These two policies have the strongest interactions. In contrast, the other three policies interact less and are therefore captured in Table 8 .

Table 6 brings out that spectrum management has developed into the key policy that will continue to hold its place and will facilitate both the further development of the telecommunications sector and the move towards deregulation of termination, of one-way access and of universal service. However, while spectrum prices under these new institutional developments will better reflect the underlying scarcity of spectrum and while more spectrum will become available, the new demands posed by the expansion of the sector may lead to greater scarcity that may limit the competitive effects that $4 \mathrm{G}$ will have on fixed network technologies, "particularly as growing demand for wireless broadband will (for mere technical reasons) dramatically decrease (cubicly) the individually available bandwidth. This is much less the case for fixed networks". ${ }^{79}$ For example, currently data caps are often imposed on mobile broadband, possibly making mobile broadband a complement rather than a substitute for fixed broadband. Increased spectrum scarcity may therefore negatively affect the efficiency of deregulating, for example, one-way wholesale access.

\footnotetext{
78 MANENTI and SCIALÀ (2013) model a somewhat similar relationship between reciprocal termination and one-way access policy, showing that the collusive outcome of reciprocal termination can induce excessive entry. 
Table 6: Interaction between spectrum management and the other four policies

\begin{tabular}{|l|l|}
\hline Termination monopoly & $\begin{array}{l}\text { B\&K increases mobile usage, requiring more spectrum availability. } \\
\text { More spectrum access reduces termination problem by reducing } \\
\text { termination costs and increasing capacity available for B\&K. CBC } \\
\text { (if done right) balances spectrum needs with spectrum availability. }\end{array}$ \\
\hline One-way access & $\begin{array}{l}\text { NGA build-out has ambiguous effects on spectrum demand: NGA is } \\
\text { substitute for 4G but will enhance the creation of high-speed appli- } \\
\text { cations that also run on } 4 \mathrm{G} \text {. More spectrum availability increases } \\
\text { alternatives to fixed network NGAs, potentially making one-way } \\
\text { access regulation superfluous. }\end{array}$ \\
\hline Net neutrality & $\begin{array}{l}\text { Net neutrality violations can reduce capacity needs of mobile } \\
\text { networks and therefore their demand for spectrum. More spectrum } \\
\text { access increases ISP competition, potentially increasing incidence but } \\
\text { reducing effects of net neutrality violations. More spectrum availabil- } \\
\text { ity reduces mobile network capacity limitations, facilitating network } \\
\text { management without net neutrality violations. }\end{array}$ \\
\hline Universal service & $\begin{array}{l}\text { Universal service via subsidizing mobile services will increase spec- } \\
\text { trum demand. However, this will mostly be in rural areas, where } \\
\text { spectrum is less scarce. More spectrum access lowers costs of telecom } \\
\text { services helping universal access; specific spectrum policies for rural } \\
\text { areas are helpful. }\end{array}$ \\
\hline
\end{tabular}

While universal service has a history of interfering with the other policies, this tendency should subside in the future along with universal service policies themselves. Also, as Table 7 shows, only spectrum policy is unambiguously helping the universal service objectives. For all other policies there is a tradeoff between coverage and price level. This creates a potential tension for regulators, whose policy objectives in legal charters almost always sound like a definition of universal service extended to all telecommunications and communications services.

Table 7: Interaction between universal service and the other four policies

\begin{tabular}{|l|l|}
\hline Termination monopoly & $\begin{array}{l}\text { A move to B\&K and/or CBC may increase subscription charges and } \\
\text { lower call charges with ambivalent effects on universal access. Initi- } \\
\text { ally, universal service policies increased termination charges in the U. } \\
\text { S. Now there is a gradual retreat from that policy. }\end{array}$ \\
\hline One-way access & $\begin{array}{l}\text { Soft one-way access policy is likely to lead to NGA build-out, but } \\
\text { end-user charges may be high (tradeoff between coverage and afford- } \\
\text { ability), which may interfere with universal service. Differentiated } \\
\text { one-way access policies at Stage 3 (including deregulation) may in- } \\
\text { crease coverage, thereby helping rural penetration, but may lead to } \\
\text { higher prices in rural areas, thereby reducing take-up, in particular by } \\
\text { the poor. High-density areas will benefit from lower prices. Universal } \\
\text { service subsidies increase investible funds of network providers. }\end{array}$ \\
\hline
\end{tabular}




\begin{tabular}{|l|l|}
\hline Net neutrality & $\begin{array}{l}\text { Net neutrality violations may increase network investments but end- } \\
\text { user charges may be high (tradeoff between coverage and affordabil- } \\
\text { ity), which may interfere with universal service. Publicly built and/or } \\
\text { subsidized networks are likely to be open access, preventing net neu- } \\
\text { trality violations. Universal service policy may require minimum } \\
\text { QoS, which would remedy net neutrality violations. }\end{array}$ \\
\hline Spectrum management & $\begin{array}{l}\text { More spectrum availability increases coverage and reduces prices for } \\
\text { telecom services, reducing the need for universal service policies. } \\
\text { Subsidized fixed NGA build-out may relieve strain on spectrum, but } \\
\text { the effect can be ambivalent if NGA build-out pushes new applica- } \\
\text { tions that also work on 4G. }\end{array}$ \\
\hline
\end{tabular}

Table 8 shows some ambivalent interactions between termination and one-way access on the one hand and net neutrality on the other. Here the price-increasing effects of net neutrality violations have to be traded off against the investment-increasing effects.

Table 8: Interactions between termination monopoly, one-way access, and net neutrality

\begin{tabular}{|l|l|l|l|}
\hline & Termination monopoly & One-way access & Net neutrality \\
\hline $\begin{array}{l}\text { Termination } \\
\text { monopoly }\end{array}$ & N.A. & $\begin{array}{l}\text { Unregulated termination } \\
\text { can lead to collusion be- } \\
\text { tween networks, thus po- } \\
\text { tentially interfering with } \\
\text { competition created by } \\
\text { one-way access policies. }\end{array}$ & $\begin{array}{l}\text { B\& can lead to high- } \\
\text { potentially inducing } \\
\text { network management } \\
\text { techniques that violate } \\
\text { net neutrality. Shut- } \\
\text { down of copper access } \\
\text { in Stage 3 may shift } \\
\text { termination issue to } \\
\text { net neutrality. }\end{array}$ \\
\hline $\begin{array}{l}\text { One-way } \\
\text { access }\end{array}$ & $\begin{array}{l}\text { One-way access creates } \\
\text { competition leading to } \\
\text { competitive bottlenecks, } \\
\text { which may deteriorate ter- } \\
\text { mination monopoly pro- } \\
\text { blem. One-way access has } \\
\text { made long-distance carriers } \\
\text { fade away, which lowers } \\
\text { resistance of networks } \\
\text { against B\&K. }\end{array}$ & N.A. & $\begin{array}{l}\text { Increased competition } \\
\text { resulting from one- } \\
\text { way access may in- } \\
\text { crease incidence but } \\
\text { lower the effects of net } \\
\text { neutrality violations. } \\
\text { One-way access may } \\
\text { reemphasize or inter- } \\
\text { fere with the no price } \\
\text { rule (BouRREAU and } \\
\text { LesTAGE 2013). }\end{array}$ \\
\hline
\end{tabular}




\begin{tabular}{|c|c|c|c|}
\hline & Termination monopoly & One-way access & Net neutrality \\
\hline $\begin{array}{l}\text { Net } \\
\text { neutrality }\end{array}$ & $\begin{array}{l}\text { Priority service implemen- } \\
\text { tation may lead to collusion } \\
\text { on call termination (CHOI, } \\
\text { JEON and KIM } 2013 \text { ), } \\
\text { which could justify contin- } \\
\text { ued termination regulation. } \\
\text { Priority service pricing and } \\
\text { network management tech- } \\
\text { niques can reduce or post- } \\
\text { pone investment } \\
\text { requirements. }\end{array}$ & $\begin{array}{l}\text { Net neutrality violation } \\
\text { may reduce network } \\
\text { competition, which could } \\
\text { increase investment } \\
\text { incentives (one detrimen- } \\
\text { tal and one beneficial } \\
\text { effect). Priority service } \\
\text { could increase or } \\
\text { decrease investments in } \\
\text { more capacity. }\end{array}$ & N.A. \\
\hline
\end{tabular}

\section{Determinants of the end game}

The question mark in the title of this survey results both from unresolved issues in the theoretical and empirical literature and to uncertainties about technical and market developments. One main result has been that deregulation will become likely for oneway access and universal service, with some exceptions. These exceptions include one-way access regulation in certain regions and some universal service policies in remote areas and for the poor. Termination will move to $\mathrm{B} \& \mathrm{~K}$ with a duty to interconnect. In addition some (symmetric) regulation may persist for net neutrality in the form of transparency requirements, (quasi-) common carrier obligations and minimum quality standards. Also, spectrum management, while moving towards full-blown ownership rights will continue to see regulators providing zoning and rezoning services, in particular for unlicensed spectrum. All these assessments are premised on the success of making enough additional spectrum as the key resource available, something that is by no means assured. They are also premised on an absence of a killer technology like P2P FTTH that potentially dominates all other technologies. Rather, we assumed that NGA would take the form of DOCSIS 3.0 and GPON FTTH, which compete with each other at eye level (or that P2P FTTH will be offered cooperatively). ${ }^{80}$ Even with a dominant new technology there may be enough room for substitution and therefore competition.

What determines the endgame in telecommunications policy? Above, we have emphasized technical and market developments that influence the regulatory efficiency frontier. In my view, they will ultimately dominate. However, the literature suggests that institutional and political economy factors have an additional and, in particular, mostly slowing effect on policy changes. ${ }^{81}$ To the extent that these delay-

80 For competition between these technologies, see HoERNIG et al. (2012a).

81 The literature on the slowing effects of regulation ranges from OWEN and BRAEUTIGAM (1978) to von WeIzSÄCKER (2013). However, past regulation can force quick regulatory changes, such as the move of DSL from regulated telecommunications service to unregulated information service in the U.S. 
ing effects reflect the influence of sunk costs they may not be as inefficient as they otherwise appear. For example, maintaining ULL for some time may be efficient in light of the (sunk) investments in networks and collocation equipment undertaken by the participants. Nevertheless, striving for global competitiveness could have an accelerating effect on countries and regulators, potentially counteracting other political influences to the contrary. It could, however, also lead to inefficient investment subsidies.

Since some successful reforms have been associated with deregulation, one might be tempted to suggest deregulation as a solution to reform problems or as a way to avoid such problems altogether. ${ }^{82}$ In my view, benefits from total deregulation include an obvious simplicity and a lack of mistakes from contradictions in a reform packet. They also potentially include the commitment power of deregulation. However, the short-term irreversibility is also the greatest danger because total deregulation will only work if competition is either sustainable at the time of deregulation or if its emergence over time cannot be prevented by the incumbent. In contrast, SAPPINGTON and WEISMAN (2012) suggest erring in favor of earlier rather than later deregulation, because the problems associated with earlier deregulation are deemed more amenable to self-correction than problems associated with falsely continuing regulation. The other side of this principle is erring in favor of later rather than earlier regulation. This could be applied to some of the net neutrality issues, such as the introduction of priority services. Since net neutrality policies remain in the regulatory realm a possible move to a single regulator for networks and content may prove advantageous. ${ }^{83}$ Some countries, such as the U.S. and the UK, already have such an integrated regulator. There appears to be, however, a major difference in approach to content regulation between the U.S. and Europe. In the U.S. content regulation is generally light and restricted to protection of free speech and of children, while Europe takes a more paternalistic approach. As emphasized in Section 2.3 on net neutrality, the increased complexity of multi-sided markets arising from convergence may require a rethinking of competition policy standards (EvANS and ScHMALENSEE 2013). ${ }^{84}$ Furthermore, the difficulty of proving violations in view of complex pricing problems, difficult measurement of price squeezes and potential necessity of ongoing supervision make regulatory agency expertise desirable for judging anticompetitive effects. This suggests the use of competition law criteria and in particular an ex post case-by-case approach by a regulatory agency.

82 Yoo (2011) suggests a three-part test for deregulation. First, are there current sufficiently competitive alternatives? If yes, there should be deregulation. Second, if no, look if competitive alternatives are likely to develop under deregulation and weigh the expected static efficiency losses against the expected (discounted) gains from that new competition. Third, weigh in potential institutional advantages of deregulation, such as regulatory failure, regulatory delays and lack of regulatory commitment power.

83 An issue not specifically addressed in this paper is that of federal vs. state regulation in the U.S. or EC vs. NRA regulation in the EU.

84 For an exposition of antitrust issues in network industries see ECONOMIDES (2006). 
The conclusions of this survey have been somewhat tentative not only because of the inevitable uncertainties surrounding policy predictions but also because of the uneven coverage of the empirical literature. There still is a long way to go towards "results-based" regulation (MAYO 2013).

\section{References}

Aghion, P., N. Bloom, R. Blundell, R. Griffith, and P. Howitt (2005): Competition and Innovation: An Inverted-U Relationship, Quarterly Journal of Economics 120, 701-728.

Altamimi, M., M. B. H. Weiss, and M. McHenry (2013): Enforcement and Spectrum Sharing: Case Studies of Federal-Commercial Sharing. Paper for the $41^{\text {st }}$ annual TPRC, September 27-29.

Areeda, P. (1990): Essential Facilities: An Epithet in Need of Limiting Principles, Antitrust Law Review 58, 841-869.

Armstrong, M. (1998): Network Interconnection in Telecommunications, Economic Journal 108, 545-564.

Armstrong, M. (2002): The Theory of Access Pricing and Interconnection. In: M. E. Cave, S. K. Majumdar, and I. Vogelsang (Eds), Handbook of Telecommunications Economics, North-Holland Elsevier, Amsterdam et al., 295-384.

Armstrong, M. (2006): Competition in Two-Sided Markets, RAND Journal of Economics 37, 668-691.

Armstrong, M., and D. E. M. Sappington (2006): Regulation, competition and liberalization, Journal of Economic Literature 44, 325-366.

Armstrong, M., and D. E. M. Sappington (2007): Recent Developments in the Theory of Regulation. In: M. Armstrong and R. Porter (Eds), Handbook of Industrial Organization, Vol. III, Amsterdam, North Holland.

Armstrong, M., and J. Wright (2009): Mobile Call Termination, Economic Journal 119 (538), F270-F307.

Avenali, A., G. Matteucci and P. Reverberi (2010): Dynamic access pricing and incentives to invest in alternative infrastructures, International Journal of Industrial Organization 28, 167-175.

Bacache, M., M. Bourreau, and G. Gaudin (2013): Dynamic Entry and Investment in New Infrastructures: Empirical Evidence from the Fixed Boradband Industry, forthcoming in Review of Industrial Organization.

Baranes, E. (2013): Net neutrality, network investment and content quality. Paper for the $41^{\text {st }}$ annual TPRC, September 27-29.

Barnett, A. H., and D. L. Kaserman (1998): The Simple Welfare Economics of Network Externalities and the Uneasy Case for Subscribership Subsidies, Journal of Regulatory Economics 13, 245-254.

Berger, U. (2004): Access Charges in the Presence of Call Externalities, Contributions to Economic Analysis \& Policy 3.1, Article 21, http://works.bepress.com/ulrich_berger/1.

Berger, U. (2005): Bill-and-Keep vs. Cost-Based Access Pricing Revisited, Economics Letters $86,107-112$.

Bichler, M., P. Shabalin, and J. Wolf (2013): Do core-selecting combinatorial clock auctions always lead to high efficiency? An experimental analysis of spectrum auction 
designs, Experimental Economics, http://dss.in.tum.de/files/bichler-research/2012_bichler_shabalin_wolf_cca.pdf.

Boffa, F., and $\overline{\text { J }}$. PANZAR (2012): Bottleneck co-ownership as a regulatory alternative, Journal of Regulatory Economics 41 (2), 201-215.

Bouckaert, J., T. Van Dijk, and F. Verboven (2010): Access regulation, competition, and broadband penetration: An international study, Telecommunications Policy 34, 661-671.

Bourreau, M., and J. Drouard (2013): Progressive Entry and the Incentives to Invest in Alternative Infrastructures, http://ses.telecom-paristech.fr/bourreau/Market_Share_ July18_2013.pdf.

Bourreau, M., and R. Lestage (2013): Net Neutrality and Access Regulation, mimeo, May 7.

Bourreau, M., C. Cambini, and P. DoĞan (2012): Access pricing, competition, and incentives to migrate from "old" to "new" technology, International Journal of Industrial Organization 30, 713-723.

Bourreau, M., C. Cambini, and P. DoĞan (2013): Access regulation and the transition from copper to fiber networks in telecoms. EUI Working paper RSCAS 2013/52, July, Robert Schuman Centre for Advanced Studies, Florence School of Regulation, http://cadmus.eui.eu/bitstream/handle/1814/27597/RSCAS_2013_52.pdf?sequence $=1$.

Bourreau, M., C. Cambini, and S. Hoernig (2012a): Geographic Access Rules and Investments. CEPR Discussion Paper No. DP9013, June 2012, http://papers.ssrn.com/ sol3/papers.cfm?abstract_id $=2153445$.

Bourreau, M., C. Cambini and S. Hoernig (2012b): Ex-ante regulation and co-investment in the transition to next generation access, Telecommunications Policy 36 (5), 399-406.

Bourreau, M., C. Cambini, and S. Hoernig (2013): My Fibre or Your Fibre? Cooperative Investment, Uncertainty and Access, January 11.

Bourreau, M., P. DoĞan, and R. Lestage (2013): Level of Access and Infrastructure Investment in Network Industries, June 12.

Bourreau, M., J. Hombert, J. Pouyet, and N. Schutz (2011): Upstream Competition between Vertically Integrated Firms, Journal of Industrial Economics LIX, 677713.

Bourreau, M., F. Kourandi, and T. Valletti (2012): Net Neutrality with Competing Internet Platforms, http://ssrn.com/abstract =2061571, May 17.

BrennAN, T. (2011): Net Neutrality or Minimum Quality Standards: Network Effects vs. Market Power Justifications. In: I. Spieker gen. Döhmann and J. Krämer (Eds), Network neutrality and open access, Nomos Publishing, Baden-Baden.

Briglauer, W. (2013): The Impact of Regulation and Competition on the Adoption of Fibre-Based Broadband Services: Recent Evidence from the European Union Member States, forthcoming in Journal of Regulatory Economics.

Briglauer, W., and I. Vogelsang (2011): The Need for a New Approach to Regulating Fixed Networks, Telecommunications Policy 35 (2), 102-114.

Briglauer, W., G. Ecker, and K. Gugler (2012): The impact of infrastructure and service-based competition on the deployment of next generation access networks: Recent evidence from the European member states, forthcoming in Information Economics and Policy.

Briglauer, W., A. Schwarz, and C. Zulehner (2011): Is Fixed-Mobile Substitution high enough to de-regulate Fixed Voice Telephony? Evidence from the Austrian Markets, Journal of Regulatory Economics 39, 50-67. 
Briglauer, W., G. Götz, and A. Schwarz (2010): Can a Margin Squeeze Indicate the Need for De-regulation? The Case of Fixed Network Voice Telephony Markets, Telecommunications Policy 34, 551-561.

Brito, D., P. Pereira, and J. Vareda (2013): Investment, Dynamic Consistency and the Sectoral Regulator's Objective, forthcoming in B.E. Journal of Economic Analysis and Policy.

Caicedo C. and J. Stine (2013): Spectrum Markets and Sharing via Spectrum Consumption Models. Paper for the $41^{\text {st }}$ annual TPRC, September 27-29.

Cambini, C., and N. Garelli (2011): Evaluation of the opportunity cost of the spectrum: Application to the digital dividend, Telecommunications Policy 35, 633-649.

CAmbini, C., and Y. JiAng (2009): Broadband investment and regulation: A literature review, Telecommunications Policy 33, 559-574.

Cambini, C., and T. Valletti (2004): Access charges and quality choice in competing networks, Information Economics and Policy 16, 391-409.

Cambini, C., and T. Valletti (2008): Information Exchange and Competition in Communications Networks, Journal of Industrial Economics 56, 707-728.

Carter, K., S. Marcus, and C. Wernick (2008): Network Neutrality: Implications for Europe. WIK Discussion Paper No. 314, December.

Cave, M. (2002): Review of Radio Spectrum Management. An independent review commission by HM Treasury, U.K. Government, March.

CAve, M. (2006): Encouraging infrastructure investment via the ladder of investment, Telecommunications Policy 30, 223-237.

Cave, M. (2013): Extending competition in network industries: can input markets circumvent the need for an administered access regime?, forthcoming in Utilities Policy.

Cave, M., and I. Vogelsang (2003): How Access Pricing and Entry Interact, Telecommunications Policy 27 (10/11), 717-727.

Cave, M., and W. WebB (2011): The unfinished history of usage rights for spectrum. 2011 IEEE Symposium on New Frontiers in Dynamic Spectrum Access Networks (DySPAN), $3^{\text {rd }-6^{\text {th }}}$ May 2011, Aachen, Germany.

Cave, M., C. Doyle, and W. Webb (2007): Essentials of modern spectrum management, Cambridge University Press, Cambridge (UK).

Cheng, H. K., S. Bandyopadhyay, and H. Guo (2011): The Debate on Net Neutrality: A Policy Perspective, Informations Systems Research 22, 1-27.

Cherry, B. A., and J. M BAuer (2002): Institutional arrangements and price rebalancing: empirical evidence from the United States and Europe, Information Economics and Policy 14, 495-517.

CHol, S. (2011): Facilities to service based competition, not service to facilities based for broadband penetration: A comparative study between the United States and South Korea, Telecommunications Policy 35, 804-817.

Chol, J. P., and B. C. KIM (2010): Net Neutrality and Investment Incentives, RAND Journal of Economics 41, 446-471.

ChOI, J. P., D.-S. JEON, and B. C. KIM (2013): Net neutrality and internet interconnection, mimeo.

Chou, Y. (2013): Access deregulation in deploying the next-generation infrastructure: an econometric analysis of mandatory unbundling, Chinese Journal of Communication 6 (2), April, 133-156.

Claffy, K. C., and D. D. Clark (2013): Platform Models for Sustainable Internet Regulation. Paper for the $41^{\text {st }}$ annual TPRC, September 27-29. 
Conse, R.H. (1959): The Federal Communications Commission, Journal of Law and Economics 2, 1-40.

Cramton, P. (2002): Spectrum Auctions. In: M. E. Cave, S. K. Majumdar and I. Vogelsang (Eds), Handbook of Telecommunications Economics, North Holland Elsevier, Amsterdam et al., 605-639.

Cramton, P. (2013): Spectrum Auction Design, Review of Network Economics 42 (2), March.

Crandall, R., and J. Hausman (2000): Competition in U.S. Telecommunications Services: Effects of the 1996 Legislation. In: S. Peltzman and C. Winston (Eds), Deregulation of Network Industries: What's Next?, AEI-Brookings Joint Center for Regulation Studies, Washington (DC).

Crandall, R., J. A. Eisenach, and A. T. Ingraham (2013): The long-run effects of copper-loop unbundling and the implications for fiber, Telecommunications Policy 37, 262-281.

CuI, L., and M. B. H. WeIss (2013): Can unlicensed bands be used by unlicensed usage?. Paper for the $41^{\text {st }}$ annual TPRC, September 27-29.

Czernich, N., O. Falck, T. Kretschmer, and Woessmann, L. (2011): Broadband Infrastructure and Economic Growth, Economic Journal 121, 505-532.

Al Daoud, A., M. Alanyali, and D. Starobinski (2013): Economic viability of private commons: Framework and guidelines for profitability, Telecommunications Policy 37 (2-3), 231-240.

DeGraba, P. (2000): Bill and Keep at the Central Office As the Efficient Interconnection Regime. FCC Office of Plans and Policy, Working Paper No. 33.

DeGraba, P. (2002): Bill and Keep as the Efficient Interconnection Regime?: A Reply, Review of Network Economics 1 (1), 61-65.

DeGraba, P. (2003): Efficient Intercarrier Compensation for Interconnected Competing Networks, Journal of Economics and Management Strategy 12, 207-230.

DeGraba, P. (2004): Reconciling the off-net cost pricing principle with efficient network utilization, Information Economics and Policy 16, 475-494.

Dewenter, R., and J. Haucap (2005): The Effects of Regulating Mobile Termination Rates for Asymmetric Networks, European Journal of Law and Economics 20, 185197.

Dewenter, R. and J. Kruse (2011): Calling party pays or receiving party pays? The diffusion of mobile telephony with endogenous regulation, Information Economics and Policy 23, 107-117.

EC (2013a): Commission recommendation of 11.9.2013 on consistent non-discrimination obligations and costing methodologies to promote competition and enhance the broadband investment environment, Brussels, C(2013) 5761 final.

EC (2013b): Proposal for a regulation of the European Parliament and of the Council laying down measures concerning the European single market for electronic communications and to achieve a Connected Continent, and amending Directives 2002/20/EC, 2002/21/EC and 2002/22/EC and Regulations (EC) No 1211/2009 and (EC) No 531/ 2012", Brussels, COM(2013) 627 final.

Economides, N. (2006): Public Policy in Network Industries. NET Institute Working Paper No. 06-01, http://papers.ssrn.com/sol3/papers.cfm?abstract_id $=936469$.

Economides, N., and B. Hermalin (2012): Network Neutrality on the Internet: A Two-sided Market Analysis, RAND Journal of Economics 43 (4), 602-629.

ECONOMIDES, N., and J. TÅ (2012): Net neutrality on the internet: A two-sided market analysis, Information Economics and Policy 24 (2), 91-104. 
Economides, N., K. Seim, and V. B. Viard (2008): Quantifying the benefits of entry into local phone service, RAND Journal of Economics 39, 699-730.

Elixmann, D., K.-H. NeumanN, and U. Stumpf (2013): Zukunft des Wettbewerbs in the Telekommunikation, Netzwirtschaften \& Recht 10 (3\&4), Beiheft.

Evans, D. S., and R. Schmalensee (2013): The Antitrust Analysis of Multi-Sided Platform Businesses. NBER Working Paper No. 18783, February.

Evans, L. T., and G. A. Guthrie (2006): Incentive regulation of prices when costs are sunk, Journal of Regulatory Economics 29, 239-264.

FABRITZ, N., and O. FAlCK (2013): Investment in Broadband Infrastructure Under Local Deregulation: Evidence from the U.K. Broadband Market. CESifo Working Paper No. 4277, June.

Fageda, X., R. Rubio, and M. Termes (2013): Determinants of Broadband Access: Is Platform Competition always the Key Variable to Success?, forthcoming in Information Economics and Policy.

Faulhaber, G. R. (1975): Cross-subsidization: Pricing in Public Enterprises, American Economic Review 65, 966-977.

Faulhaber, G. R. (2003): Policy-induced competition: the telecommunications experiments, Information Economics and Policy 15, 73-97.

Faulhaber, G. R. (2005): Bottlenecks and Bandwagons: Access Policy in the New Telecommunications. In: S. K. Majumdar, I. Vogelsang, and M. E. Cave (Eds), Handbook of Telecommunications Economics, $2^{\text {nd }}$ edition, North Holland Elsevier, Amsterdam et al., 487-516.

Faulhaber, G. R. (2006): The Governing Regime of Spectrum. Vodafone Policy Paper Series No. 5.

Faulhaber, G. R. (2011): Economics of Net Neutrality: A Survey, Communications \& Convergence Review 3 (1), 53-64.

Faulhaber, G. R., and D. J. Farber (2010a): The open Internet: A Customer-Centric Approach, International Journal of Communication 4, 1-20.

Faulhaber, G. R., and D. J. Farber (2010b): Innovation in the Wireless Ecosystem: A Customer-Centric Framework, International Journal of Communication 4, 73-112.

FCC (1996): Implementation of the Local Competition Provisions in the Telecommunications Act of 1996: First Report and Order. CC Docket No. 96-98, FCC 96-325, August 8.

FCC (2008): Auction 73: $700 \mathrm{MZ}$ Band, http://wireless.fcc.gov/auctions/default.htm?jo$\mathrm{b}=$ auction_summary\&id $=73$.

FCC (2010): Connecting America: The national broadband plan, http://www.broadband. gov/plan/.

FCC (2011): In the Matter of Establishing Just and Reasonable Rates for Local Exchange Carriers. NOPR and Further Notice of Proposed Rulemaking, WC Docket No. 07-135.

FCC (2013): Annual Report and Analysis of Competitive Markets With Respect to Mobile Wireless, Including Commercial Mobile Services. Sixteenth Report, FCC 13-34, 21 March 2013, http://transition.fcc.gov/Daily_Releases/Daily_Business/2013/db0321/ FCC-13-34A1.pdf.

FITCHARD, K. (2013): AT\&T's latest home broadband service isn't DSL or fiber. It's LTE, July 29, http://gigaom.com/2013/07/29/atts-latest-home-broadband-service-isnt-dsl-orfiber-its-lte/?utm_source $=$ feedburner\&utm_medium $=$ feed\&utm_campaign $=$ Feed $\% 3 \mathrm{~A}$ + OmMalik + \%28GigaOM $\% 3 \mathrm{~A}+$ Tech $\% 29$. 
Flacher, D., and H. Jennequin (2012): Access regulation and geographic deployment of a new generation infrastructure. Proceedings of the $19^{\text {th }}$ ITS Biennial Conference 2012, Bangkok.

ForD, G. S. (2007): Does a municipal's supply of communications crowd out private communications investment? An empirical study, Energy Economics 29, 467-478.

Frieden, R. (2013a): The Mixed Blessing of a Deregulatory Endpoint for the Public Switched Telephone Network, Telecommunications Policy 37 (4-5), 400-412.

Frieden, R. (2013b): The Rise of Quasi-Common Carriers and Conduit Convergence. Paper for the $41^{\text {st }}$ annual TPRC, September 27-29.

Gandhi, S., C. Buragohain, L. CaO, H. Zheng, and S. Suri (2007): A General framework for Wireless Spectrum Auctions, UCSB Technical Report.

Gans, J. S., and S. P. KING (2001): Using 'Bill and Keep' Interconnection Arrangements to Soften Network Competition, Economics Letters 71, 413-420.

Gans, J., and S. KING (2002): Access Holidays and the Timing of Infrastructure Investment. Melbourne Business School Working Paper No. 2002-14, http://ssrn.com/sol3/ papers.cfm?abstract_id $=361500$.

GANS, J., and S. KING (2003): Access Holidays for Network Infrastructure Investment, Agenda 10, 163-178.

Gans, J. S., S. P. King, and J. Wright (2005): Wireless Communications. In: S. K. Majumdar, I. Vogelsang, and M. E. Cave (Eds), Handbook of Telecommunications Economics, $2^{\text {nd }}$ edition, North Holland Elsevier, Amsterdam et al., 241-285.

Garrone, P., and M. Zaccagnino (2012): A too short ladder? Broadband investments and local loop unbundling in EU countries, http://papers.ssrn.com/sol3/papers.cfm?abstract_id = 2109423, July 16.

GeE, E. (2013): Essays on the Economic Effects of Net Neutrality Regulation. Unpublished doctoral dissertation, Graduate School of Arts and Sciences, Boston University.

Genakos, C., and T. Valletti (2011a): Testing the 'Waterbed' Effect in Mobile Telephony, Journal of the European Economic Association 9 (6), 1114-1142.

Genakos C, and T. Valletti (2011b): Seesaw in the air: Interconnection regulation and the structure of mobile tariffs, Information Economics and Policy 23, 159-170.

Genakos C, and T. Valletti (2012): Regulating prices in two-sided markets: The waterbed experience in mobile telephony, Telecommunications Policy 36, 360-368.

Geradin, D., and J. G. Sidak (2005): European and American Approaches to Antitrust Remedies and the Institutional Design of Regulation in Telecommunications. In: S. K. Majumdar, I. Vogelsang, and M. E. Cave (Eds), Handbook of Telecommunications Economics, $2^{\text {nd }}$ edition, North Holland Elsevier, Amsterdam et al., 517-553.

Gerpott, T. J., and P. WinZer (2013): Entgelte für kupferbasierte Teilnehmeranschlussleitungen und Entwicklung des Marktes für Anschlussnetze der nächsten Generation, Netzwirtschaften \& Recht 10 (5), 178-184.

Gillett, S. E., W. H. Lehr, and C. A. Osorio (2006): Municipal electric utilities' role in telecommunications services, Telecommunications Policy 30, 540-549.

Given, J. (2010): Take your partners: Public private interplay in Australian and New Zealand plans for next generation broadband, Telecommunications Policy 34, 540-549.

Götz, G. (2009): Competition, Regulation, and Broadband Access to the Internet. MAGKS Discussion Paper No. 24, February 2009.

GrajeK, M., and L.-H. Röller (2012): The Effect of Regulation on Investment in Network Industries: Evidence from European Telecoms, Journal of Law and Economics $55,189-216$. 
Grandblaise, D., C. Kloeck, T. Renk, P. Bag, P. Levine, K. Moessner, J. YANG, M. PAN and K. Zhang (2007): Microeconomics Inspired Mechanisms to Manage Dynamic Spectrum Allocation, New Frontiers in Dynamic Spectrum Access Networks, DySPAN 2007, 2nd IEEE International Symposium, 452-461.

Growitsch, C., J. Marcus, and C. Wernick (2010): The Effects of Lower Mobile Termination Rates (MTRs) on Retail Price and Demand, Communications and Strategies 80 (4), 119-140, http://ssrn.com/abstract $=1813687$.

Gruber, H., and P. Koutroumpis (2013): Competition enhancing regulation and diffusion of innovation: the case of broadband networks, Journal of Regulatory Economics 43 (2), 168-195.

Grzybowski, L. (2005): Regulation of Mobile Telephony across the European Union: An Empirical Analysis, Journal of Regulatory Economics 28, 47-67.

GuAL, J. (2003): Market definition in the telecoms industry, IESE, DI-517-E, 09/2003.

Hahn, R., and H. Singer (2012): Wireless Competition: An Update. Georgetown University, Center for Business \& Public Policy, Economic Policy Vignette 2012-05-02.

Harbord, D., and S. Hoernig (2012): Welfare Analysis of Regulating Mobile Termination Rates in the UK with an Application to the Orange/T-Mobile Merger, mimeo, November 5 .

Harbord, D., and M. Pagnozzi (2010), Network-Based Price Discrimination and 'Billand-Keep' vs. 'Cost-Based' Regulation of Mobile Termination Rates, Review of Network Economics 9 (1), Article 1.

Hauge, J. A., M. A. Jamison, and T. Jewel (2008): Discounting telephone service: An examination of participation in the Lifeline Assistance Program using panel data, Information Economics and Policy 20, 135-149.

Hauge, J. A., Jamison, M. A., and R. J. Gentry (2008): Bureaucrats as entrepreneurs: Do municipal telecommunications providers hinder private entrepreneurs?, Information Economics and Policy 20, 89-102.

Hausman, J. and J. Wright (2006): Two Sided Markets with Substitution: Mobile Termination Revisited, http://economics.mit.edu/files/1038.

Hausman, J., T. Tardiff, and A. Belifante (1993): The effects of the breakup of AT\&T on telephone penetration in the United States, American Economic Review, Papers and Proceedings 83, 178-184.

Hazlett, T. W. (2008a): Optimal Abolition of FCC Spectrum Allocation, Journal of Economic Perspectives 22, 103-128.

Hazlett, T. W. (2008b): Property Rights and Wireless License Values, Journal of Law and Economics 51, 563-598.

Hazlett, T. W. (2012): Gravitational Shift. Barron's, Editorial Commentary, Saturday, March 31.

Hazlett, T. W., and R. E. MuÑoz (2009): A welfare analysis of spectrum allocation policies, RAND Journal of Economics 40, 424-454.

Hermalin, B., and M. Katz (2011): Customer or Complementor? Intercarrier Compensation with Two-Sided Benefits, Journal of Economics \& Management Strategy 20, 379-408.

HöFfler, F. (2007): Cost and benefits from infrastructure competition: Estimating welfare effects from broadband access competition, Telecommunications Policy 31, 401418.

Hoernig, S. (2007): On-net and off-net pricing on asymmetric telecommunications networks, Information Economics and Policy 19, 171-188.

Hoernig, S. (2012): The Breakdown of Connectivity Breakdowns, mimeo, September 27. 
Hoernig, S., M. Bourreau, and C. Cambini (2013): Fixed-Mobile Integration, forthcoming in Journal of Regulatory Economics, http://papers.ssrn.com/sol3/papers.cfm? abstract_id $=2228684$.

Hoernig, S., R. Inderst, and T. VAlletti (2013): Calling clubs: Network Competition with Non-Uniform Calling Patterns, forthcoming in RAND Journal of Economics.

Hoernig, S., S. Jay, K.-H. Neumann, M. Peitz, T. Plückebaum, and I. VogelSANG (2012a): The impact of different fibre access network technologies on cost, competition and welfare, Telecommunications Policy 36, 96-112.

Hoernig, S., S. Jay, W. Neu, K.-H. Neumann, T. Plückebaum, and I. VogelSANG (2012b): Wholesale pricing, NGA take-up and competition, Communications and Strategies $86(2), 153-174$.

Hogendorn, C. (2007): Broadband Internet: net neutrality versus open access, Economics and Economic Policy 4, 185-208.

Hogendorn, C. (2012): Spillovers and Net Neutrality. In: G. R. Faulhaber, G. Madden, and J. Petchey (Eds), Regulation and the Performance of Communication and Information Networks, Edward Elgar, Cheltenham (UK).

Hurkins, S. and D.-S. JeOn (2012), "Promoting Network Competition by Regulating Termination Charges", International Journal of Industrial Organization 30, pp. 541552.

Hurkins, S. and Á. Lopéz (2013): Mobile Termination, Network Externalities, and Consumer Expectations, mimeo, January 2013, http://angelluislopez.net/ficheros/ MTNECE_Jan_2013.pdf.

Jay, S., K.-H. Neumann, and T. Plückebaum (2013): Comparing FTTH access networks based on P2P and PMP fibre technologies, forthcoming in Telecommunications Policy.

Jeon, D.-S., and S. Hurkins (2008): A Retail Benchmarking Approach to Efficient Two-Way Access Pricing: No Termination-Based Access Discrimination, RAND Journal of Economics 39, 822-849.

JeOn, D.-S., J.-J. LAFFont, and J. Tirole (2004): On the 'receiver-pays' principle, RAND Journal of Economics 35 (1), 85-110.

Jullien, B., P. Rey, and W. Sand-Zantman (2012): Termination fees revisited, mimeo, March 2012, http://idei.fr/doc/by/rey/termination.pdf.

Katz, M., and C. Shapiro (1985): Network Externalities, Competition and Compatibility, American Economic Review 75, 424-440.

Kennet, D. M., and E. K. RAlph (2007): Efficient interconnection charges and capacity-based pricing, International Economics and Economic Policy 4, 135-158.

Klemperer, P. (2002): How (not) to run auctions: The European 3G auctions, European Economic Review 46, 829-845.

KniePs, G. (2011): Market Driven Network Neutrality and the Fallacies of Internet Traffic Quality Regulation, International Telecommunications Policy Review 18 (3), 1-22.

Knieps, G., and I. Vogelsang (2007): Digital economy and regulatory issues - Introduction, International Economics and Economic Policy 4, 101-107.

Kocsis, V., and P. W. J. DE BiJL (2007): Network neutrality and the nature of competition between network operators, International Economics and Economic Policy 4, 159184.

Kourandi, F., J. Krämer, and T. Valletti (2013): Net Neutrality, Exclusive Contracts and Internet Fragmentation, mimeo, February 4. 
Krämer, J., and D. Schnurr (2013): A Unified Framework for Open Access Regulation of Telecommunications Infrastructure: Literature Review and Policy Guidelines, mimeo, August 2.

Krämer, J., and I. Vogelsang (2012): Co-Investments and Tacit Collusion in Regulated Network Industries: Experimental Evidence, http://papers.ssrn.com/sol3/papers. cfm?abstract_id $=2119927$, July 30.

Krämer, J., and L. Wiewiorra (2012): Network Neutrality and Congestion Sensitive Content Providers: Implications for Content Variety, Broadband Investment and Regulation, Information Systems Research 23 (4), 1303-1321.

Krämer, J., L. Wiewiorra, and C. Weinhardt (2013): Net neutrality: A progress report, forthcoming in Telecommunications Policy.

Kwerel, E., and J. Williams (2002): A Proposal for A Rapid Transition to Market Allocation of Spectrum. Federal Communications Commission OPP Working Paper 38, November.

Kwerel, E., P. LaFontaine, and M. Schwartz (2012): Economics at the FCC, 20112012: Spectrum Incentive Auctions, Universal Service and Intercarrier Compensation Reform, and Mergers, Review of Industrial Organization 41 (4), 271-302.

Laffont, J.-J., and J. Tirole (2000): Competition in Telecommunications. MIT Press, Cambridge (MA).

Laffont, J.-J., P. Rey, and J. Tirole (1998a): Network Competition: I. Overview and Nondiscriminatory Pricing, RAND Journal of Economics 29, 1-37.

Laffont, J.-J., P. Rey, and J. Tirole (1998b): Network Competition: II. Price Discrimination, RAND Journal of Economics 29, 38-56.

Laffont, J.-J., S. Marcus, P. Rey, and J. Tirole (2003): Internet Interconnection and the Off-Net-Cost Pricing Principle, RAND Journal of Economics 34, 370-390.

Lafontaine, F., and M. Slade (2007): Vertical Integration and Firm Boundaries: The Evidence, Journal of Economic Literature 45, 629-685.

Lafontaine, F., and M. Slade (2008): Exclusive Contracts and Vertical Restraints: Empirical Evidence and Public Policy. In: P. Buccirossi (Ed.), Handbook of Antitrust Economics, MIT Press, Cambridge (MA), 391-414.

LEE, R., and T. Wu (2009): Subsidizing creativity through network design: Zero pricing and net neutrality, The Journal of Economic Perspectives 23, 61-76.

Littlechild, S. C. (2006): Mobile termination charges: Calling Party Pays versus Receiving Party Pays, Telecommunications Policy 30, 242-277.

Mandy, D. M. (2009): Pricing Inputs to Induce Efficient Make-or-Buy Decisions, Journal of Regulatory Economics 36, 29-43.

Manenti, F. M., and A. Scialà (2013): Access regulation, entry and investment in telecommunications, Telecommunications Policy 37 (6-7), 450-468.

Marcus, S. (2002): The potential relevance to the United States of the European Union's newly adopted regulatory framework for telecommunications. Federal Communications Commission, OPP Working Paper 36, July.

Mattos, C. (2009): Open access policies, regulated charges and non-price discrimination in telecommunications, Information Economics and Policy 21, 253-260.

MacAvoy, P. (1996): The Failure of Antitrust and Regulation to Establish Competition in Long-distance Telephone Services. MIT Press and AEI Press, Cambridge (MA) et al..

Mayo, J. (2013): The Evolution of Regulation: Twentieth Century Lessons and TwentyFirst Century Opprtuninites, Federal Communications Law Journal 65, 119-156. 
Mayo, J., and S. Wallsten (2010): Enabling Wireless Communications, Information Economics and Policy 22, 61-72.

McAfee, P. R., and J. McMillan (1996): Analyzing the Airwaves Auction, Journal of Economic Perspectives 10, 159-175.

McMillan, J. (1994): Selling Spectrum Rights, Journal of Economic Perspectives 8, $145-162$.

Minaminashi, N. (2012): Natural Monopoly and Distorted Competition: Evidence from Unbundling Fibre-Optic Networks, mimeo.

Morris, A. (2005): Spectrum auctions: distortionary input tax or efficient revenue instrument?, Telecommunications Policy 29.

Mueller, M. (1997): Universal service: Competition, interconnection, and monopoly in the making of the American telephone system. MIT Press, Cambridge (MA).

Musacchio, J., G. Schwartz, and J. Walrand (2009): A two-sided market analysis of provider investment incentives with an application to the net neutrality issue, Review of Network Economics 8, 22-39.

Nardotto, M., T. Valletti, and F. Verboven (2013): Unbundling the incumbent: Evidence from UK broadband, mimeo, February 27.

Neu, W., K.-H. Neumann, and I. Vogelsang (2011): Cost Methodologies and Pricing Schemes to Supportthe Transitionto NGA. wik-consult Report to ECTA, Bad Honnef, December.

Neumann, K.-H, and I. Vogelsang (2013): How to price the unbundled local loop in the transition from copper to fiber access networks?, Telecommunications Policy 37 (10), 893-903.

Nitsche, R. and L. Wiethaus (2011): Regulation and Investment in Next Generation Networks-a Ranking of Regulatory Regimes, International Journal of Industrial Organization 29 (2), 263-272.

Nuoroge, P., R. Ozdaglar, N. Stier Moses, and G. Weintraub (2010): Investment in two-sided markets and the net neutrality debate. Columbia Business School Working paper DRO 2010-05.

NoAm, E. (2002): Interconnection Practices. In: M. E. Cave, S. K. Majumdar, and I. Vogelsang (Eds), Handbook of Telecommunications Economics, North Holland Elsevier, Amsterdam et al., 385-421.

Nuechterlin, J. E., and P. J. Weiser (2013): Digital Crossroads. MIT Press, Cambridge (MA), and London, $2^{\text {nd }}$ edition.

OĞuz, F. (2013): Universal service in Turkey: Recent developments, Telecommunications Policy 37 (1), 13-23.

Owen, B., and R. Braeutigam (1978): The Regulation Game: Strategic Use of the Administrative Process. Ballinger Press, Cambridge (MA).

PARKer, P. M., and L. H. Röller (1997): Collusive conduct in duopolies: Multimarket contact and cross-ownership in the mobile telephone industry, RAND Journal of Economics 28, 304-322.

Parsons S., and J. Bixby (2010): Universal service in the United States: A focus on mobile communications, Federal Communications Law Journal 62, 119-152.

PCAST (2012): Report to the President-Realizing the Full Potential of Government-held Spectrum to Spur Economic Growth, President's Council of Advisors on Science and Technology, http://www.whitehouse.gov/administration/eop/ostp/pcast/docsreports, July.

Pereira, P., and J. Vareda (2013): How will telecommunications bundles impact competition and regulatory analysis?, Telecommunications Policy 37 (6-7), 530-539. 
PINDYCK, R. S. (2007): Mandatory Unbundling and Irreversible Investment in Telecom Networks, Review of Network Economics 6, 274-298.

Rao, J. M., and D. H. Reiley (2012): The Economics of Spam, Journal of Economic Perspectives 26 (3), 87-110.

RendA, A. (2010): Competition-regulation interface in telecommunications: What's left of the essential facilities doctrine?, Telecommunications Policy 34, 24-35.

Rendon Schneir, J., and Y. Xiong (2013): Economic implications of a co-investment scheme for FTTH/PON architectures, Telecommunications Policy 37 (10), 849-860.

Rhee, H. (2012): A review of the spectrum license fee under demand uncertainty, Asian Journal of Information and Communications 4 (2), 1-4.

Riordan, M. H., (2002): Universal Residential Telephone Service. In: M. E. Cave, S. K. Majumdar, and I. Vogelsang (Eds), Handbook of Telecommunications Economics, North Holland Elsevier, Amsterdam et al., 423-473.

Rochet, J. C., and J. Tirole (2006): Two-sided markets: A progress report, RAND Journal of Economics 37, 645-667.

Röller, L. H., and L. WAVERman (2001): Telecommunications Infrastructure and Economic Development: A Simultaneous Approach, American Economic Review 91, 909923.

Rosston, G. L., S. T. Savage, and B. S. Wimmer (2013): Effect of Network Unbundling on Retail Prices: Evidence from the Telecommunications Act of 1996, Journal of Law and Economics 56 (2), 487-519.

Sappington, D. E. M. (2005): On the Irrelevance of Input Prices for Make-or-Buy Decisions, American Economic Review 95, 1631-1638.

Sappington, D. E. M., and D. L. Weisman (2012): Regulating regulators in transitionally competitive markets, Journal of Regulatory Economics 41, 19-40.

Schiff, A. (2008): The 'Waterbed Effect' and Price Regulation, Review of Network Economics 7 (3), 392-414.

Schuett, F. (2010): Network Neutrality: A Survey of the Economic Literature, Review of Network Economics 9 (2), 1-15.

Shleifer, A. (1998): State versus Private Ownership, Journal of Economic Perspectives $12,133-150$.

Shleifer, A. (2011): Efficient Regulation. In: D. P. Kessler (Ed.), Regulation vs. Litigation: Perspectives from Economics and the Law, University of Chicago Press, Chicago.

Shy, O. (2001): The Economics of Network Industries. Cambridge University Press, Cambridge (UK).

Sluijs, J. P., F. Schuett, and B. Henze (2011): Transparency regulation in broadband markets: Lessons from experimental research, Telecommunications Policy 35, 593-602.

Solon (2011): Broadband on Demand: Cable's 2020 Vision. Solon Management Consulting, March 2011.

Spulber, D. F., and C. S. Yoo (2009): Networks in Telecommunications. Cambridge University Press, Cambridge (UK) et al..

Stumpf, U. (2007): Regulatory Approach to Fixed-Mobile Substitution, Bundling and Integration. WIK Discussion Paper No. 290, Bad Honnef, March.

TARDIFF, T. J. (2007): Changes in industry structure and technological convergence: implications for competition policy and regulation in telecommunications, International Economics and Economic Policy 4, 109-133.

Telecommunications Policy (2013): Special Issue on 'Cognitive Radio: Regulation and Markets' and 'Dynamic Spectrum Assignment'. 
Troulos C., and V. Maglaris (2011): Factors determining municipal broadband strategies across Europe, Telecommunications Policy 35, 842-856.

Turner, S. D. (2006): Universal Service Reform and Convergence: USF Policy for the $21^{\text {st }}$ Century. TPRC 2006, http://papers.ssrn.com/sol3/papers.cfm?abstract_id = 2103852.

Valletti, T., and C. CAmbini (2005): Investments and Network Competition, RAND Journal of Economics 36, 446-468.

Valletti, T., and G. Houpis (2005): Mobile termination: What is the 'right' charge?, Journal of Regulatory Economics 28, 235-258.

Valletti, T. M., S. Hoernig, and P. P. Barros (2002): Universal Service and Entry: Pricing and Coverage Constraints, Journal of Regulatory Economics 21, 169-190.

Vogelsang, I. (2003a): Price Regulation of Access to Telecommunications Networks, Journal of Economic Literature XLI, 830-862.

Vogelsang, I. (2003b): The German Telecommunications Reform - Where did it Come from, Where is it, and Where is it Going?, Perspektiven der Wirtschaftspolitik 4, 313340 .

Vogelsang, I. (2006): Network Utilities in the United States: Sector Reforms without Privatization. In: M. Köthenbürger, W. Sinn, and J. Whalley (Eds), Privatization Experiences in the European Union, MIT Press, Cambridge (MA), 50-85.

Vogelsang, I. (2009): Convergence and Net Neutrality. In: J. Krämer and S. Seifert (Eds), Communications Regulation in the Age of Digital Convergence, Universitätsverlag der Universität Karlsruhe, Karlsruhe, 19-27.

Vogelsang, I. (2010): The relationship between mobile and fixed line communications: A survey, Information Economics and Policy 22 (1), 4-17.

Vogelsang, I. (2012): Incentive Regulation, Investments and Technological Change. In: G. R. Faulhaber, G. Madden and J. Petchey (Eds), Regulation and the Performance of Communication and Information Networks, chapter 4, Edward Elgar, Cheltenham (UK).

Vogelsang, I., and R.-G. Wöhrl (2002): Determining Interconnection Charges Based on Network Capacity Utilized. In: K.-H. Neumann, S. Strube Martins and U. Stumpf (Eds), Price Regulation, WIK Proceedings No. 8, Bad Honnef.

Von Weizsäcker, C. C. (2013): Freedom, Wealth and Adaptive Preferences. Unpublished manuscript.

Wallsten, S. (2013): Two Cheers for the FCC's Mobility Fund Reverse Auction. Technology Policy Institute, Washington, April 1.

Weiser, P., and D.N. Hatfield (2007/2008): Spectrum Policy Reform and the Next Frontier of Property Rights, George Mason Law Review 60 (3), 549-610.

Werbach, K. (2004): Supercommons: Toward a Unified Theory of Wireless Communication, Texas Law Review 82, 863-974.

Werbach, K. (2013): No dialtone: The end of the public switched telephone network. Paper for the $41^{\text {st }}$ annual TPRC, September 27-29.

WolaK, F. A. (1996): Can universal service survive in a competitive telecommunications environment? Evidence from the United States consumer expenditure survey, Information Economics and Policy 8, 163-203.

Wright, J. (2002a): Bill and Keep as the Efficient Interconnection Regime?, Review of Network Economics 1, 54-60.

Wright, J. (2002b): Access Pricing under Competition: an Application to Cellular Networks, Journal of Industrial Economics 50, 289-316.

Yoo, C. S. (2011): Deregulation vs. Reregulation of Telecommunications: A Clash of Regulatory Paradigms, Journal of Corporation Law 36, 847-867. 
Zimmerman, P. R. (2007): Recent developments in U.S. wireline telecommunications, Telecommunications Policy 31, 419-437.

Zimmerman, P. R. (2008): Strategic incentives under vertical integration: the case of wireline-affiliated wireless carriers and intermodal competition in the U.S., Journal of Regulatory Economics 34, 282-298. 
